\title{
EQUILIBRIUM BEACH PROFILE WITH NET CROSS-SHORE
}

\section{SAND TRANSPORT}

by

Annapurna Surya Sravani Mallavarapu

A thesis submitted to the Faculty of the University of Delaware in partial fulfillment of the requirements for the degree of Master of Civil Engineering

Spring 2018

(C) 2018 Annapurna Surya Sravani Mallavarapu All Rights Reserved 


\section{EQUILIBRIUM BEACH PROFILEWITH NET CROSS-SHORE SAND TRANSPORT}

by

Annapurna Surya Sravani Mallavarapu

Approved:

Nobuhisa Kobayashi, Ph.D.

Professor in charge of thesis on behalf of the Advisory Committee

Approved:

Sue McNeil, Ph.D.

Chair of the Department of Civil and Environmental Engineering

Approved:

Babatunde A. Ogunnaike, Ph.D.

Dean of the College of Engineering

Approved:

Ann L. Ardis, Ph.D.

Senior Vice Provost for Graduate and Professional Education 


\section{ACKNOWLEDGMENTS}

This study was partially supported by Delaware Sea Grant under Grant No- NOAA SG2016-18 R/RCE-9.

First of all, I am indebted to my advisor, guide and mentor - Professor Nobuhisa Kobayashi, University of Delaware, for patiently guiding and supervising me throughout these two academic years. He extended his thoughtful guidance wherever necessary, which laid a strong foundation for my career in ocean engineering. I would also extend my gratitude to Tingting Zhu, First year PhD scholar, for her friendship and immense support extended throughout the period of this study.

Secondly, I would like to thank Professor Jack A Puleo, Director of CACR at university of Delaware, for giving me enough and more opportunities to inculcate curiosity and interest, gain knowledge and hands on experience in the field of coastal engineering.

Last, but not least, I revere the patronage and moral support extended with love, by my parents Dr. and Mrs. Mallavarapu and my sister Yogitha, whose financial support and passionate encouragement made it possible for me to complete my Master's degree. Additionally, I would like to thank my friends Kiran Raju Alluri and Jayasuryaa Hareendran for their encouragement, love and support. 


\section{TABLE OF CONTENTS}

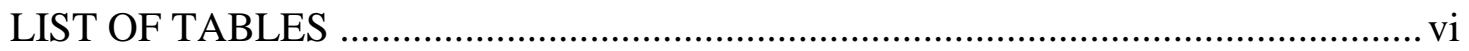

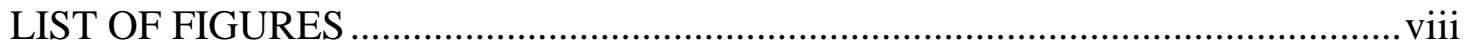

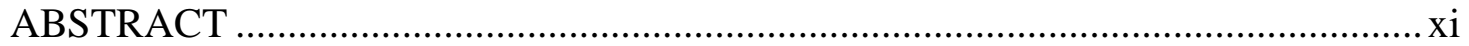

Chapter

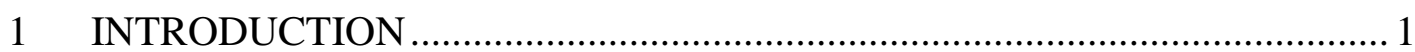

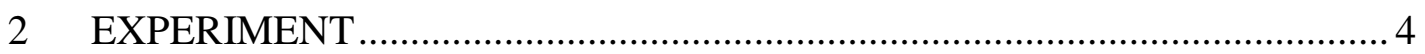

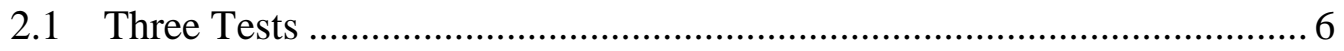

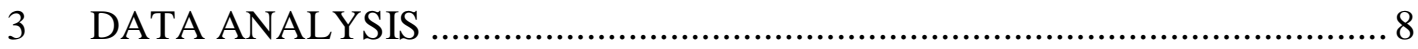

3.1 Free Surface and Velocity Statistics...................................................... 8

3.2 Beach Profile Evolution ..................................................................... 13

4 CONVENTIONAL SHORELINE TRANSLATION MODEL …..................... 16

4.1 Comparison of Data with Conventional Method....................................... 16

4.2 Computed and Measured Shoreline Displacement................................... 20

5 NEW EQUILIBRIUM PROFILE MODEL .................................................... 24

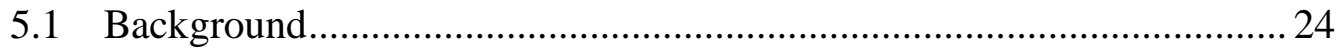

5.2 Formulation of Analytical Solution...................................................... 25

5.3 Horizontal Profile Shift ................................................................... 26

5.4 Comparison of the Analytical Model with Three Tests ........................... 27

6 FIELD APPLICATION OF THE NEW MODEL ………………………….... 34

7 COMPARISION WITH NUMERICAL PROFILE EVOLUTION MODEL.. 37

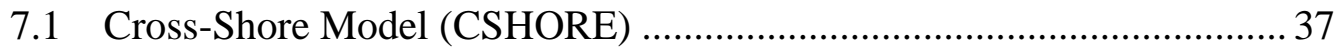

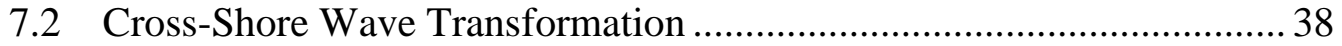

7.3 Wave Overtopping and Overwash Rates................................................ 40

7.4 Beach Profile Evolution ....................................................................... 40 


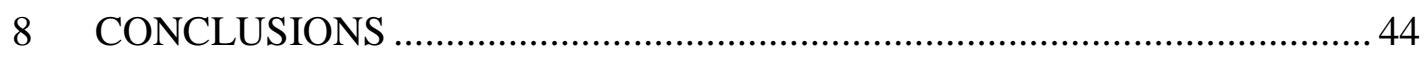

8.1 Experimental Findings ............................................................ 44

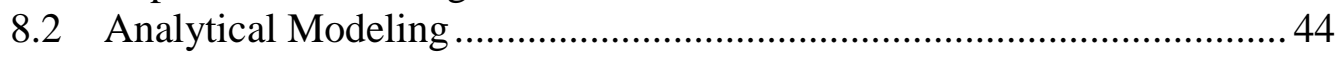

8.3 Numerical Modeling ................................................................ 45

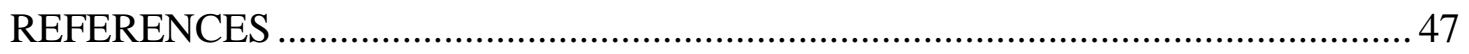

Appendix

CROSS-SHORE SEDIMENT TRANSPORT TESTS ............................... 49

A.1 Zero (Z) Net Cross-shore Sediment Transport Test .............................50

A.2 Negative (N) Net Cross-shore Sediment Transport Test.........................56

A.3 Positive (P) Net Cross-shore Sediment Transport Test .......................... 68 


\section{LIST OF TABLES}

Table 2.1: $\quad$ Sequence of three tests with zero $(\mathrm{Z})$, negative $(\mathrm{N})$, and positive net cross-shore sand transport. ..................................................................... 5

Table 4.1: Closure depth $\left(\mathrm{d}_{\mathrm{c}}\right)$ and Berm Height (B) for Tests Z, N, and P. ............ 20

Table 4.2: Measured location $\mathrm{x}_{0}(\mathrm{~m})$ at elevation $\mathrm{z}=0 \mathrm{~m}$ for Test $\mathrm{Z}$ in $88-\mathrm{cm}$ water depth and computed shoreline displacement $\Delta \mathrm{x}_{0}(\mathrm{~cm}) \ldots \ldots \ldots \ldots \ldots . . .22$

Table 4.3: Measured location $\mathrm{x}_{0}(\mathrm{~m})$ at elevation $\mathrm{z}=0 \mathrm{~m}$ for Test $\mathrm{N}$ in $88-\mathrm{cm}$ water depth and computed shoreline displacement $\Delta \mathrm{x}_{0}(\mathrm{~cm})$

Table 4.4: Measured location $\mathrm{x}_{0}(\mathrm{~m})$ at elevation $\mathrm{z}=0 \mathrm{~m}$ for Test $\mathrm{P}$ in $92-\mathrm{cm}$ water depth and computed shoreline displacement $\Delta \mathrm{x}_{0}(\mathrm{~cm}) \ldots \ldots \ldots \ldots \ldots \ldots . .22$

Table A.1: Incident wave chracteristics for Test $\mathrm{Z}$.............................................52

Table A.2: $\quad$ Mean free-surface elevation $\bar{\eta}(\mathrm{cm})$ at seven wave gauge locations ........53

Table A.3: Free-surface standard deviation $\sigma_{\eta}(\mathrm{cm})$ at seven wave gauge locations 53

Table A.4: Wet probability $P_{w}$, its mean free-surface elevation $\bar{\eta}(\mathrm{cm})$ and freesurface standard deviation $\sigma_{\eta}(\mathrm{cm})$ at WG8. ...........................................5 54

Table A.5: $\quad$ Mean cross-shore velocity $\bar{U}$ and standard deviation $\sigma_{U}$ of the 2D ADV co-located with WG4 at $x=8.30 \mathrm{~m}$, Red Vectrino co-located with WG5 at $x=12.90 \mathrm{~m}$ and Blue Vectrino co-located with WG6 at $x$

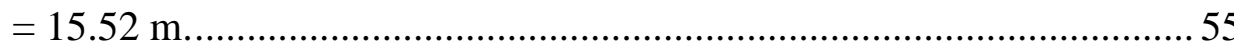

Table A.6: Incident wave characteristics for Test $\mathrm{N}$................................................63

Table A.7: $\quad$ Mean free-surface elevation $\bar{\eta}(\mathrm{cm})$ at seven wave gauge locations ........64

Table A.8: Free-surface standard deviation $\sigma_{\eta}(\mathrm{cm})$ at eight wave gauge locations . 65

Table A.9: Wet probability $P_{w}$, its mean free-surface elevation $\bar{\eta}(\mathrm{cm})$ and free-

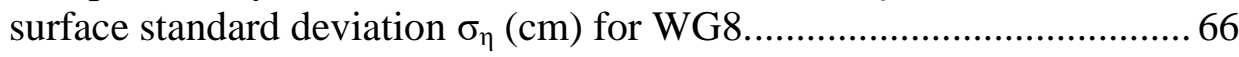


Table A.10: Mean cross-shore velocity $\bar{U}$ and standard deviation $\sigma_{U}$ of the $2 \mathrm{D}$ ADV co-located with WG4 at $x=8.30 \mathrm{~m}$, Red Vectrino co-located with WG5 at $x=12.90 \mathrm{~m}$ and Blue Vectrino co-located with WG6 at $x$ $=15.52 \mathrm{~m}$.

Table A.11: Incident wave characteristics for Test $\mathrm{P}$ 70

Table A.12: Mean free-surface elevation $\bar{\eta}(\mathrm{cm})$ at seven wave gauge locations....... 71

Table A.13: Free-surface standard deviation $\sigma_{\eta}(\mathrm{cm})$ at seven wave gauge locations 72

Table A.14: Wet probability $P_{w}$, its mean free-surface elevation $\bar{\eta}(\mathrm{cm})$ and freesurface standard deviation $\sigma_{\eta}(\mathrm{cm})$ for WG8.

Table A.15: Mean cross-shore velocity $\bar{U}$ and standard deviation $\sigma_{U}$ of the 2D ADV co-located with WG4 at $x=8.30 \mathrm{~m}$, Red Vectrino co-located with WG5 at $x=12.90 \mathrm{~m}$ and Blue Vectrino co-located with WG6 at $x$ $=15.52 \mathrm{~m}$. 


\section{LIST OF FIGURES}

Figure 2.1: Experimental setup at the start of Test $\mathrm{Z}$ with zero net sand transport rate

Figure 3.1: Mean and standard deviation of free surface elevation $\bar{\eta}$ and horizontal velocity $\bar{U}$ together with wet probability $\mathrm{P}_{\mathrm{w}}$ for 10 runs during time $\mathrm{t}=$ $0-4,000 \mathrm{~s}$ in Test Z ................................................................... 10

Figure 3.2: Mean and standard deviation of free surface elevation $\bar{\eta}$ and horizontal velocity $\bar{U}$ together with wet probability $\mathrm{P}_{\mathrm{w}}$ for 10 runs during time $\mathrm{t}=$ $4,000-8,000 \mathrm{~s}$ in Test N........................................................... 11

Figure 3.3: Mean and standard deviation of free surface elevation $\bar{\eta}$ and horizontal velocity $\bar{U}$ together with wet probability $\mathrm{P}_{\mathrm{w}}$ for 10 runs during time $\mathrm{t}=$ $4,000-8,000 \mathrm{~s}$ in Test $\mathrm{P}$

Figure 3.4: Initial and final beach profiles for Tests $\mathrm{Z}, \mathrm{N}$ and $\mathrm{P}$ 14

Figure 3.5: Temporal variations of wave overtopping rate $\mathrm{q}_{\mathrm{o}}$ and sand overwash rate $\mathrm{q}_{\mathrm{bs}}$ for Test $\mathrm{P}$

Figure 4.1: Zero $(Z)$ net cross-shore sediment transport test with 10 runs and elevation increase from $\mathrm{Z} 0$ to $\mathrm{Z} 5$ and $\mathrm{Z} 5$ to $\mathrm{Z10}$.

Figure 4.2: Negative (N) net cross-shore sediment transport test with 20 runs and elevation increase from N0 to N5, N5 to N10 and N10 to N20

Figure 4.3: Positive (P) net cross-shore sediment transport test with 20 runs and elevation increase from P0 to P5, P5 to P10 and P10 to P20

Figure 4.4: Time series of cumulative sand volume per unit width for Tests $\mathrm{N}$ and P.

Figure 4.5: Measured and computed shoreline displacement $\Delta \mathrm{x}_{0}$ which is negative for Test $\mathrm{N}$ and positive for Test $\mathrm{P}$

Figure 5.1: Measured profile and analytical profiles for Test $\mathrm{Z}$ with fitted $\mathrm{A}=0.059 \mathrm{~m}^{1 / 3}$ from $\mathrm{x}_{\mathrm{c}}=11.7 \mathrm{~m}$ where $\mathrm{x}_{0}=17.9 \mathrm{~m}$ at zero elevation ........ 28

Figure 5.2: Measured and computed horizontal profile shift from N0 to N20 ......... 30 
Figure 5.3: Measured and computed profile of N20 starting from initial profile of N0

Figure 5.4: Measured and computed horizontal shift from P0 to P20 ........................ 32

Figure 5.5: Measured and computed profile of P20 starting from initial profile of $\mathrm{P} 0$.

Figure 6.1: Seaward shoreline displacement $\mathrm{D}(\mathrm{m})$ as a function of closure depth $\mathrm{d}_{\mathrm{c}}(\mathrm{m})$ for $\alpha=0.003 \mathrm{~m}^{1 / 2} / \mathrm{s}$ and $\left(-\mathrm{q}_{\mathrm{n}}\right)=10 \mathrm{~m}^{2} / \mathrm{yr}, 50 \mathrm{~m}^{2} / \mathrm{yr}$, and 100 $\mathrm{m}^{2} / \mathrm{yr}$

Figure 6.2: Seaward shoreline displacement $\mathrm{D}(\mathrm{m})$ as a function of closure depth $\mathrm{d}_{\mathrm{c}}(\mathrm{m})$ for $\left(-\mathrm{q}_{\mathrm{n}}\right)=50 \mathrm{~m}^{2}$ and $\alpha=1 \times 10^{-3}, 2 \times 10^{-3}$ and $3 \times 10^{-3} \mathrm{~m}^{1 / 2} / \mathrm{s} \ldots \ldots \ldots . .36$

Figure 7.1: Mean and standard deviation of free surface elevation $\bar{\eta}$ and horizontal velocity $\bar{U}$ together with wet probability $\mathrm{P}_{\mathrm{w}}$ for 10 runs during time $\mathrm{t}=$ 0 to $4,000 \mathrm{~s}$ for Test $\mathrm{Z}$

Figure 7.2: Mean and standard deviation of free surface elevation $\bar{\eta}$ and horizontal velocity $\bar{U}$ together with wet probability $\mathrm{P}_{\mathrm{w}}$ for 20 runs during time $\mathrm{t}=$ 0 to $8,000 \mathrm{~s}$ for Test $\mathrm{N}$.

Figure 7.3: Mean and standard deviation of free surface elevation $\bar{\eta}$ and horizontal velocity $\bar{U}$ together with wet probability $\mathrm{P}_{\mathrm{w}}$ for 20 runs during time $\mathrm{t}=$ 0 to $8,000 \mathrm{~s}$ for Test $\mathrm{P}$

Figure 7.4: Water overtopping rate $\mathrm{q}_{\mathrm{o}}$ and sand overwash rate $\mathrm{q}_{\mathrm{bs}}$ during Test $\mathrm{P}$..... 40

Figure 7.5: Initial, measured and computed profiles for $\mathrm{t}=2,000 \mathrm{~s}$ and $\mathrm{t}=4,000 \mathrm{~s}$ of Test Z

Figure 7.6: Initial, measured and computed profiles at $\mathrm{t}=2,000 \mathrm{~s}, \mathrm{t}=4,000 \mathrm{~s}$ and $\mathrm{t}$ $=8,000 \mathrm{~s}$ for Test $\mathrm{N}$

Figure 7.7: Initial, measured and computed profiles at $\mathrm{t}=2,000 \mathrm{~s}, \mathrm{t}=4,000 \mathrm{~s}$ and $\mathrm{t}$ $=8,000 \mathrm{~s}$ for Test $\mathrm{P}$

Figure A.1: Zero $(Z)$ net cross-shore sediment transport test with 10 runs indicated by the numeral $1-10$. For example, $Z 5$ is run 5 in test $Z$. The measured profiles were $\mathrm{Z} 0$ before the $\mathrm{Z}$ test, $\mathrm{Z} 5$ after 5 runs, and $\mathrm{Z} 10$ after 10 runs. The elevation $\mathrm{z}$ is zero at the still water level in $88-\mathrm{cm}$ water depth. 
Figure A.2: Negative (N) net cross-shore sediment transport test with 20 runs. The initial profile N0 corresponds to the profile Z10 added with the placed sand at the shoreline

Figure A.3 Final profile for zero net cross-shore sand transport test (Z10) and initial profile for net offshore sand transport test (NO) with placed sand

Figure A.4: Enlarged view of Figure A.3 near the shoreline 57

Figure A.5: Profile after 5 runs for net offshore sand transport test (N5) and profile with placed sand for net offshore sand transport test (N5P)

Figure A.6: Enlarged view of Figure A.5 near the shoreline 58

Figure A.7: Profile before sand placement (N10), and profile (N10P) with the placed sand after run $\mathrm{N} 10$ and before run N11

Figure A.8: Enlarged view of Figure A.7 near the shoreline

Figure A.9: Initial dune profile (N0) and profile after 5 runs (N5) for net offshore sand transport test. Sand was placed again after run N5 to produce the profile N5P with placed sand before run N6

Figure A.10: Profile with placed sand and profile after 5 additional runs (N10) for net offshore sand transport test

Figure A.11: Measured profiles N10P and N20 after additional 10 runs for net offshore sediment transport test

Figure A.12: Placed sand near the shoreline for $\mathrm{N}$ test with no wave overtopping and overwash

Figure A.13: Wave overtopping and overwash. 68

Figure A.14: Beach profiles during run $\mathrm{P} 1$ and run $\mathrm{P} 10$ for positive net cross-shore sediment transport test with water depth of $92 \mathrm{~cm}$

Figure A.15: Positive (P) net cross-shore sediment transport test with 20 runs where the still water level is located at the elevation of $\mathrm{z}=0.04 \mathrm{~m}$

Figure A.16: Temporal variation of sand overwash rate $q_{b s}$ (top), wave overtopping rate $\mathrm{q}_{\mathrm{o}}$ (middle) and their ratio $\mathrm{q}_{\mathrm{bs}} / \mathrm{q}_{\mathrm{o}}$ (bottom). 


\begin{abstract}
Periodic beachfill placement and frequent overwash result in net offshore and onshore sand transport, respectively. Three tests consisting of fifty 400 -s runs were conducted in a small-scale wave flume to examine the effect of net cross-shore sand transport on an equilibrium profile. The foreshore of an equilibrium profile with no net sand transport shifted seaward after periodic sand placement near the shoreline. Frequent sand overwash resulted in the landward shift of the shoreline. The profile changes among the three tests were relatively small and the shoreline shifts were less than $0.1 \mathrm{~m}$. An analytical model for an equilibrium profile with net cross-shore sand transport is developed by approximating existing formulas for onshore bed load and offshore suspended sand transport in the inner surf zone. The model predicts the horizontal shift of the equilibrium profile under net cross-shore sand transport, which is the maximum at the shoreline and approaches zero at the closure depth. The model calibrated using the three tests are used to estimate the seaward shift of the shoreline on periodically-nourished beaches of prototype scale. The estimated shift is of the order of $1 \mathrm{~m}$ or less but will need to be verified using field data
\end{abstract}




\section{Chapter 1 \\ INTRODUCTION}

The concept of an equilibrium beach profile (Dean 1991) is expedient and has been adopted for the design of beachfills for beach nourishment (USACE 2003). The nourished beach maintained by periodic beachfill placement near the shoreline may become steeper to transport placed sand offshore. The present beachfill design does not account for the equilibrium profile modification caused by periodic beachfill placement. On the other hand, morphological changes of barrier islands caused by overwash during storms have been investigated in a number of studies [e.g., Jiménez et al. (2006); Rosati and Stone (2009)]. Frequent overwash may reduce the seaward beach slope to accommodate onshore sand transport near the shoreline. The beach profile modification caused by frequent overwash may not have been investigated previously.

The concept of an equilibrium profile has also been adopted for the prediction of shoreline response to sand sources, sinks, longshore sand transport gradients, and sea level rise [e.g., Dean and Houston (2016)]. The temporal change of sand volume in an active beach profile is expressed in terms of the temporal change of the crossshore shoreline location of an equilibrium profile. This expression coupled with longterm shoreline change data was used to estimate an onshore transport rate of sand from beyond closure depth. The estimated rates were about $3 \mathrm{~m}^{3} / \mathrm{m}$ per year during 18722007 along the 275-km Florida southwest coast (Dean and Houston 2016). Houston (2016) performed a similar analysis for the Florida east coast. The expression between 
the sand volume and shoreline changes does not account for the equilibrium profile modification caused by sand sources and sinks.

The degree of the equilibrium beach profile modification caused by periodic beachfill placement or overwash may be difficult to quantify for natural beaches whose profiles change with water level and wave conditions. No reliable model exists to predict long-term beach profile evolution including periodic beachfill placement or frequent overwash (Kobayashi 2016). A laboratory experiment was conducted in this study to measure the beach profile changes caused by periodic beachfill placement and overwash. First, a quasi-equilibrium beach was established under constant water level and wave conditions. Second, sand was placed periodically near the shoreline of the equilibrium beach to produce a quasi-equilibrium profile with net offshore sand transport. Third, the still water level was increased to initiate wave overwash and produce a quasi-equilibrium profile with net onshore sand transport. The measured shoreline changes in the three tests are compared with the conventional method based on the cross-shore translation of an active profile caused by the source (periodic beachfill placement) and sink (overwash).

An equilibrium beach profile is regarded as a profile with no net cross-shore sediment transport rate $\left(\mathrm{q}_{\mathrm{n}}\right)$. Kobayashi et al. (2008) proposed formulas for offshore suspended sediment transport rate $\mathrm{q}_{\mathrm{s}}$ and onshore bed load transport rate $\mathrm{q}_{\mathrm{b}}$ and derived the equilibrium profile equation of Dean (1991) for the case of $q_{n}=\left(q_{s}+q_{b}\right)$ $=0$ where onshore transport is positive in the following. Their model is extended analytically to equilibrium profiles with net offshore and onshore sediment transport rates. 
The analytical model is compared with the measured quasi-equilibrium profiles in the small-scale experiment and used to estimate the offshore shoreline shift of a prototype beach under different nourishment rates. The analytical model is presented after the laboratory experiment and data analysis. 


\section{Chapter 2}

\section{EXPERIMENT}

This Chapter provides an overview of the experiment which was conducted in University of Delaware wave flume located in basement of the Dupont Hall.

The experiment was conducted in a wave tank that is $30 \mathrm{~m}$ long, $2.5 \mathrm{~m}$ wide, and $1.5 \mathrm{~m}$ high. A dividing wall in the middle of the tank was installed to reduce the amount of sand used in the experiment, the water level change due to wave overtopping, and seiching development in the tank. Three tests listed in Table 2.1 were carried out in a $23-\mathrm{m}$ long and $115-\mathrm{cm}$ wide flume as shown in Figure 2.1. The sand beach in the flume consisted of well-sorted fine sand with a median diameter of $0.18 \mathrm{~mm}$. The fall velocity, density, and porosity of the sand were $2.0 \mathrm{~cm} / \mathrm{s}, 2.6 \mathrm{~g} / \mathrm{cm}^{3}$, and 0.4 , respectively. This small-scale experiment was not intended to reproduce specific prototype conditions. This experimental setup and data collection were originally used by Figlus et al. (2011) to provide detailed measurements of overwash processes. The fine sand used in the experiment might be regarded as coarse sand at prototype scale. Both bed load and suspended load were discernible in the experiment.

A 400-s run of irregular wave train with a Texel, Marsen and Arsloe (TMA) spectral shape was generated by the paddle of the piston-type wave maker in a water depth of $88 \mathrm{~cm}$ for the first two $(\mathrm{Z}$ and $\mathrm{N}$ ) tests with no wave overtopping and overwash. The spectral significant wave height and peak period were approximately $17 \mathrm{~cm}$ and $2.6 \mathrm{~s}$. Nine wave gauges were placed in the flume. Wave gauges 1 to 8 (WG1-WG8) were used to measure the free surface elevation outside and inside the 
surf zone and in the swash zone and WG9 was used to measure the wave level in the basin after each run to measure the volume of overtopped water. The fluid velocities were measured by one acoustic Doppler velocimeter (ADV) sensor and two Vectrinos (Nortek, Rud, Norway) which were co-located at WG4, WG5, and WG6 (WG4 with 2D ADV and WG5-WG6 with Red and Blue Vectrinos) at an elevation of one-third of the local water depth. A vertical wall was located at the onshore coordinate $\mathrm{x}=19.9 \mathrm{~m}$ with $\mathrm{x}=0$ at WG1. The vertical coordinate $\mathrm{z}$ was positive upward with $\mathrm{z}=0$ at the still water level (SWL). The still water level of tests $\mathrm{N}$ and $\mathrm{P}$ was $88 \mathrm{~cm}$ and that $\mathrm{P}$ test was $92 \mathrm{~cm}$. The elevation of the wall crest was $106 \mathrm{~cm}$ above the horizontal flume bottom. The wave overtopping rate $\mathrm{q}_{\mathrm{o}}$ and sand overwash rate $\mathrm{q}_{\mathrm{bs}}$ for the third $(\mathrm{P})$ test in $92-\mathrm{cm}$ water depth were measured by collecting overtopped water and sand in a water collection basin and a sand trap during each 400-s run.

Table 2.1: $\quad$ Sequence of three tests with zero $(\mathrm{Z})$, negative(N), and positive net crossshore sand transport

\begin{tabular}{|l|l|l|l|}
\hline Test & $\begin{array}{l}\text { Cross-shore sand } \\
\text { transport }\end{array}$ & $\begin{array}{l}\text { Water depth } \\
(\mathbf{c m})\end{array}$ & Duration (s) \\
\hline & Zero (equilibrium) & 88 & \\
$\mathrm{Z}$ & Negative (offshore) & 88 & 4,000 \\
$\mathrm{~N}$ & Positive (onshore) & 92 & 8,000 \\
$\mathrm{P}$ & & 8,000 \\
\hline
\end{tabular}

Acuity AR4000- LIR laser line scanner system was used to obtain accurate three dimensional profile data after each 10 runs (4,000 s) with constant SWL. The scanner mounted on a motorized cart recorded alongshore transects at 2-cm crossshore intervals with a vertical error of about $1 \mathrm{~mm}$ after draining water in the tank. 
The three-dimensional bathymetry data were averaged alongshore after confirmation of alongshore uniformity.

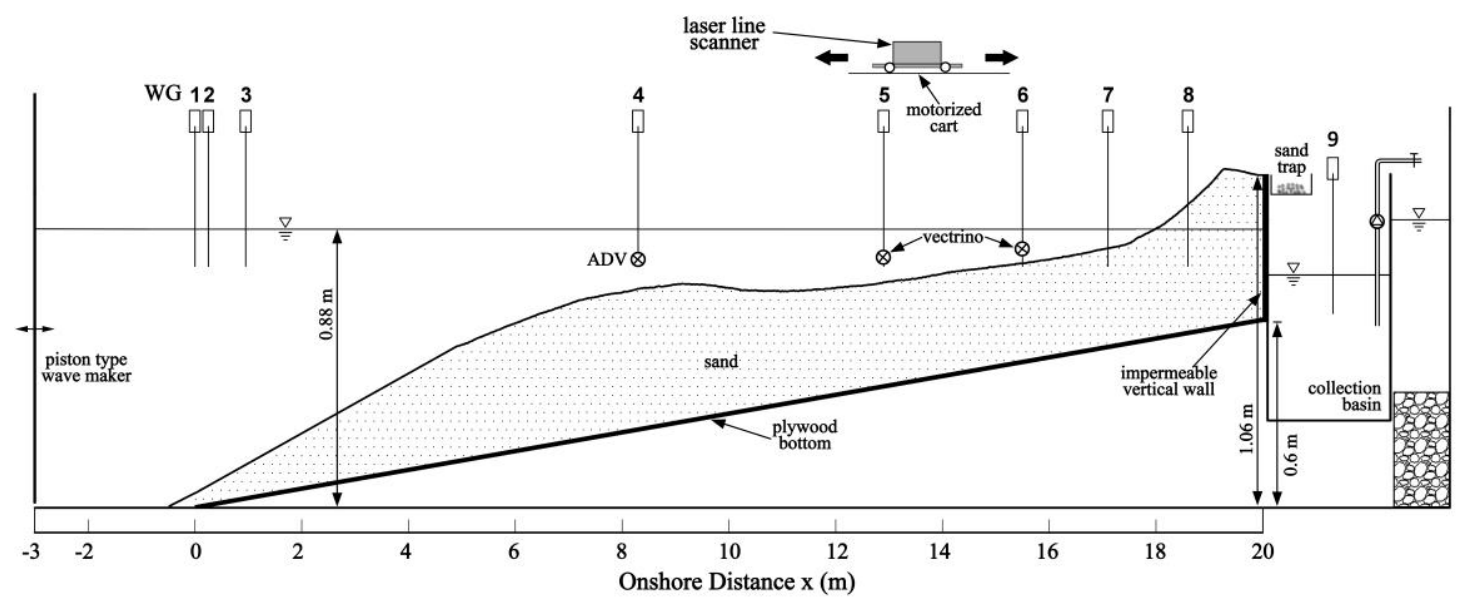

Figure 2.1: Experimental setup at the start of Test $\mathrm{Z}$ with zero net sand transport rate

\subsection{Three Tests}

The initial profile of the $\mathrm{Z}$ test is depicted in Figure 2.1. Preliminary tests were conducted to finalize the $\mathrm{Z}, \mathrm{N}$, and $\mathrm{P}$ tests. The initial profile of $\mathrm{Z} 0$ was almost equilibrium under the specified water level and wave conditions. The run number starting from run number 0 for the initial profile is affixed to the test name to indicate a specific run in each test. Ten 400 -s runs were performed in the $\mathrm{Z}$ test. The profiles of $\mathrm{Z5}$ and Z10 were measured after 5 and 10 runs. The measured profiles of Z0, Z5, and Z10 were compared to confirm the establishment of a quasi-equilibrium profile with elevation changes of a few millimeters.

The initial profile of the $\mathrm{N}$ test was the final profile of Z10. Sand was placed uniformly across the $115-\mathrm{cm}$ wide flume near the shoreline of the initial profile of N0. The placed sand mass per unit width corresponded to the sand volume (no void) of 
$12 \mathrm{~cm}^{3} / \mathrm{cm}$. The placed sand was dispersed quickly during the first 400-s run. Additional four runs were generated and the beach profile of N5 was measured. The sand volume of $12 \mathrm{~cm}^{3} / \mathrm{cm}$ was placed again and exposed to five runs and the beach profile of N10 was measured and compared with the profiles of N0 and N5. Since the profile changes were small, the placed sand volume was increased to $24 \mathrm{~cm}^{3} / \mathrm{cm}$ and exposed to 10 runs. The beach profile of N20 was measured and compared with the profile of N10. The two profiles were very similar apart from the offshore shift of the foreshore slope of approximately $1 / 8$ (vertical/horizontal). For the $\mathrm{N}$ test, the total placed sand volume per unit width was $48 \mathrm{~cm}^{2}$ for the duration of $8,000 \mathrm{~s}$. The average rate of the sand placement per unit width was $0.006 \mathrm{~cm}^{2} / \mathrm{s}$.

The initial profile of the P test was the final profile of N20. The SWL was raised by $4 \mathrm{~cm}$ and the water depth of $88 \mathrm{~cm}$ in Figure 2.1 increased to $92 \mathrm{~cm}$ in the $\mathrm{P}$ test. The 4-cm SWL increase was selected on the basis of a preliminary test in which the measured sand overwash rate $\mathrm{q}_{\mathrm{bs}}$ was about $0.006 \mathrm{~cm}^{2} / \mathrm{s}$. The beach profiles of $\mathrm{P} 5$, $\mathrm{P} 10$, and P20 were measured during 20 runs in the $\mathrm{P}$ test. The wave overtopping rate $\mathrm{q}_{\mathrm{o}}$ and sand overwash rate $\mathrm{q}_{\mathrm{bs}}$ were measured for each run. 


\section{Chapter 3}

\section{DATA ANALYSIS}

Analysed data are summarized in the following. Detailed data are presented in the Appendix.

\subsection{Free Surface and Velocity Statistics}

The time series from Wave Gauges WG1 - WG3 located at $\mathrm{x}=0.0,0.25$, and $0.95 \mathrm{~m}$ for each run were used to separate incident and reflected waves at the location $\mathrm{x}=0$ of WG1. The spectral significant wave height $\mathrm{H}_{\mathrm{mo}}$ and peak period $\mathrm{T}_{\mathrm{p}}$ of incident waves were approximately $17 \mathrm{~cm}$ and $2.6 \mathrm{~s}$. The reflection coefficient, defined as the ratio between the values of $\mathrm{H}_{\mathrm{mo}}$ for the reflected and incident waves, was approximately 0.14 . The measured time series of the free surface elevation $\eta$ above the SWL and velocities for the 50 runs were analysed to examine the crossshore wave transformation in the $\mathrm{Z}, \mathrm{N}$, and $\mathrm{P}$ tests. The analysed data for the 10 runs of Z1-Z10, N11-N20, P11-P20 are presented in Figure 3.1, Figure 3.2 and Figure 3.3 respectively. The variability among the 10 runs resulted from the slight bottom profile change and the errors of the measurements and wave reproduction.

The measured values of the mean $\bar{\eta}$ were slightly negative (wave set down) at WG1 - WG3 outside the surf zone and at WG4 $(x=8.3 \mathrm{~m})$ in the outer surf zone where large waves broke. The relatively steep bottom slope of about 1/10 in the offshore zone of $x<5 \mathrm{~m}$ in Figure 2.1 was necessary because of the limited flume length. A small bar below WG4 may have been caused by breaking of large waves. 
The values of $\bar{\eta}$ were positive (wave setup) at WG5 - WG7 at $\mathrm{x}=12.9,15.5$, and 17.1 $\mathrm{m}$ in the inner surf zone. The value $\bar{\eta}$ of WG8 at $\mathrm{x}=18.6 \mathrm{~m}$ in the swash zone was the sum of the bottom elevation $(10.1-10.2 \mathrm{~cm}$ for Test P) above the SWL and the mean depth $\bar{h}(1.5-2.3 \mathrm{~cm}$ for Test P). The averaging for WG8 buried partially in the sand was performed for the wet duration. The wet probability $\mathrm{P}_{\mathrm{w}}$ was defined as the ratio between the wet and total duration. $\mathrm{P}_{\mathrm{w}}=1.0$ at WG1 $-\mathrm{WG} 7$ and $\mathrm{P}_{\mathrm{w}}=0.60-$ 0.64 at WG8 in Figure.3.3. The standard deviation (SD) $\sigma_{\eta}$ of the free surface elevation was related to the wave height decay caused by irregular wave breaking where the local significant wave height $H_{\text {mo }}$ was defined as $H_{m o}=4 \sigma_{\eta}$. Wave shoaling from $\mathrm{x}=0.0-0.95 \mathrm{~m}$ to $\mathrm{x}=8.3 \mathrm{~m}$ was not discernible in Figures 3.1, 3.2 and 3.3. Wave breaking reduced $\sigma_{\eta}$ noticeably from $\mathrm{x}=8.3 \mathrm{~m}$ to $\mathrm{x}=12.9 \mathrm{~m}$ and gradually in the inner surf zone $(\mathrm{x}=12.9-17.1 \mathrm{~m})$. Waves broke near the toe of the foreshore slope and ran up in the swash zone $(\mathrm{x}=18.6 \mathrm{~m})$.

The measured alongshore and vertical velocities were small in comparison with the cross-shore velocity $\mathrm{U}$. The mean velocity $\bar{U}$ was negative (undertow) because of the wave-induced offshore return current. The offshore current decreased from the outer surf zone $(x=8.3 \mathrm{~m})$ to the inner surf zone $(\mathrm{x}=12.9-15.5 \mathrm{~m})$. The standard deviation $\sigma_{U}$ of the oscillatory component of the velocity $U$ also decreased landward. 

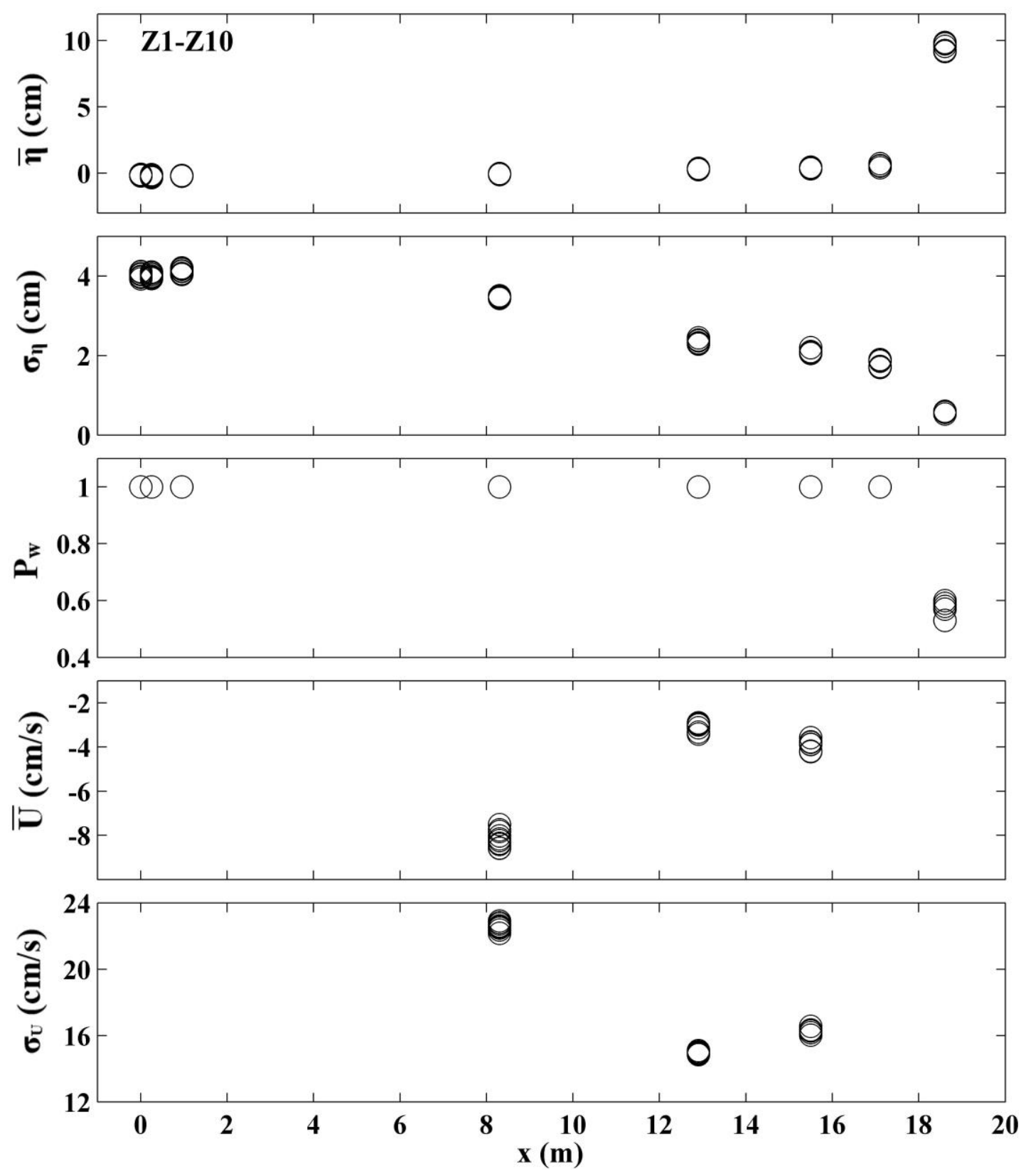

Figure 3.1: Mean and standard deviation of free surface elevation $\bar{\eta}$ and horizontal velocity $\bar{U}$ together with wet probability $\mathrm{P}_{\mathrm{w}}$ for 10 runs during time $\mathrm{t}=0$ $-4,000 \mathrm{~s}$ in Test $\mathrm{Z}$ 

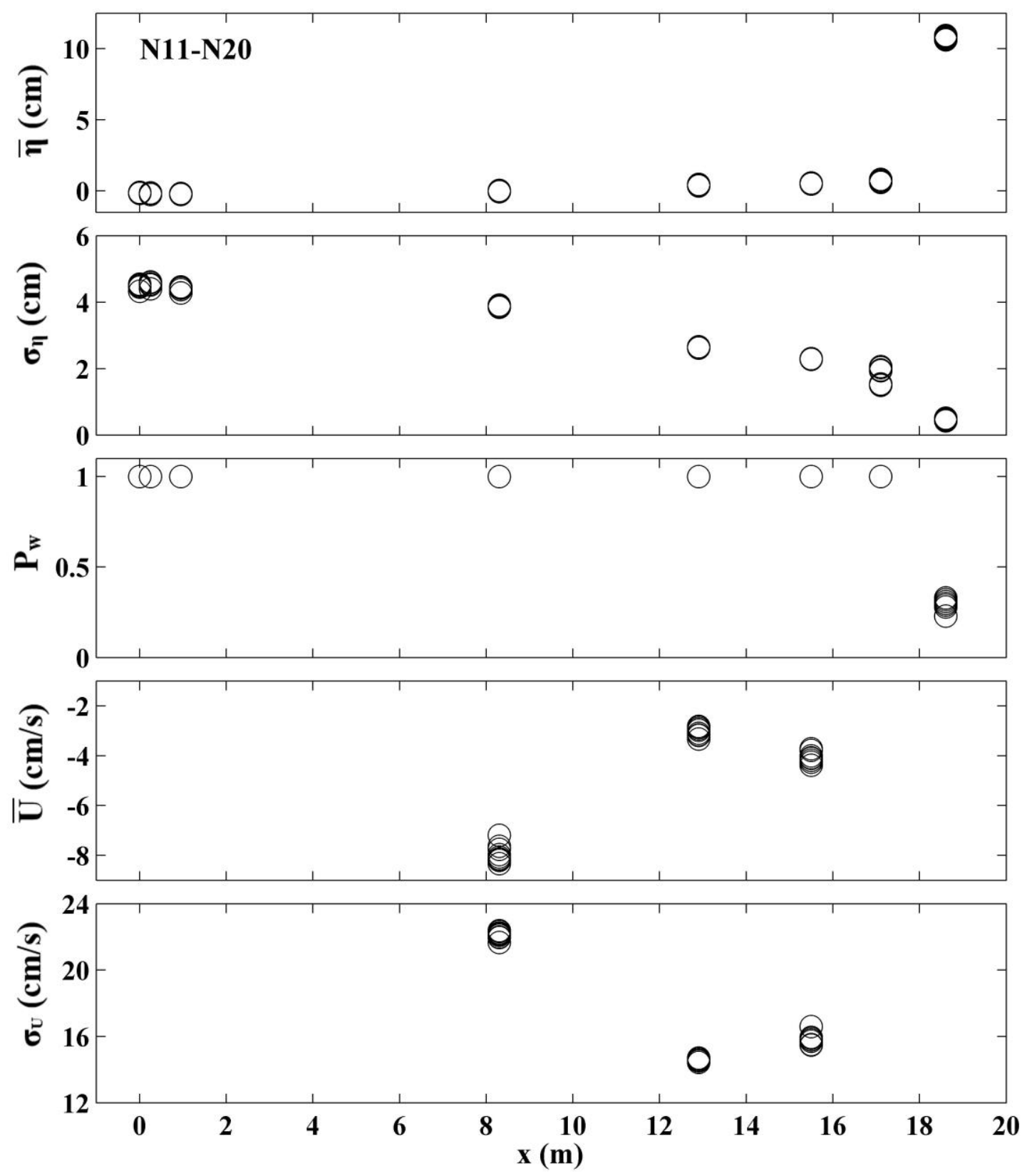

Figure 3.2: Mean and standard deviation of free surface elevation $\bar{\eta}$ and horizontal velocity $\bar{U}$ together with wet probability $\mathrm{P}_{\mathrm{w}}$ for 10 runs during time $\mathrm{t}=$ $4,000-8,000 \mathrm{~s}$ in Test $\mathrm{N}$ 

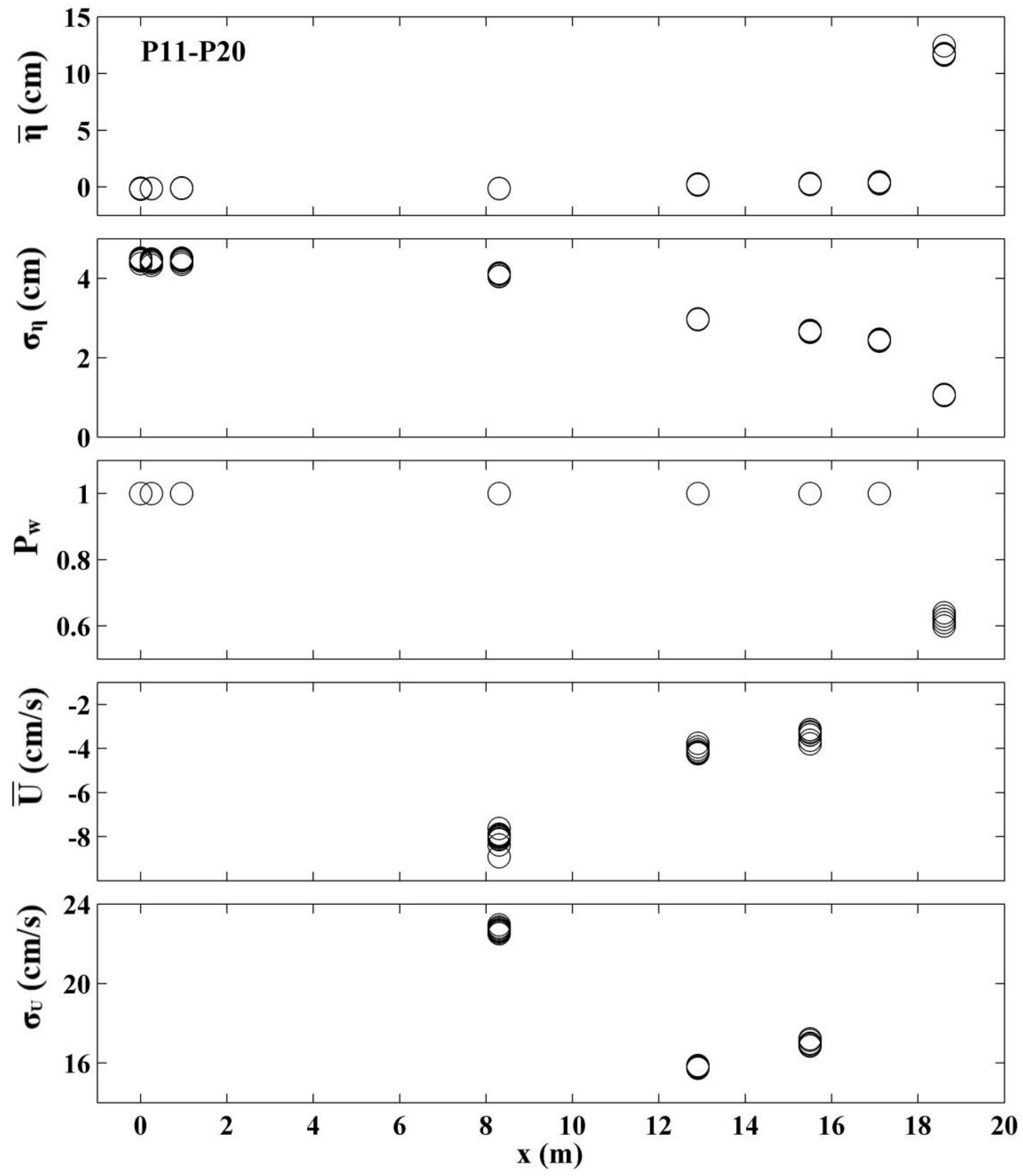

Figure 3.3: Mean and standard deviation of free surface elevation $\bar{\eta}$ and horizontal velocity $\bar{U}$ together with wet probability $\mathrm{P}_{\mathrm{w}}$ for 10 runs during time $\mathrm{t}=$ $4,000-8,000 \mathrm{~s}$ in Test $\mathrm{P}$ 


\subsection{Beach Profile Evolution}

The measured beach profiles in each test were plotted together to examine the degree of the profile changes. The vertical profile changes during the 5 or 10 runs were a few millimeters in the zone of $x<11 \mathrm{~m}$ and up to $1 \mathrm{~cm}$ in the zone of $\mathrm{x}>17 \mathrm{~m}$. Figure 3.4 shows the initial and final profiles of the $\mathrm{Z}, \mathrm{N}$, and $\mathrm{P}$ tests in the zone of $\mathrm{x}>11 \mathrm{~m}$. The intermediate profiles of Z5, N5, N10, P5, and P10 between the initial and final profiles are not plotted in Figure 3.4 for clarity. During the $\mathrm{Z}$ test, a step-like feature developed at the lower limit of wave downrush on the foreshore slope, slight erosion and accretion occurred seaward and landward of the step, respectively. The SWL shoreline of the profile Z0 shifted seaward by $3.6 \mathrm{~cm}(4.1 \mathrm{~cm})$ for the profile $\mathrm{Z} 5$ (Z10). The profile change from $\mathrm{Z} 5$ to $\mathrm{Z10}$ was less than $5 \mathrm{~mm}$ and the profile Z10 was regarded as quasi-equilibrium.

For the $\mathrm{N}$ test with sand placement near the shoreline, the foreshore slope and step translated seaward and the beach profile in the zone of $\mathrm{x}<17 \mathrm{~m}$ changed little. The SWL shoreline of the profile N0 shifted seaward by 3.7, 4.1, and $9.0 \mathrm{~cm}$ for N5, N10, and N20, respectively. For the P test with wave overtopping and sand overwash, erosion (accretion) occurred on the lower (upper) part of the foreshore and its slope became slightly steeper. The step at the toe of the foreshore migrated onshore as the foreshore crest became higher by $1 \mathrm{~cm}$. The SWL shoreline of the profile P0 shifted landward by 7.3, 7.0, and $8.1 \mathrm{~cm}$ for P5, P10, and P20. The conservation of sand volume is examined in the next section.

For the P test, the volumes of water and sand transported over the vertical wall in Figure.2.1 were used to obtain the water overtopping rate $\mathrm{q}_{\mathrm{o}}$ and sand overwash rate $\mathrm{q}_{\mathrm{bs}}$ per unit width averaged over each 400-s run. Figure 3.5 shows the temporal variations of $\mathrm{q}_{\mathrm{o}}$ and $\mathrm{q}_{\mathrm{bs}}$ for the 20 runs. The average rates are plotted at 
time $\mathrm{t}\left(\mathrm{t}=0\right.$ at the start of the test) corresponding to the end of each run. Both $\mathrm{q}_{\mathrm{o}}$ and $\mathrm{q}_{\mathrm{bs}}$ decreased with time $\mathrm{t}$ as the foreshore crest became higher. The ratio of $\mathrm{q}_{\mathrm{o}} / \mathrm{q}_{\mathrm{bs}} \mathrm{did}$ not change much and was about 0.035 . The overwashed sand volume per unit width was $27 \mathrm{~cm}^{2}$ for the duration of $8,000 \mathrm{~s}$.
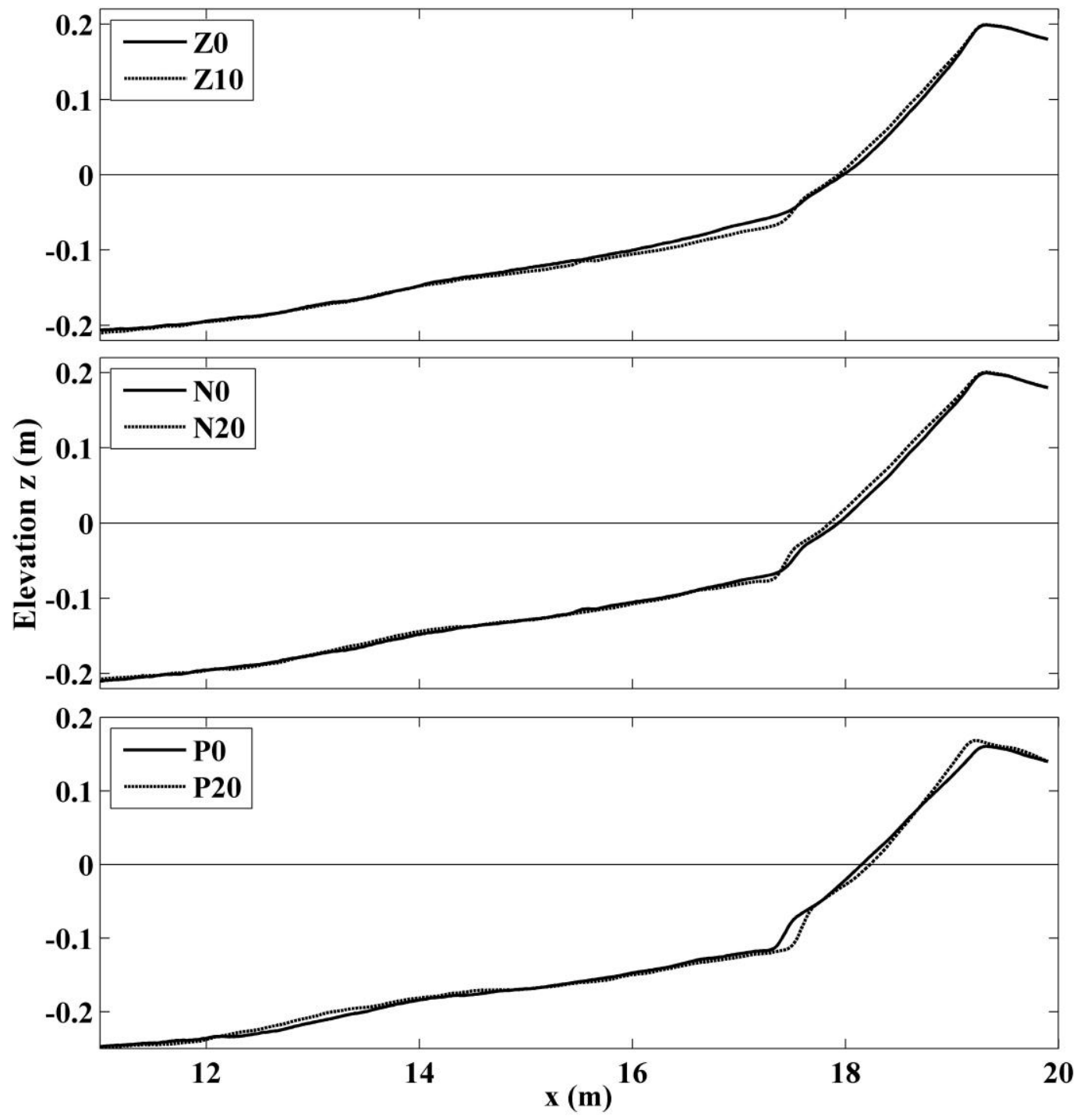

Figure 3.4: Initial and final beach profiles for Tests Z,N and $\mathrm{P}$ 

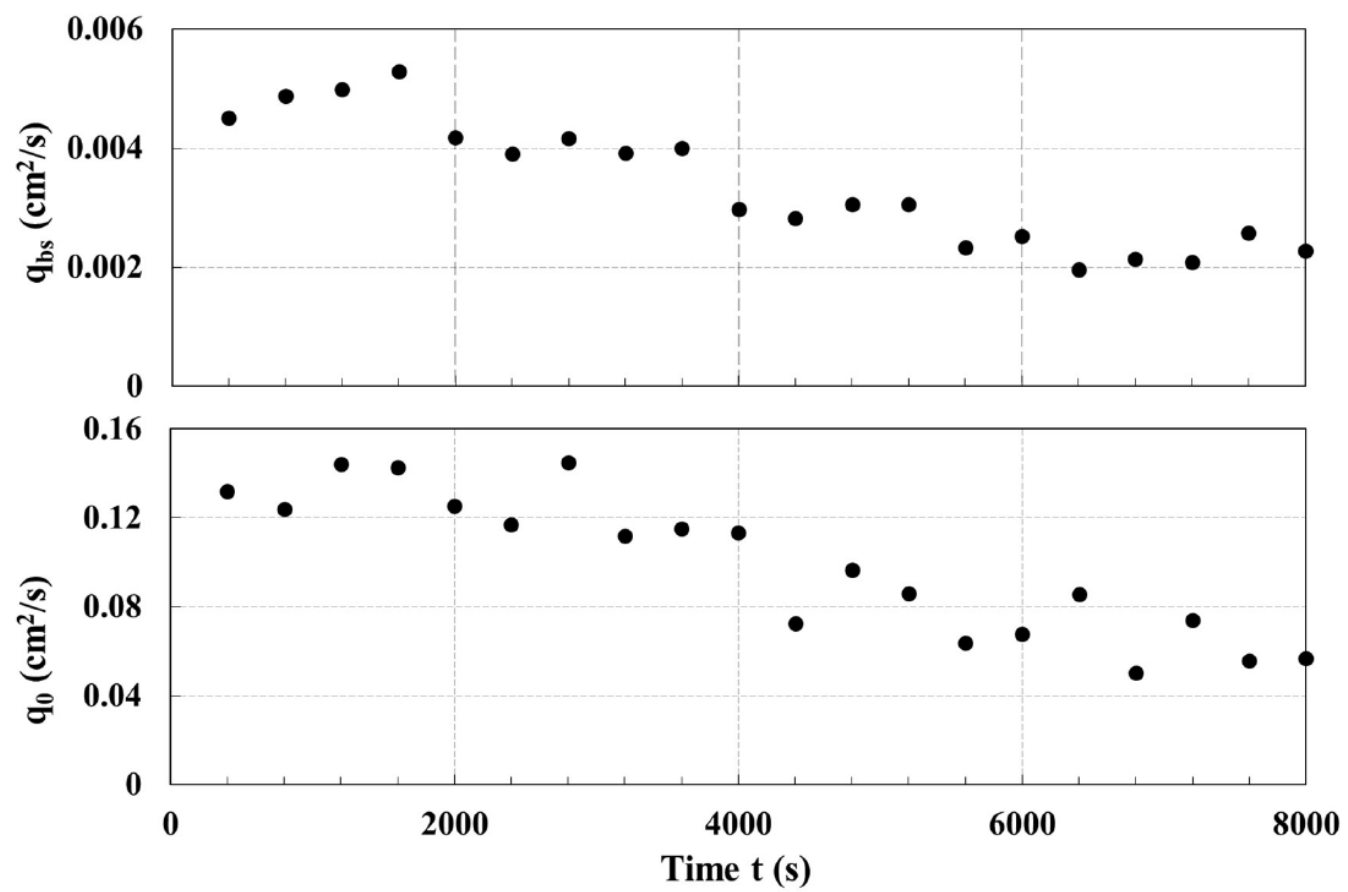

Figure 3.5: Temporal variations of wave overtopping rate $\mathrm{q}_{\mathrm{o}}$ and sand overwash rate $\mathrm{q}_{\mathrm{bs}}$ for Test $\mathrm{P}$ 


\section{Chapter 4}

\section{CONVENTIONAL SHORELINE TRANSLATION MODEL}

In this chapter a conventional shoreline translation model has been developed and is compared to the data obtained from the experiment.

\subsection{Comparison of Data with Conventional Method}

The shoreline shifts in the $\mathrm{N}$ and $\mathrm{P}$ tests were caused by the periodic sand placement (source) and overwash (sink). An equation with terms representing all phenomena affecting shoreline change including Bruun-rule recession, onshore sand transport, sand sources and sinks, and longshore transport gradients was already established [e.g., Dean and Houston (2016)]. The measured shoreline shifts are compared with the conventional method based on the conservation of sand volume and active profile translation. The relationship between the SWL shoreline located at $\mathrm{x}=\mathrm{x}_{\mathrm{O}}$ and the net cross-shore sand transport rate $\mathrm{q}_{\mathrm{n}}$ is expressed as

$$
\left(B+d_{c}\right) \frac{d x_{0}}{d t}=\frac{q_{n}}{1-n_{p}}
$$

where, $t=$ time; $B=$ berm height above the $S W L ; d_{c}=$ closure depth; $n_{p}=$ sand porosity $\left(\mathrm{n}_{\mathrm{p}}=0.4\right.$ in this experiment). The net rate $\mathrm{q}_{\mathrm{n}}$ is positive onshore and the shoreline location $\mathrm{x}_{\mathrm{o}}$ shifts landward for $\mathrm{q}_{\mathrm{n}}>0$ and seaward for. $\mathrm{q}_{\mathrm{n}}<0$. An equilibrium profile is assumed in Equation (4.1) because $\mathrm{x}_{\mathrm{o}}$ is constant for $\mathrm{q}_{\mathrm{n}}=0$. Equation (4.1) cannot explain the shoreline shift in the $\mathrm{Z}$ test with $\mathrm{q}_{\mathrm{n}}=0$. 

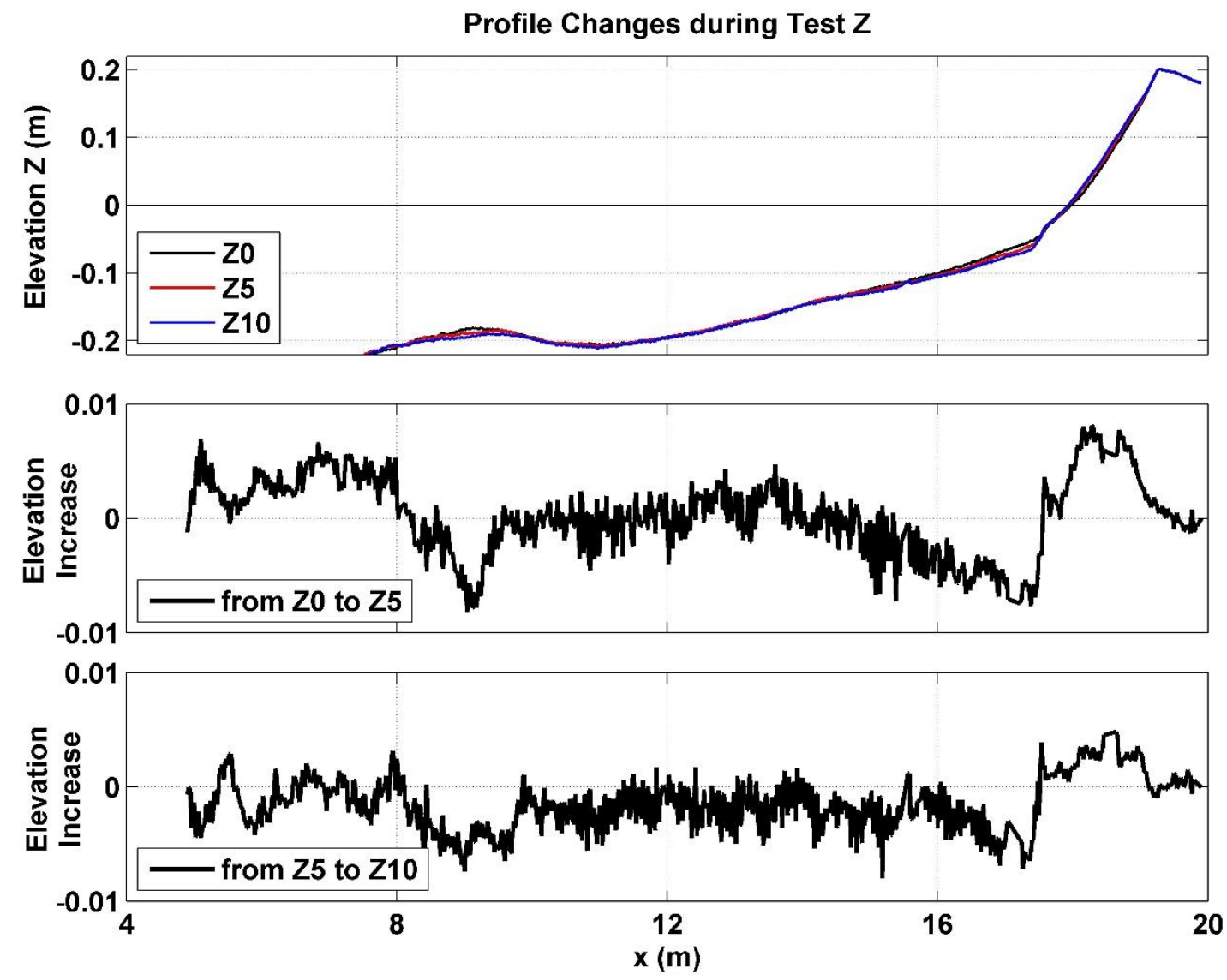

Figure 4.1: Zero (Z) net cross-shore sediment transport test with 10 runs and elevation increase from Z0 to Z5 and Z5 to Z10 

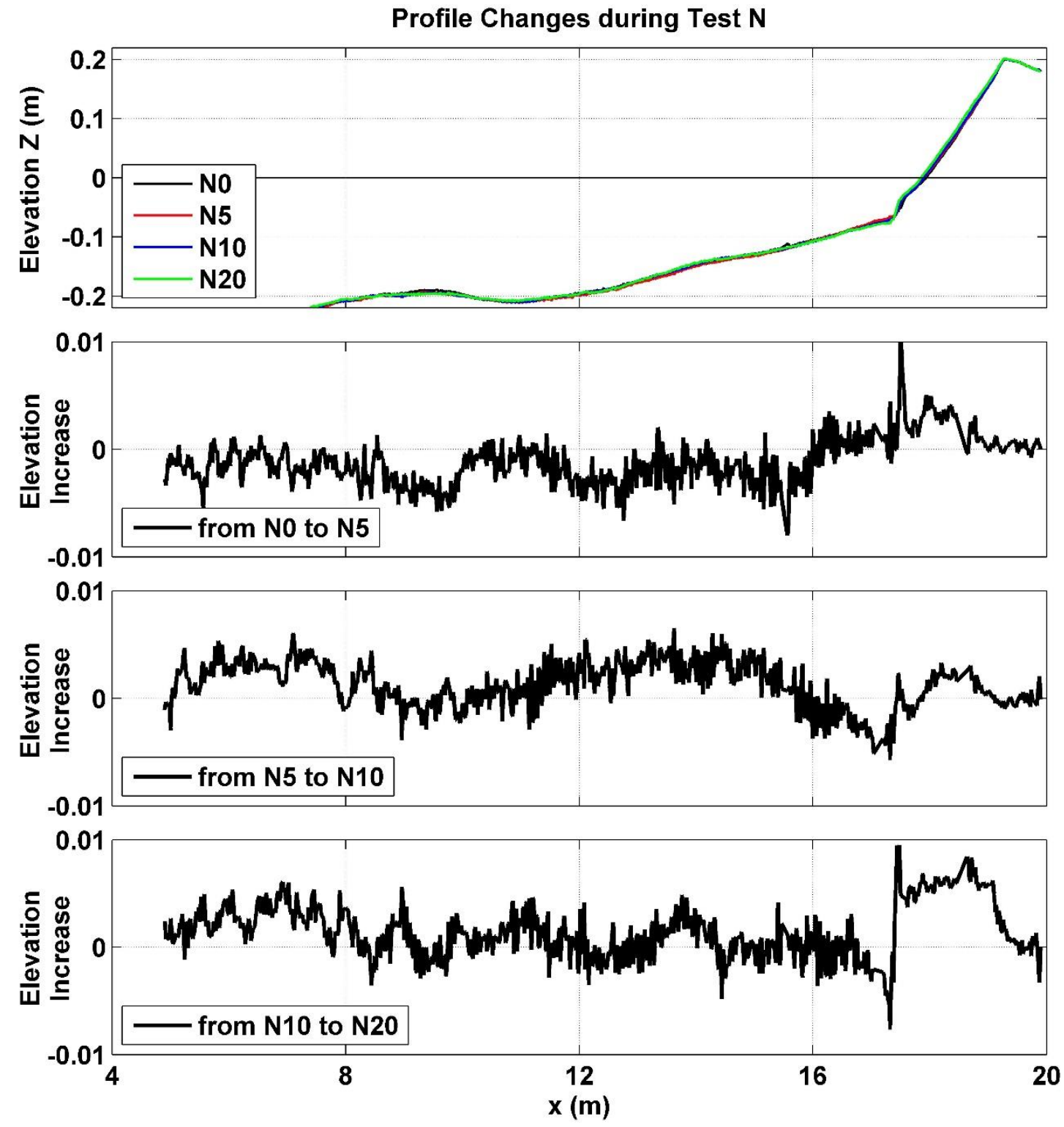

Figure 4.2: Negative $(\mathrm{N})$ net cross-shore sediment transport test with 20 runs and elevation increase from N0 to N5, N5 to N10 and N10 to N20 

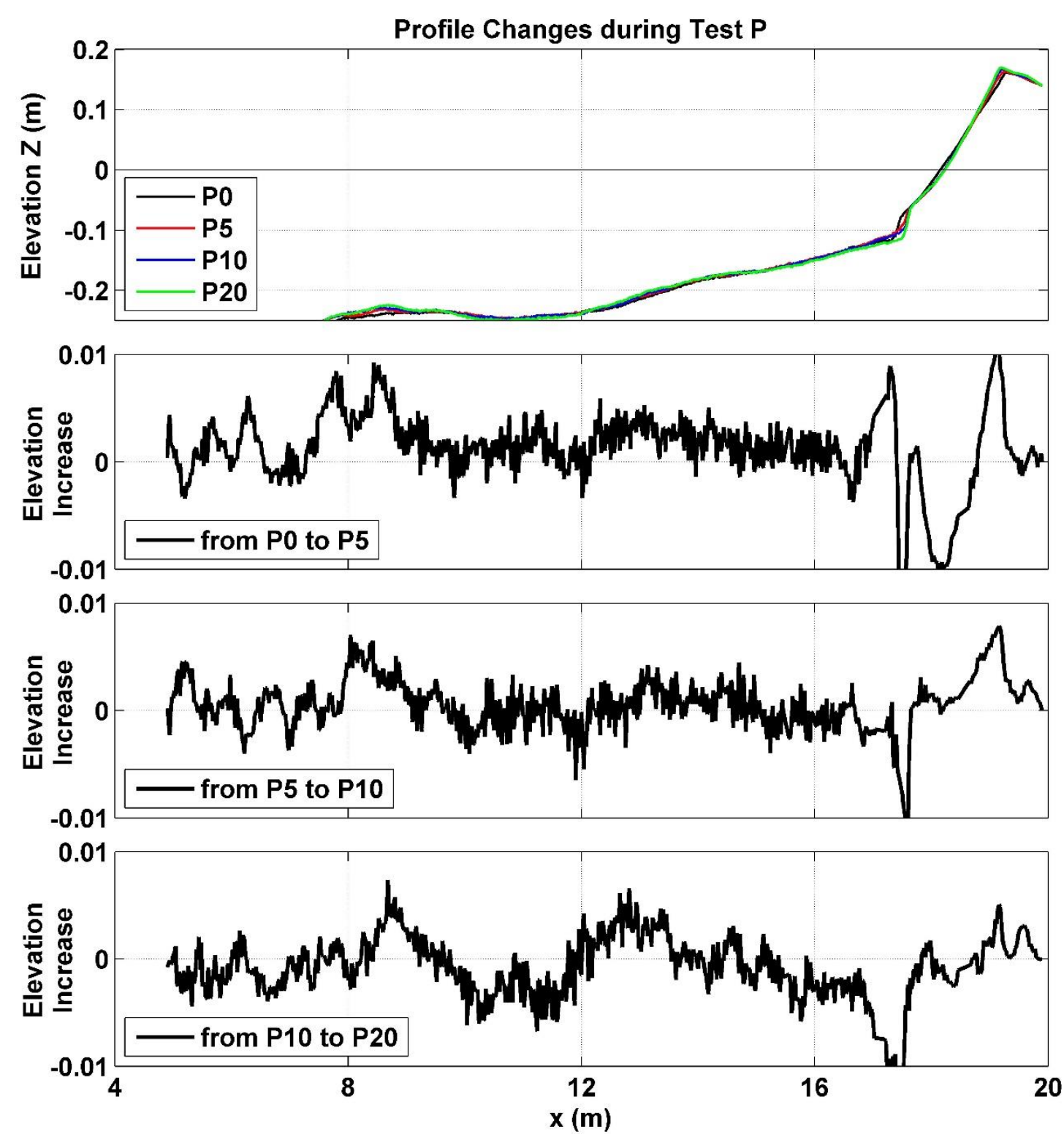

Figure 4.3: Positive (P) net cross-shore sediment transport test with 20 runs and elevation increase from P0 to P5, P5 to P10 and P10 to P20

Figure 4.1, Figure 4.2 and Figure 4.3 are used to estimate the berm height B and the closure depth $d_{c}$ for the Z, N and P tests, respectively and the degree of profile equilibrium in each test. The foreshore crest height above the SWL is used to estimate 
$\mathrm{B}=0.20 \mathrm{~m}$ for the $\mathrm{Z}$ and $\mathrm{N}$ tests and $\mathrm{B}=0.17 \mathrm{~m}$ for the $\mathrm{P}$ test. The cross-shore location $\mathrm{x}_{\mathrm{c}}=11.7 \mathrm{~m}$ of the minimum $(1 \mathrm{~mm})$ profile change near the seaward edge of the inner surf zone is assumed to correspond to the closure location where $d_{c}=0.20 \mathrm{~m}$ for the $\mathrm{Z}$ and $\mathrm{N}$ tests and $\mathrm{d}_{\mathrm{c}}=0.24 \mathrm{~m}$ for the $\mathrm{P}$ test. The estimated depth of closure and berm height are tabulated in Table 4.1 .

Table 4.1: Closure depth $\left(\mathrm{d}_{\mathrm{c}}\right)$ and Berm Height (B) for Tests Z, N, and P

\begin{tabular}{|l|l|l|l|}
\hline Test & $\mathbf{d}_{\mathbf{c}}(\mathbf{m})$ & $\mathbf{B}(\mathbf{m})$ & $\left(\mathbf{B}+\mathbf{d}_{\mathbf{c}}\right)(\mathbf{m})$ \\
\hline $\mathbf{Z}$ & 0.20 & 0.20 & 0.40 \\
\hline $\mathbf{N}$ & 0.20 & 0.20 & 0.40 \\
\hline $\mathbf{P}$ & 0.24 & 0.17 & 0.41 \\
\hline
\end{tabular}

The minimum profile change implies almost zero gradient of the net crossshore sand transport rate at the closure depth. The active profile height $\left(B+d_{c}\right)$ is approximately $0.4 \mathrm{~m}$. The net rate $\mathrm{q}_{\mathrm{n}}$ for the $\mathrm{N}$ test is assumed to be constant and given by $\mathrm{q}_{\mathrm{n}}=-0.006 \mathrm{~cm}^{2} / \mathrm{s}$. The net rate $\mathrm{q}_{\mathrm{n}}$ for the $\mathrm{P}$ test is taken as the sand overwash rate $\mathrm{q}_{\mathrm{bs}}$ in Figure 3.5.

\subsection{Computed and Measured Shoreline Displacement}

Integration of Equation (4.1) yields the shoreline displacement $\Delta \mathrm{x}_{\mathrm{o}}$ defined as

$$
\begin{aligned}
& \Delta x_{o}(t)=\left[x_{o}(t)-x_{o}(t=0)\right] \\
& \qquad x_{o}(t)=\frac{Q_{n}(t)}{\left(B+d_{c}\right)\left(1-n_{p}\right)} ; Q_{n}(t)=\int_{0}^{t} q_{n} d t
\end{aligned}
$$

where, $\mathrm{Q}_{\mathrm{n}}=$ cumulative sand volume per unit width which is added (negative) or removed (positive) from the active profile. The temporal variations of $Q_{n}$ for the $N$ 
test and $Q_{n}$ for the $P$ test are shown in Figure 4.4. The placed sand volume in the $N$ test was selected so that the absolute values of $\mathrm{Q}_{\mathrm{n}}$ for the $\mathrm{N}$ and $\mathrm{P}$ tests would become similar. However, the reduction of $\mathrm{q}_{\mathrm{bs}}$ caused by the foreshore crest accretion decreased $Q_{n}$ in the $P$ test.

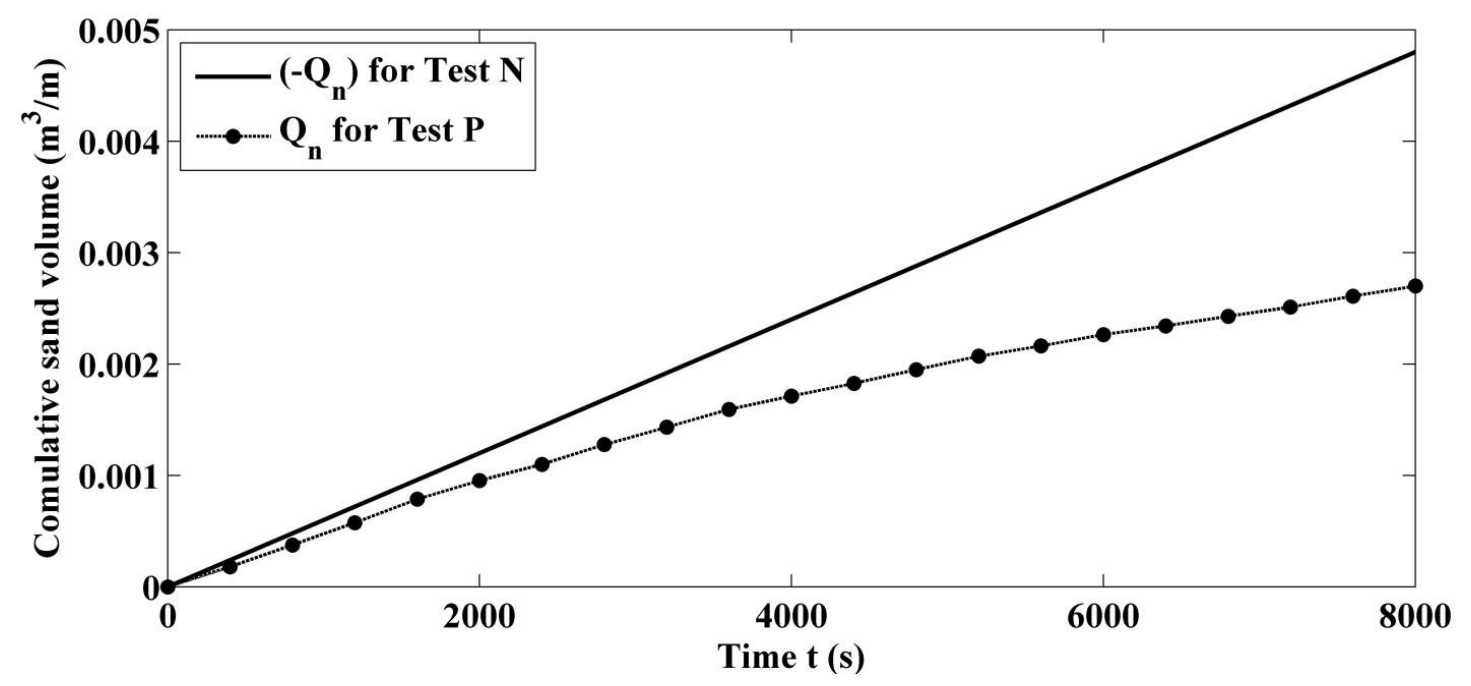

Figure 4.4: Time series of cumulative sand volume per unit width for Tests $\mathrm{N}$ and $\mathrm{P}$

Figure 4.5 compares the measured and computed shoreline displacements, which are negative (seaward) for the $\mathrm{N}$ test and positive (landward) for the $\mathrm{P}$ test. The computed displacement is too small partly because the entire active profile did not adjust itself within the test duration of $8,000 \mathrm{~s}$. The profile adjustment was slower than expected. Using the measured value of $\Delta \mathrm{x}_{\mathrm{o}}$ at $\mathrm{t}=8,000 \mathrm{~s}$ in Equation (4.2), the calculated value of $\left(B+d_{c}\right)$ is $9 \mathrm{~cm}$ for the $\mathrm{N}$ test and $6 \mathrm{~cm}$ for the $\mathrm{P}$ test 
Table 4.2: $\quad$ Measured location $\mathrm{x}_{0}(\mathrm{~m})$ at elevation $\mathrm{z}=0 \mathrm{~m}$ for Test $\mathrm{Z}$ in 88 -cm water depth and computed shoreline displacement $\Delta \mathrm{x}_{0}(\mathrm{~cm})$

\begin{tabular}{|l|l|l|l|}
\hline Time $\mathbf{t}(\mathbf{s})$ & $\mathbf{0}$ & $\mathbf{2 0 0 0}$ & $\mathbf{4 0 0 0}$ \\
\hline $\mathbf{x}_{\mathbf{0}}(\mathbf{m})$ & 17.981 & 17.945 & 17.940 \\
\hline Measured $\Delta \mathbf{x}_{\mathbf{0}}(\mathbf{c m})$ & 0 & -3.6 & -4.1 \\
\hline Computed $\Delta \mathbf{x}_{\mathbf{0}}(\mathbf{c m})$ & 0 & 0 & 0 \\
\hline
\end{tabular}

Table 4.3: Measured location $\mathrm{x}_{0}(\mathrm{~m})$ at elevation $\mathrm{z}=0 \mathrm{~m}$ for Test $\mathrm{N}$ in $88-\mathrm{cm}$ water depth and computed shoreline displacement $\Delta \mathrm{x}_{0}(\mathrm{~cm})$

\begin{tabular}{|l|l|l|l|l|}
\hline Time $\mathbf{t}(\mathbf{s})$ & $\mathbf{0}$ & $\mathbf{2 0 0 0}$ & $\mathbf{4 0 0 0}$ & $\mathbf{8 0 0 0}$ \\
\hline $\mathbf{x}_{\mathbf{0}}(\mathbf{m})$ & 17.940 & 17.903 & 17.899 & 17.850 \\
\hline Measured $\Delta \mathbf{x}_{\mathbf{0}}(\mathbf{c m})$ & 0 & -3.7 & -4.1 & -9.0 \\
\hline Computed $\Delta \mathbf{x}_{\mathbf{0}}(\mathbf{c m})$ & 0 & -0.5 & -1.0 & -2.0 \\
\hline
\end{tabular}

Table 4.4: $\quad$ Measured location $\mathrm{x}_{0}(\mathrm{~m})$ at elevation $\mathrm{z}=0 \mathrm{~m}$ for Test $\mathrm{P}$ in 92-cm water depth and computed shoreline displacement $\Delta \mathrm{x}_{0}(\mathrm{~cm})$

\begin{tabular}{|l|l|l|l|l|}
\hline Time $\mathbf{t}(\mathbf{s})$ & $\mathbf{0}$ & $\mathbf{2 0 0 0}$ & $\mathbf{4 0 0 0}$ & $\mathbf{8 0 0 0}$ \\
\hline $\mathbf{x}_{\mathbf{0}}(\mathbf{m})$ & 18.152 & 18.225 & 18.222 & 18.233 \\
\hline Measured $\Delta \mathbf{x}_{\mathbf{0}}(\mathbf{c m})$ & 0 & 7.3 & 7.0 & 8.1 \\
\hline Computed $\Delta \mathbf{x}_{\mathbf{0}}(\mathbf{c m})$ & 0 & 0.4 & 0.7 & 1.1 \\
\hline
\end{tabular}

The measured and computed shoreline displacements for the Z, N and P tests are tabulated in Table 4.2, Table 4.3 and Table 4.4 respectively. For the $\mathrm{N}$ test, the initial profile of N0 was quasi-equilibrium under the specified water level and waves. The profile adjustment was caused by the periodic sand placement near the shoreline. The placed sand was distributed on the foreshore and step in the zone of $\mathrm{x}>17 \mathrm{~m}$ in Figure 3.4. The accreted area was $167 \mathrm{~cm}^{2}$ and the eroded area in the vicinity of the 
step was $59 \mathrm{~cm}^{2}$. The difference was $108 \mathrm{~cm}^{2}$ in comparison to the placed sand area of $80 \mathrm{~cm}^{2}$ including void. For the $\mathrm{P}$ test, the initial profile of $\mathrm{P} 0$ was not in equilibrium with the SWL raised by $4 \mathrm{~cm}$. The profile adjustment to the raised SWL was included in the measured shoreline displacement. The step migrated landward and the eroded area in the vicinity of the step was $186 \mathrm{~cm}^{2}$. The deposited area on the upper foreshore was $91 \mathrm{~cm}^{2}$ and the overwashed sand volume per unit width was 45 $\mathrm{cm}^{2}$ including void. The unaccounted area of $50 \mathrm{~cm}^{2}$ (e.g., $1 \mathrm{~mm}$ over a distance of 5 $\mathrm{m}$ ) indicates the amplified error in the sand volume conservation resulting from the profile measurement error.

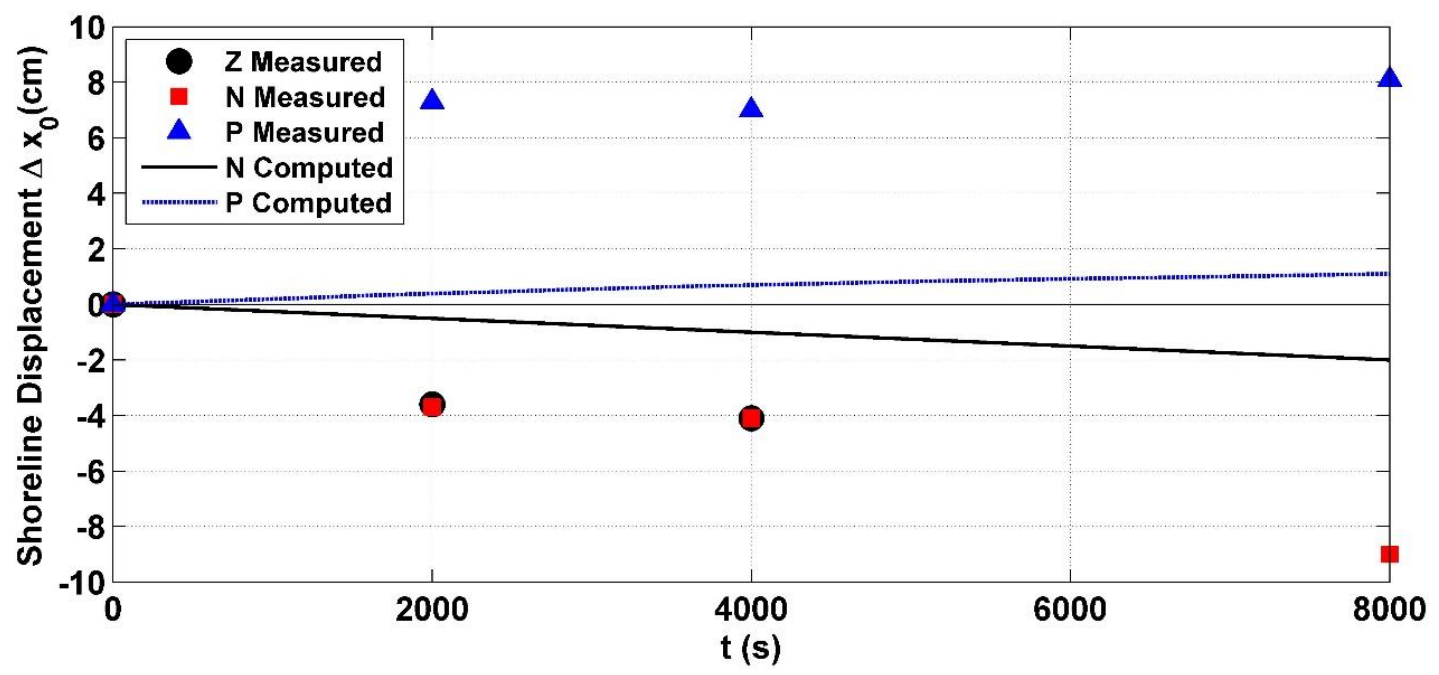

Figure 4.5: Measured and computed shoreline displacement $\Delta \mathrm{x}_{0}$ which is negative for Test $\mathrm{N}$ and positive for Test $\mathrm{P}$ 


\section{Chapter 5}

\section{NEW EQUILIBRIUM PROFILE MODEL}

Some features of a beach profile include (1) a concave upward profile, (2) smaller and larger sand diameters are associated with milder and steeper slopes respectively and (3) an approximately planar slope near the shoreline.

\subsection{Background}

The continuity equation of bottom sand for an equilibrium (no temporary change) profile under the assumption of alongshore uniformity requires no cross-shore gradient of the net cross-shore sand transport rate $\mathrm{q}_{\mathrm{n}}$. This requirement yields

$$
q_{b}+q_{s}=q_{n} ; q_{n}=\text { constant }
$$

where, $q_{b}$ and $q_{s}$ are the cross-shore bed load and suspended load transport rates per unit width, respectively. Kobayashi et al. (2008) approximated their formulas for the onshore rate $q_{b}$ and the offshore rate $q_{s}$ to derive the equilibrium profile popularized by Dean (1991). The approximations, which may be reasonable in the inner surf zone, included the assumptions of shallow water, negligible wave setup, and constant ratio $\sigma_{\eta} / \mathrm{h}$ with $h=$ still water depth in the inner surf zone where $h$ is assumed to decrease landward monotonically. This study does not address the issue of $q_{n}$ outside the inner surf zone. 


\subsection{Formulation of Analytical Solution}

The approximate expressions of $q_{b}$ and $q_{s}$ can be shown to be written using $y=h^{1.5}$

$$
\begin{gathered}
q_{b}=\alpha y \quad ; \quad \alpha=\alpha_{*} \frac{\sqrt{g}}{(s-1)} \\
q_{s}=\beta y \frac{d y}{d x} ; \quad \beta=\beta_{*} \frac{g}{(s-1) w_{f}}
\end{gathered}
$$

where, $\alpha_{*}$ and $\beta_{*}=$ dimensionless parameters related to bed load and suspended load, respectively; $g$ = gravitational acceleration; $s$ and $w_{f}=$ specific gravity and fall velocity of the sand with $s=2.6$ and $w_{f}=2.0 \mathrm{~cm} / \mathrm{s}$ in this experiment. The dimensional parameters $\alpha$ and $\beta$ depend on the sand characteristics even if $\alpha *$ and $\beta *$ are constant. Equations (5.2) and (5.3) are valid only in the inner surf zone because the magnitudes

of $q_{b}$ and $q_{s}$ increase seaward with the increase of the depth $h=y^{2 / 3}$. The original formulas of $q_{b}$ and $q_{s}$ without the approximations predict the seaward decrease of the magnitudes of $q_{b}$ and $q_{s}$ outside the surf zone (Kobayashi and Jung 2012).

The effect of $q_{n}$ on the equilibrium profile based on Equation (5.1) can be assessed qualitatively using Equation (5.2) for the onshore rate $q_{b}$ depending on h only and Equation (5.3) for the offshore rate $q_{s}$ depending on $h$ and $(d h / d x)$, which is negative for $h$ decreasing with the onshore coordinate $x$. The equilibrium profile with $q_{n}=0$ should become gentler (steeper) when $q_{n}$ becomes positive (negative) in order to decrease (increase) the offshore rate $q_{s}$ at the given depth $h$. The gentler (steeper) profile implies the landward (seaward) shift of the shoreline as observed in the $\mathrm{P}(\mathrm{N})$ test in Figure 4.5. 
Equations (5.1) - (5.3) are solved analytically

$$
y-y_{r}+\frac{q_{n}}{\alpha} \ln \left|\frac{\alpha y-q_{n}}{\alpha y_{r}-q_{n}}\right|=\frac{\alpha}{\beta}\left(x_{r}-x\right) ; y_{r}=h_{r}^{1.5}
$$

where, $x_{r}$ and $h_{r}=$ reference cross-shore location and depth on the equilibrium profile. For analytical convenience, Equation (5.4) is regarded to express $x$ as a function of $y=$ $h^{1.5}$. The equilibrium profile $x_{e}(y)$ for $q_{n}=0$ is expressed as

$$
y-y_{r}=\frac{\alpha}{\beta}\left(x_{r}-x_{e}\right) ; q_{n}=0
$$

The reference location is normally taken as the shoreline $(h=0)$ located at $x=x_{o}$. Equation (5.5) with $y_{r}=0$ and $x_{r}=x_{o}$ yields

$$
h=A\left(x_{o}-x_{e}\right)^{\frac{2}{3}} ; A=\left(\frac{\alpha}{\beta}\right)^{2 / 3} \text { for } q_{n}=0
$$

which, expresses the water depth $h$ as a function of $\left(x_{o}-x_{e}\right)$ offshore distance from the shoreline. The dimensional parameter $A$ in Equation (5.6) was estimated using laboratory and field data (Dean 1991). The expressions of $\alpha$ and $\beta$ in Equations (5.2)

and (5.3) indicate that the parameter $A$ is proportional to $\left(w_{f}^{2} / g\right)^{1 / 3}$ as proposed by Kriebel et al. (1991). In the following, $\alpha$ and $A$ are treated as independent parameters and $\left(\beta=\alpha / A^{1.5}\right)$ because $\mathrm{A}$ is better known than $\beta$.

\subsection{Horizontal Profile Shift}

The horizontal shift $S(y)$ of the equilibrium profile $x(y)$ for arbitrary $q_{n}$ from that for $q_{n}=0$ is expressed as $S(y)=x(y)-x_{e}(y)$. Subtraction of Equation (5.5) from Equation (5.4) yields 


$$
S(y)=\frac{q_{n}}{\alpha A^{1.5}} F(y) ; F(y)=\ln \left|\frac{\alpha y_{r}-q_{n}}{\alpha y-q_{n}}\right|
$$

where, $F(y)=0$ at $y=y_{r}$ with $y_{r}=h_{r}{ }^{1.5}$. The reference depth $h_{\mathrm{r}}$ is taken as the closure depth $d_{c}$ in order to predict the shift $S(y)$ in the vicinity of the shoreline. The dimensionless function $F$ is given by

$$
F\left(y_{*}\right)=\ln \left|\frac{1-q_{*}}{y_{*}-q_{*}}\right| ; y_{*}=\left(\frac{h}{d_{c}}\right)^{1.5} ; q_{*}=\frac{q_{n}}{\alpha d_{c}^{1.5}}
$$

which, is limited to the range of $0 \leq h \leq d_{\mathrm{c}}$ and $0 \leq y_{*} \leq 1$. The normalized rate $q_{*}$ is the ratio between the net rate $\mathrm{q}_{\mathrm{n}}$ and the bed load transport rate $q_{b}$ in Equation (5.2) at the closure depth $d_{c}$. For the $\mathrm{N}$ and $\mathrm{P}$ tests, the magnitude of $q *$ is found to be of the order of 0.002 . The net rates $\mathrm{q}_{\mathrm{n}}$ for the $\mathrm{N}$ and $\mathrm{P}$ tests are much smaller than the onshore and offshore sand transport rates. $\left|y_{*}-q_{*}\right|=q_{*}$ is used if $y<2 q^{*}$ for the case of $q_{*}>0$ to avoid zero when $y_{*}=q_{n}$.

\subsection{Comparison of the Analytical Model with Three Tests}

The equilibrium profile model is compared with the $\mathrm{Z}, \mathrm{N}$, and $\mathrm{P}$ tests. The equilibrium profile of Z10 with $q_{n}=0$ is compared with Equation (5.6) to estimate the parameter A. The shoreline location was $x_{o}=17.9 \mathrm{~m}$. The closure depth was $d_{c}=0.2 \mathrm{~m}$ at $x_{c}=11.7 \mathrm{~m}$. Equation (5.6) with $h=0.2 \mathrm{~m}$ at $x_{e}=11.7 \mathrm{~m}$ yields $A=0.059 \mathrm{~m}^{1 / 3}$. Figure 5.4 compares the measured and fitted profiles for $\mathrm{Z} 10$. The agreement is reasonable except for the step zone at the toe of the foreshore. The measured profiles of N20 and P20 could be fitted to Equation (5.6) with slightly different values of $A$ but use is made of $A=0.059 \mathrm{~m}^{1 / 3}$ for the $\mathrm{N}$ and $\mathrm{P}$ tests because $A$ is supposed to depend on the sand characteristics only. 
Measured and Analytical Profiles of Z10
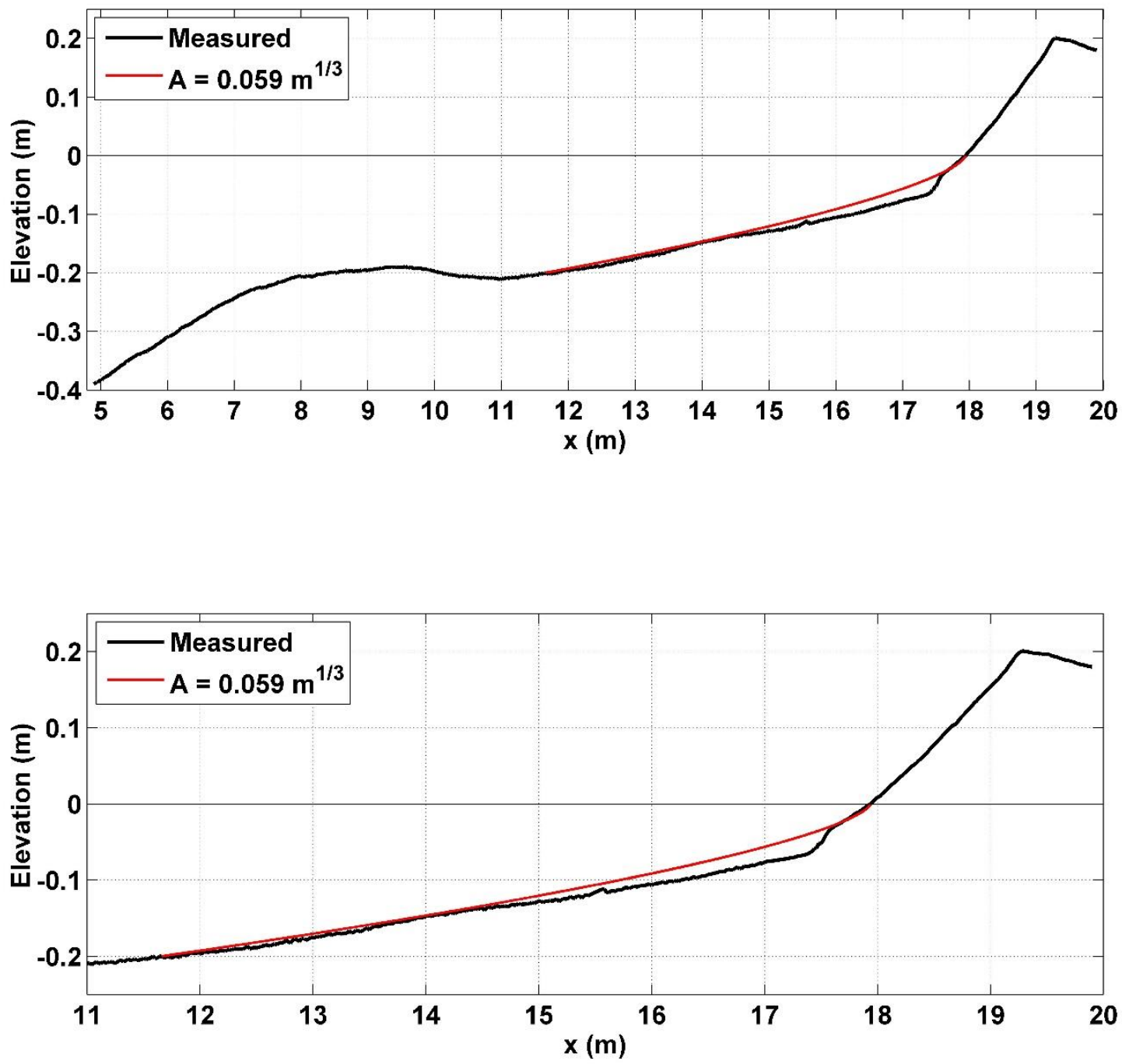

Figure 5.1: Measured profile and analytical profiles for Test $\mathrm{Z}$ with fitted $\mathrm{A}=0.059$ $\mathrm{m}^{1 / 3}$ from $\mathrm{x}_{\mathrm{c}}=11.7 \mathrm{~m}$ where $\mathrm{x}_{0}=17.9 \mathrm{~m}$ at zero elevation

The measured horizontal shift from the initial profile of N0 (same as Z10) to the final profile of $\mathrm{N} 20$ is compared with $S(y)$ given by Equation (5.7) with $y=h^{1.5}$. For the $\mathrm{N}$ test, $q_{n}=-0.006 \mathrm{~cm}^{2} / \mathrm{s}$ and $d_{c}=0.2 \mathrm{~m}$. Figure 5.2 compares the measured and computed values of $S$ at the given elevation $z=(-h)$. The dimensional parameter 
$\alpha$ is calibrated to yield the measured shift $S=-9 \mathrm{~cm}$ at the shoreline $(\mathrm{z}=0)$. The calibrated value is $\alpha=0.003 \mathrm{~m}^{1 / 2} / \mathrm{s}$. The dimensionless parameters in Equations (5.2) and (5.8) are $\alpha_{*}=0.0015$ and $q_{*}=0.0022$. The computed shift $\mathrm{S}$ is limited to the zone of $\mathrm{z}<0$ below the SWL and decreases downward with $S=0$ at the closure depth elevation $\mathrm{z}=-0.2 \mathrm{~m}$. The measured horizontal shift of the order of $0.1 \mathrm{~m}$ on the gentle slope seaward of the step is not predicted by Equation (5.7) because the analytical model cannot predict the formation and migration of the step at the toe of the foreshore. Figure 5.6 compares the measured and computed profiles of N20. The computed profile is obtained by adding the computed horizontal shift in Figure 5.2 horizontally to the measured initial profile of N0 because the equilibrium profile of Equation (5.6) does not include the step-like feature of N0 (Z10) as shown in Figure 5.1. The agreement has improved because of the use of the measured equilibrium profile of $\mathrm{Z} 10$ for $q_{n}=0$.

For the $\mathrm{P}$ test, the initial profile of $\mathrm{P} 0$ was not an equilibrium profile with $q_{n}=0$ after the 4-cm increase of the SWL, which resulted in wave overtopping and overwash of the foreshore crest. Figure 5.4 compares the measured and computed horizontal profile shift from P0 and P20. Use is made in Equations (5.7) and (5.8) of $q_{n}=0.0034 \mathrm{~cm}^{2} / \mathrm{s}$ (average during $8,000 \mathrm{~s}$ in Figure 3.5 ), $A=0.059 \mathrm{~m}^{1 / 3}$ (same), calibrated $\alpha=0.0015 \mathrm{~m}^{1 / 2} / \mathrm{s}$ (halved), and $d_{c}=0.24 \mathrm{~m}$ (4-cm SWL increase). The dimensionless parameters are $\alpha_{*}=0.0008$ and $q_{*}=0.0019$. The landward 8-cm shift of the shoreline at $\mathrm{z}=0$ did not represent the entire foreshore slope unlike in Figure 5.2 because of sand deposition on the upper foreshore. The measured horizontal shift below the foreshore included the profile adjustment after the 4-cm SWL increase and cannot be predicted by Equation (5.7). Figure 5.5 compares the 
measured and computed profiles of P20. The computed profile is the sum of the initial profile of P0 and the computed shift $S$ in Figure 5.4. The agreement of P20 is worse than that of N20 in Figure 5.3 partly because wave overwash was produced by the 4$\mathrm{cm}$ SWL increase which created a non-equilibrium initial profile.

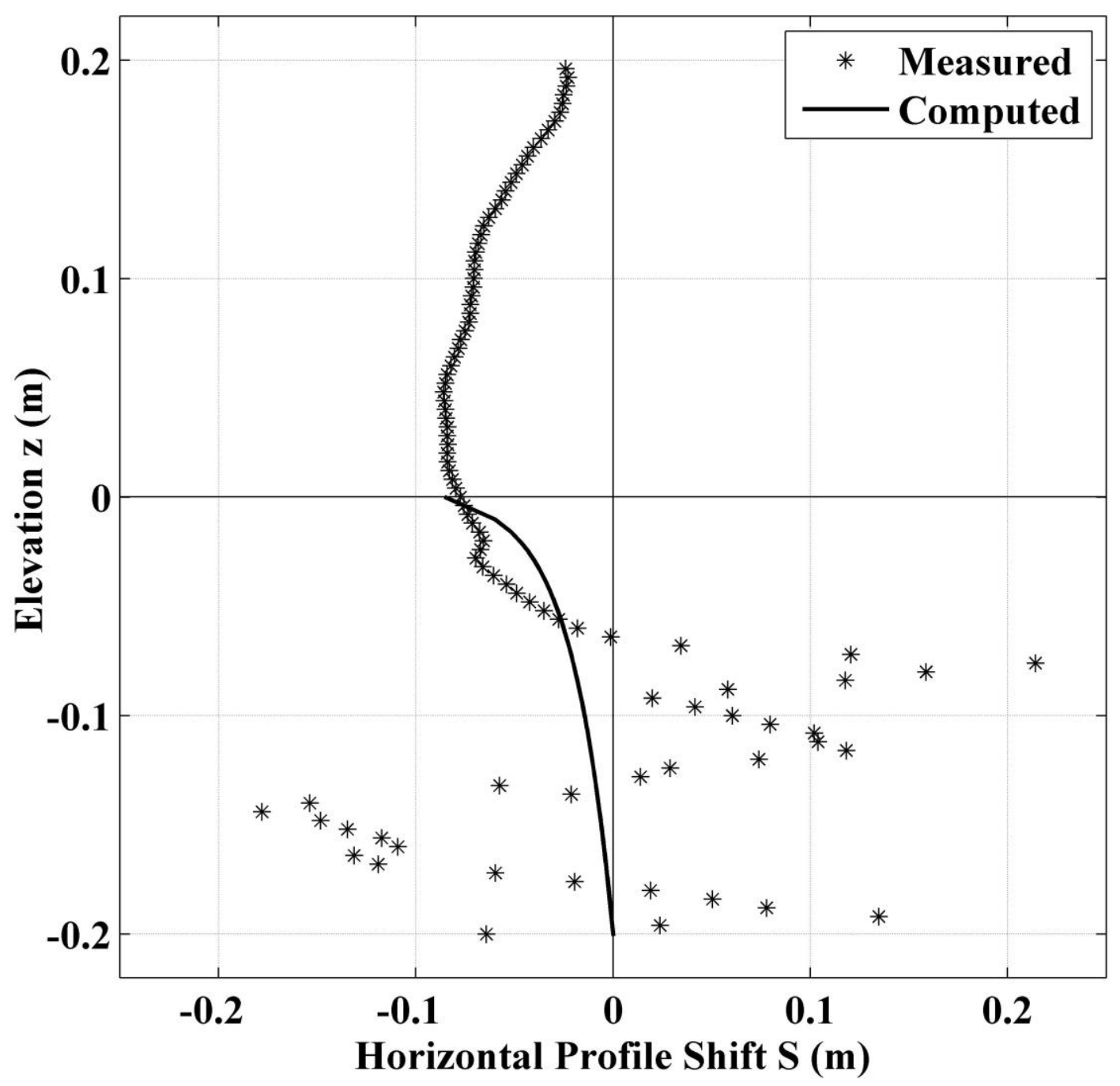

Figure 5.2: $\quad$ Measured and computed horizontal profile shift from N0 to N20 


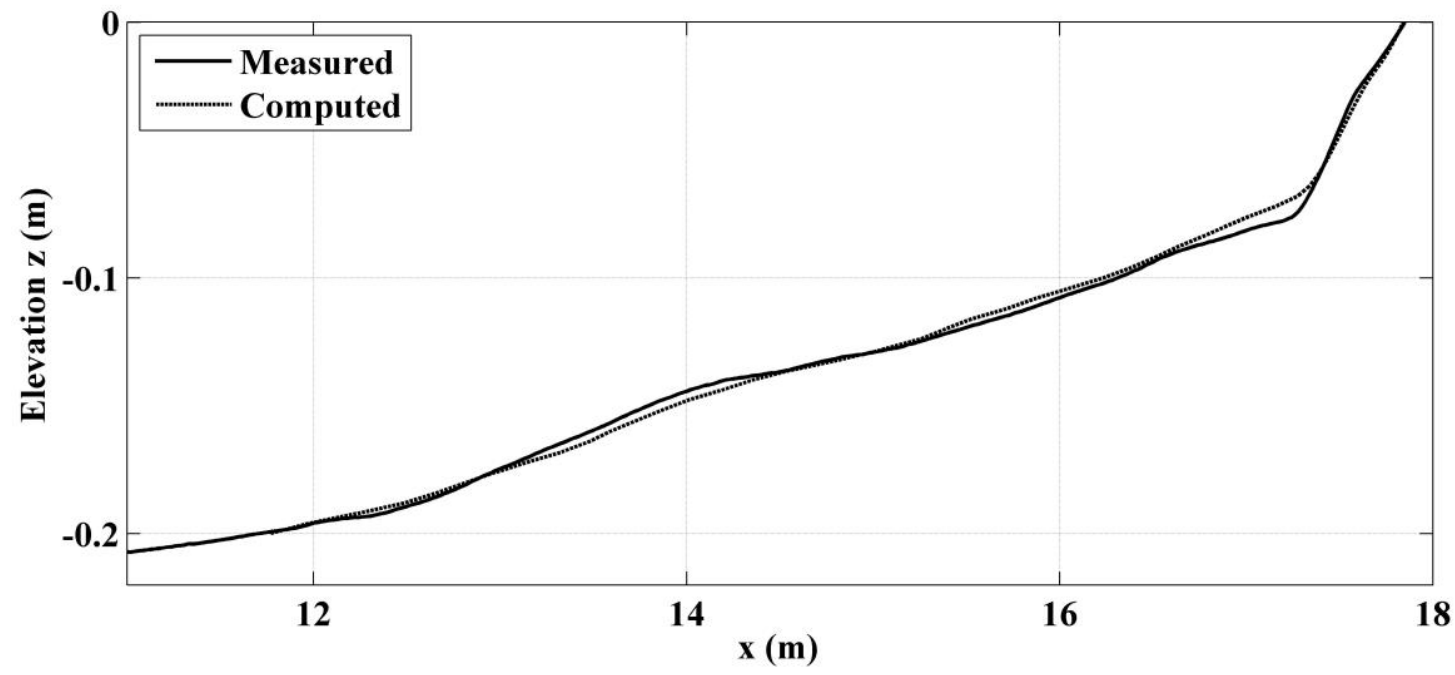

Figure 5.3: Measured and computed profile of N20 starting from initial profile of N0 


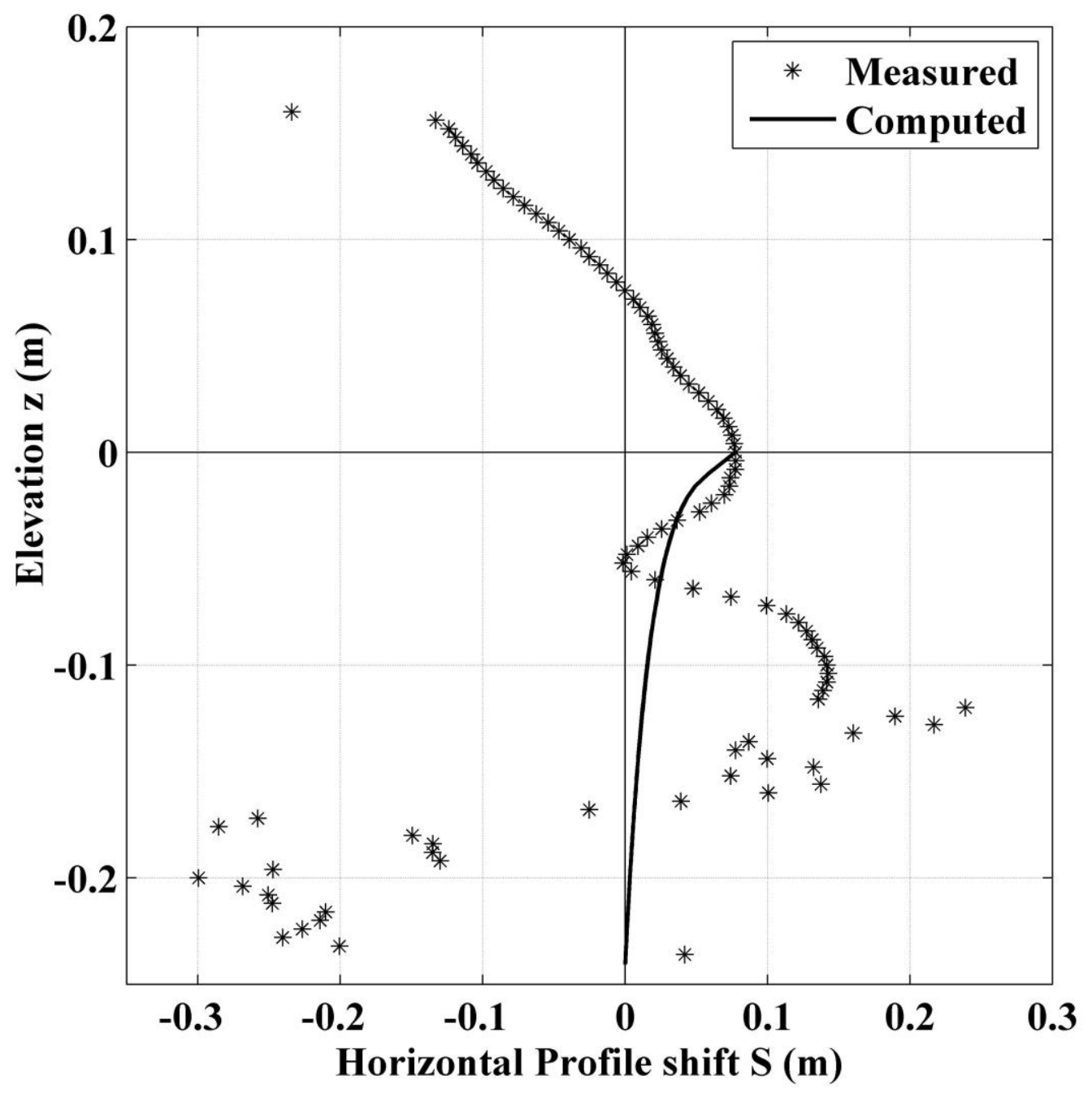

Figure 5.4: Measured and computed horizontal shift from P0 to P20 


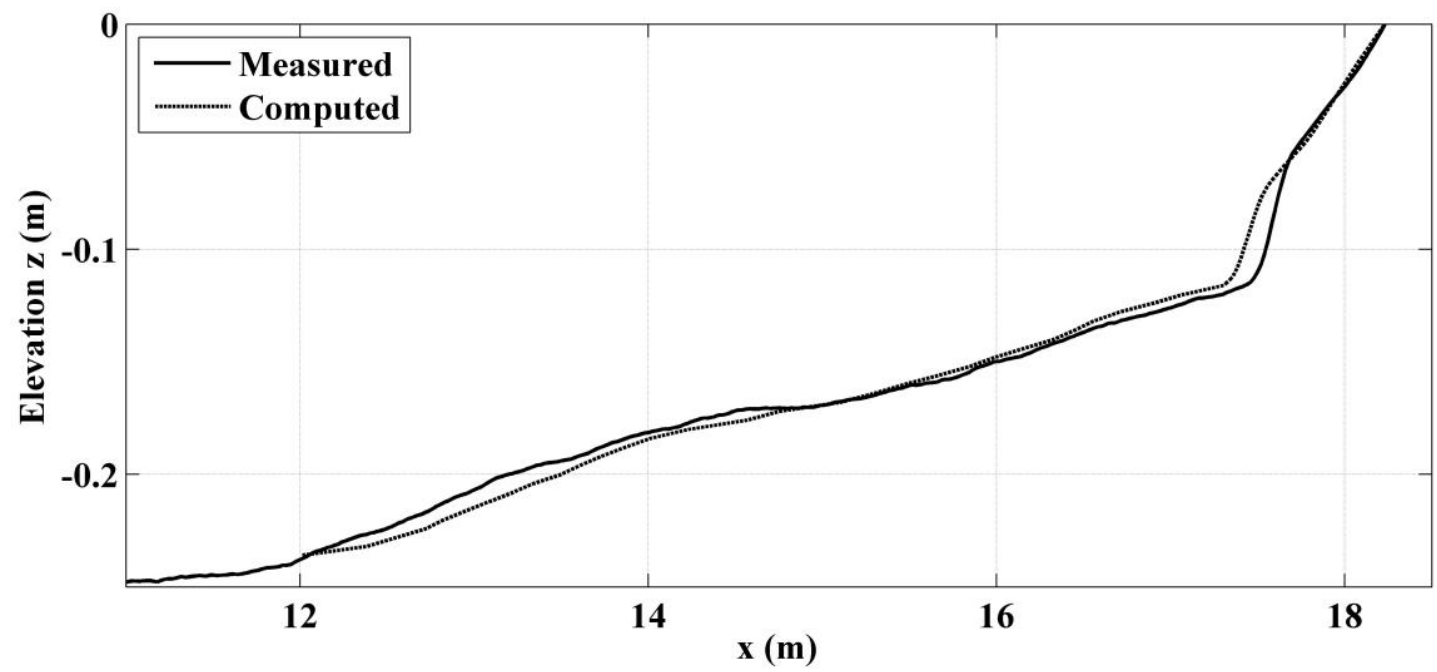

Figure 5.5: Measured and computed profile of P20 starting from initial profile of P0 


\section{Chapter 6}

\section{FIELD APPLICATION OF THE NEW MODEL}

The simple equilibrium profile model with net cross-shore sand transport rate $q_{n}$ may not be very accurate but may be used to estimate the shoreline shift of an equilibrium profile with $q_{n}=0$ caused by periodic sand placement $q_{n}<0$ near the shoreline or frequent sand overwash $\left(q_{n}>0\right)$ resulting from sea level rise. The following application of Equations (5.7) and (5.8) evaluates the present beachfill design which does not account for the equilibrium profile modification caused by periodic beachfill placement.

The seaward shoreline displacement $\mathrm{D}$ caused by $\mathrm{q}_{\mathrm{n}}<0$ is estimated as $D=[-S(y=0)]$ in Equation (5.7).

$$
D=\frac{-q_{n}}{\alpha A^{1.5}} \ln \left|\frac{1-q_{*}}{-q_{*}}\right| ; q_{*}=\frac{q_{n}}{\alpha d_{c}^{1.5}}
$$

The value of $A=0.059 \mathrm{~m}^{1 / 3}$ is kept the same because the functional relation between

$D$ and $A$ is simple. For the $\mathrm{N}$ test, $\alpha=0.003 \mathrm{~m}^{1 / 2} / \mathrm{s},\left(-q_{n}\right)=0.006 \mathrm{~cm}^{2} / \mathrm{s}\left(19 \mathrm{~m}^{2} / \mathrm{y}\right)$, and $d_{c}=0.2 \mathrm{~m}$. 


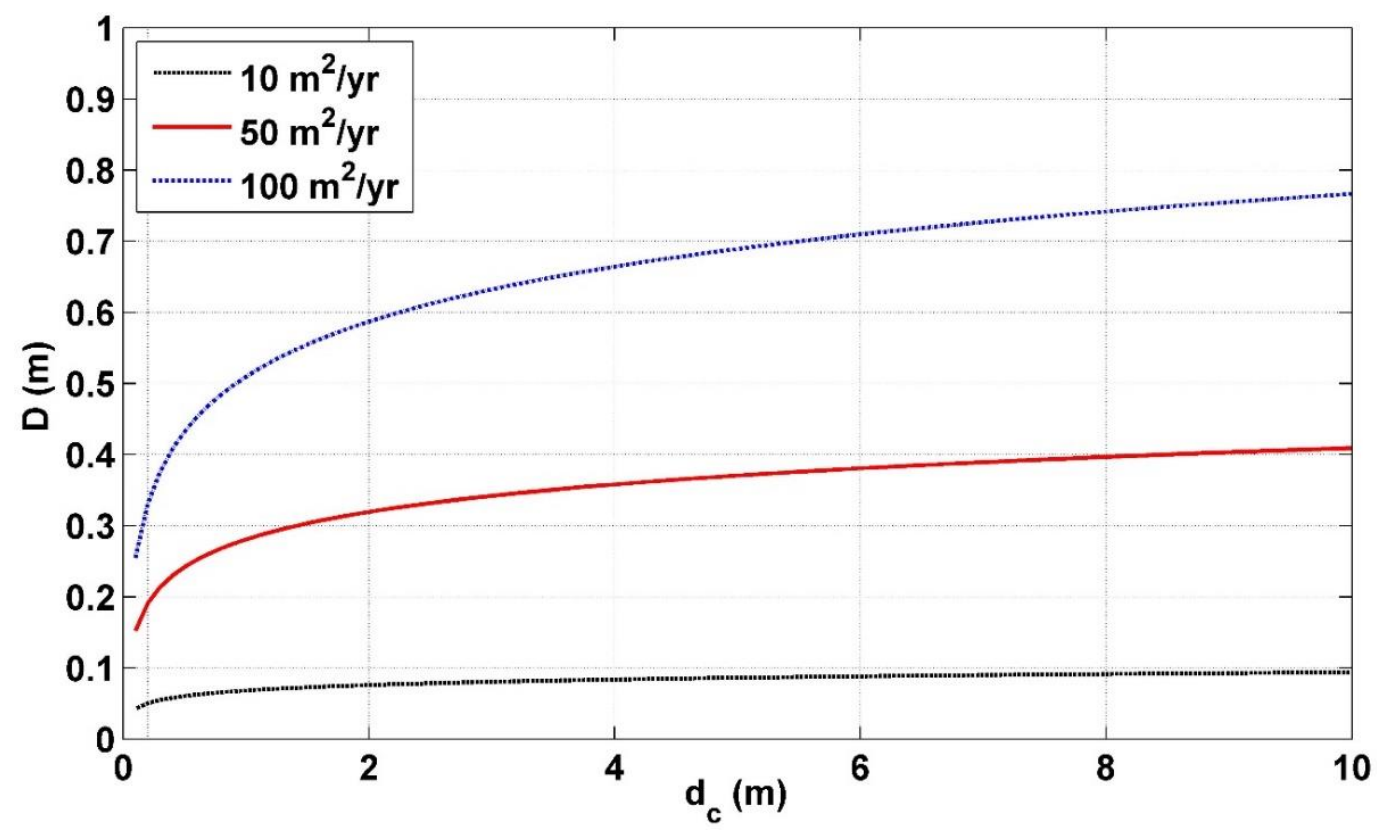

Figure 6.1: Seaward shoreline displacement $D(m)$ as a function of closure depth $d_{c}$ (m) for $\alpha=0.003 \mathrm{~m}^{1 / 2} / \mathrm{s}$ and $\left(-\mathrm{q}_{\mathrm{n}}\right)=10 \mathrm{~m}^{2} / \mathrm{yr}, 50 \mathrm{~m}^{2} / \mathrm{yr}$, and $100 \mathrm{~m}^{2} / \mathrm{yr}$

Figure 6.1 shows the seaward shoreline displacement $D$ as a function of the closure depth $d_{c}$ for $\left(-\mathrm{q}_{\mathrm{n}}\right)=10,50$, and $100 \mathrm{~m}^{2} / \mathrm{y}$. The increase of $D$ with the increase of $d_{c}$ is rapid at $\mathrm{d}_{\mathrm{c}}=0.1 \mathrm{~m}$ but becomes slow for $\mathrm{d}_{\mathrm{c}}$ exceeding $2 \mathrm{~m}$. For field applications with $d_{c}$ of about $6 \mathrm{~m}, D$ is not very sensitive to $d_{c}$. It is noted that the present model allows net cross-shore sand transport at the closure depth. The displacement $D$ increases with the rate of beachfill placement which is normally less than $100 \mathrm{~m}^{2} / \mathrm{y}$. Figure 6.1 suggests that the displacement $D$ should be less than $1 \mathrm{~m}$. The dimensional parameter $\alpha$ is supposed to be constant for the sand with $s=2.6$ in light of Equation (5.2) but $\alpha=0.0015 \mathrm{~m}^{1 / 2} / \mathrm{s}$ was necessary to reproduce the measured shoreline shift of P20. Figure 6.2 shows the displacement $D$ as a function of $\mathrm{d}_{\mathrm{c}}$ for $\left(-q_{n}\right)=50 \mathrm{~m}^{2} / \mathrm{y}$ and $\alpha=0.001,0.002$, and $0.003 \mathrm{~m}^{1 / 2} / \mathrm{s}$. 
The displacement $D$ is sensitive to $\alpha$ but may not exceed $1 \mathrm{~m}$. Equation (6.1) will need to be verified using large-scale laboratory data and field data.

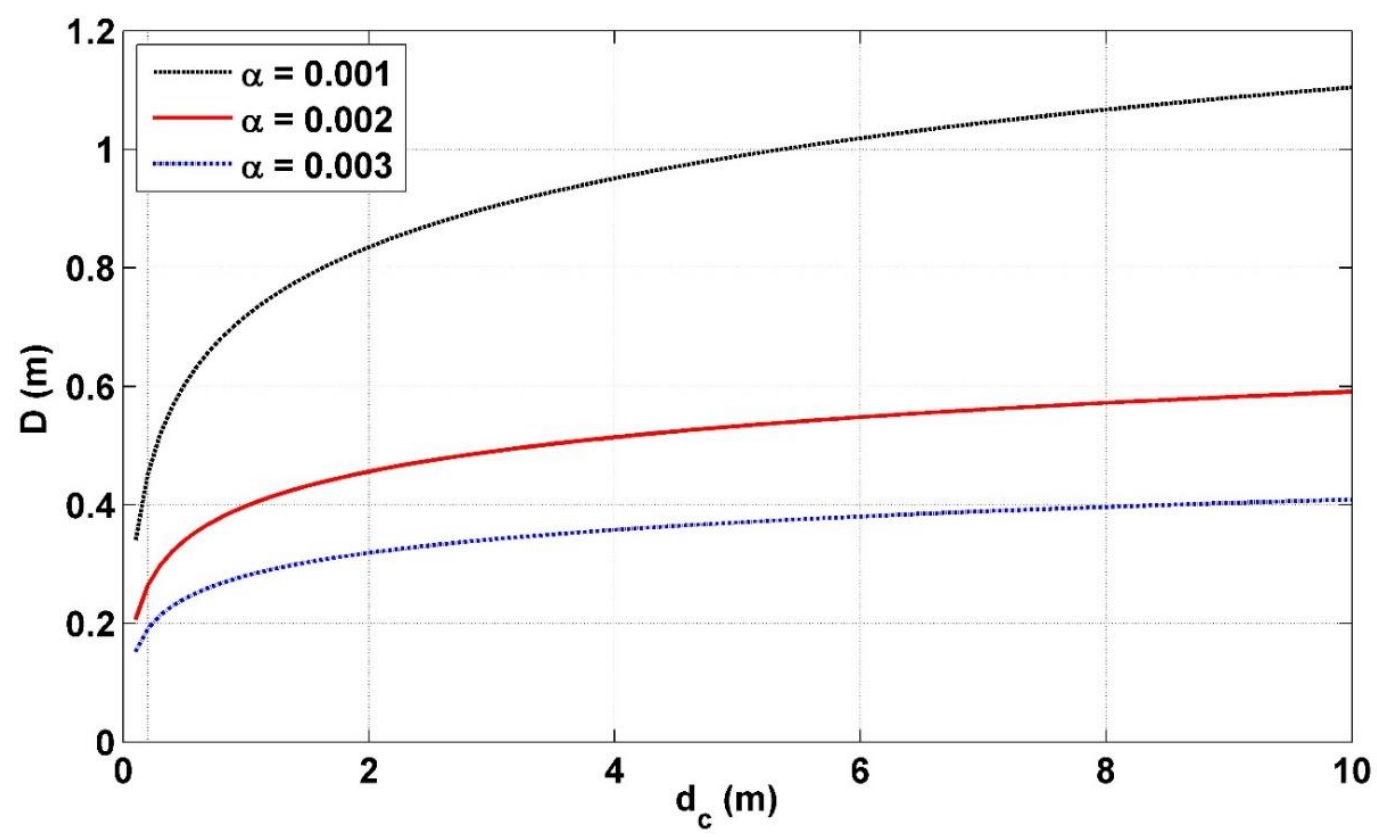

Figure 6.2: Seaward shoreline displacement $D(m)$ as a function of closure depth $d_{c}$ (m) for $\left(-\mathrm{q}_{\mathrm{n}}\right)=50 \mathrm{~m}^{2}$ and $\alpha=1 \times 10^{-3}, 2 \times 10^{-3}$ and $3 \times 10^{-3} \mathrm{~m}^{1 / 2} / \mathrm{s}$ 


\section{Chapter 7}

\section{COMPARISION WITH NUMERICAL PROFILE EVOLUTION MODEL}

This chapter explains the cross-shore numerical model CSHORE and compare CSHORE with the three tests. The numerical model of CSHORE is described in detail in Kobayashi (2016).

\subsection{Cross-Shore Model (CSHORE)}

The components of CSHORE for normally incident waves used in this study include: a combined wave and current model based on time- averaged continuity, momentum, wave action, and roller energy equations; a sediment transport model for bed load and suspended load coupled with the continuity equation of bottom sediment; and a probabilistic swash model on an impermeable bottom. The fine sand used in the experiment is assumed to be impermeable. Input to the numerical model for each test includes the measured bottom elevation $z_{b}$ of sand surface at time $t=0$, measured values of $\bar{\eta}, \mathrm{H}_{\mathrm{mo}}$, and $\mathrm{T}_{\mathrm{p}}$ at $\mathrm{x}=0$ for all the runs in the tests. The input parameters for CSHORE are taken as standard values in order to assess the degree of agreement in light of previous comparisons discussed in Kobayashi (2016).

The cross-shore model CSHORE computes the mean and standard deviation (SD) of the free surface elevation above SWL and the depth-averaged cross-shore velocity $U$ above the bottom elevation $\mathrm{z}_{\mathrm{b}}$. The cross-shore bed load and suspended load transport rates $\mathrm{q}_{\mathrm{b}}$ and $\mathrm{q}_{\mathrm{s}}$ are estimated using the empirical formulas in CSHORE. 


\subsection{Cross-Shore Wave Transformation}

The CSHORE is compared with the measured data of the cross-shore wave transformation, wave overtopping and sand overwash rates, and beach profile evolutions for $\mathrm{Z}, \mathrm{N}$ and $\mathrm{P}$ tests. The measured cross-shore variations of $\bar{\eta}, \sigma_{\eta}, P w, \bar{U}$, and $\sigma_{U}$ are plotted for 10 or 20 runs with constant SWL in each test together with the computed cross-shore variations in Figures 7.1-7.3. These hydrodynamic variables are predicted within errors of about $20 \%$ except for WG8 at $\mathrm{x}=18.6 \mathrm{~m}$ in the swash zone.

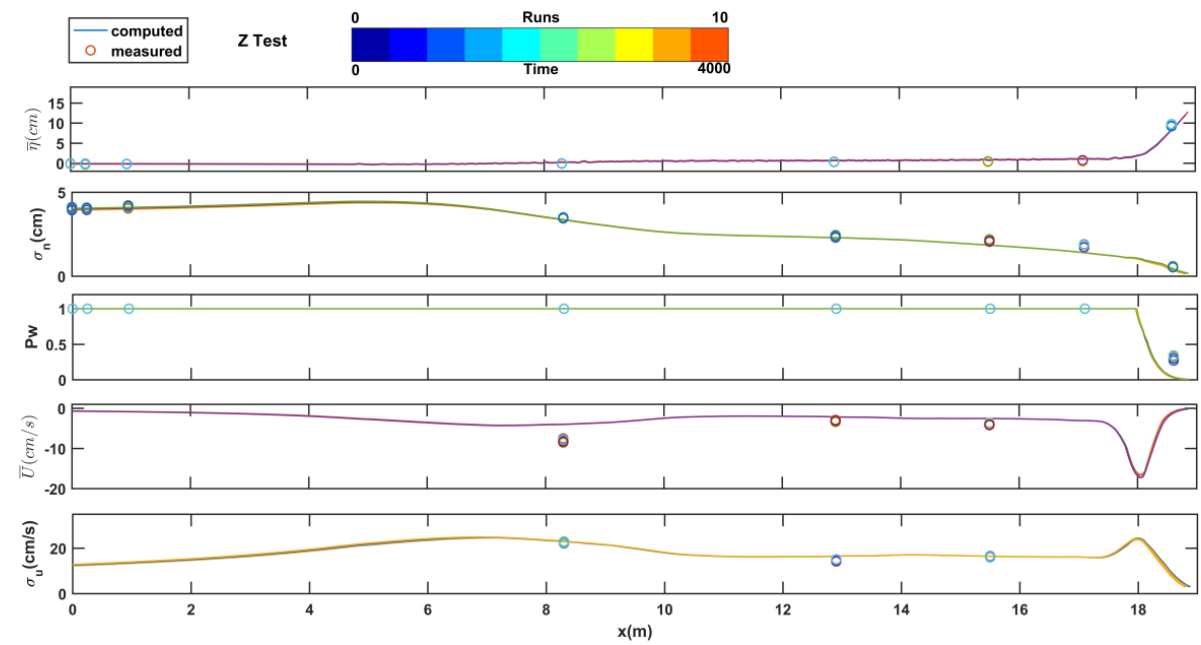

Figure 7.1: Mean and standard deviation of free surface elevation $\bar{\eta}$ and horizontal velocity $\bar{U}$ together with wet probability $\mathrm{P}_{\mathrm{w}}$ for 10 runs during time $\mathrm{t}=0$ to $4,000 \mathrm{~s}$ for Test $\mathrm{Z}$ 


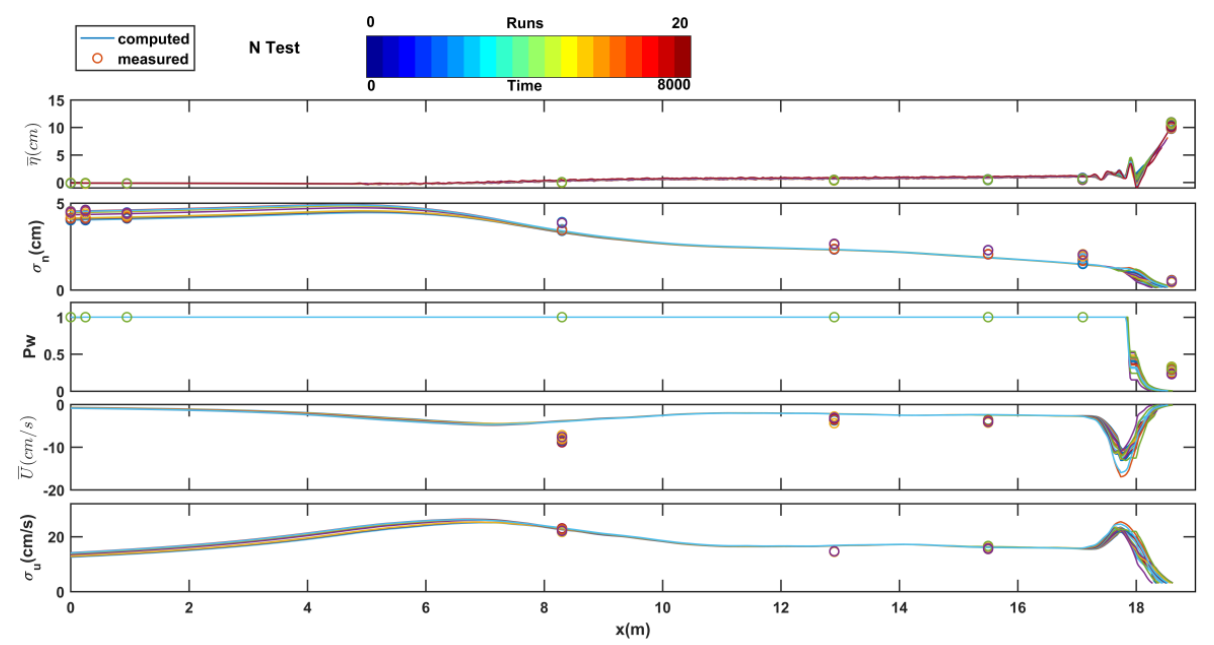

Figure 7.2: Mean and standard deviation of free surface elevation $\bar{\eta}$ and horizontal velocity $\bar{U}$ together with wet probability $\mathrm{P}_{\mathrm{w}}$ for 20 runs during time $\mathrm{t}=0$ to $8,000 \mathrm{~s}$ for Test $\mathrm{N}$

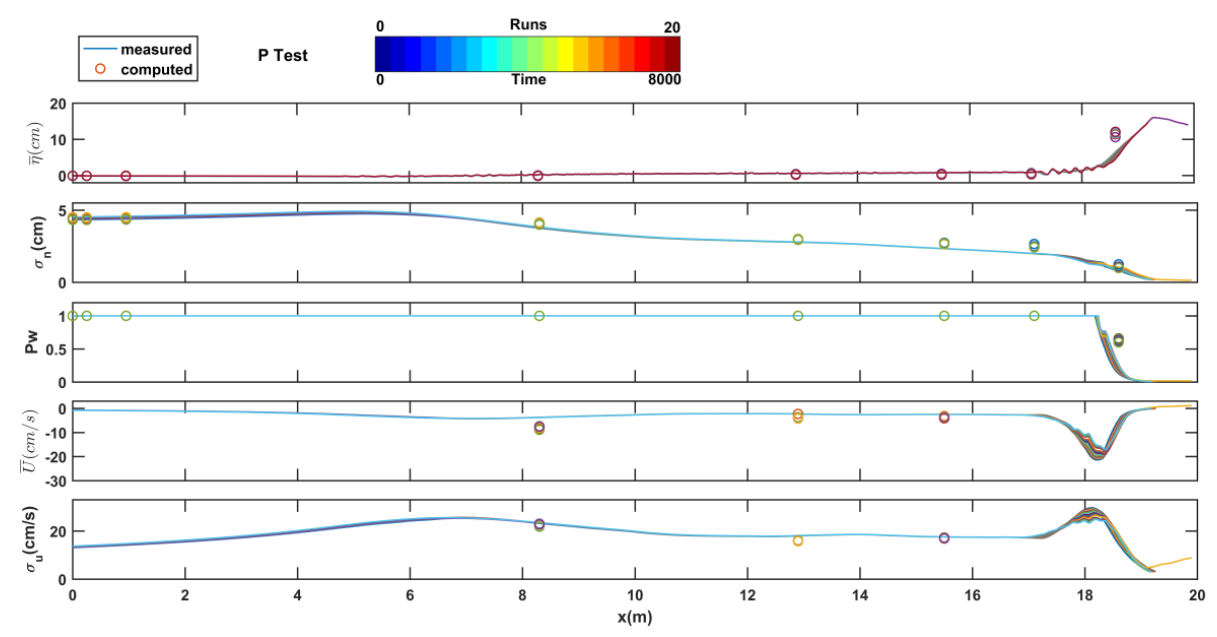

Figure 7.3: Mean and standard deviation of free surface elevation $\bar{\eta}$ and horizontal velocity $\bar{U}$ together with wet probability $\mathrm{P}_{\mathrm{w}}$ for 20 runs during time $\mathrm{t}=0$ to $8,000 \mathrm{~s}$ for Test $\mathrm{P}$ 


\subsection{Wave Overtopping and Overwash Rates}

The average wave overtopping rate $\mathrm{q}_{\mathrm{o}}$ and sand overwash rate $\mathrm{q}_{\mathrm{bs}}$ during each run for Test $\mathrm{P}$ are shown in Figure 7.4. These small rates are associated with the mean water depth on the berm of the order of $0.1 \mathrm{~cm}$. No overtopping and overwash occurred in the $\mathrm{Z}$ and $\mathrm{N}$ during $\mathrm{t}=0-4,000 \mathrm{~s}$ and $\mathrm{t}=0-8,000 \mathrm{~s}$ respectively. The small rates are difficult to predict accurately.
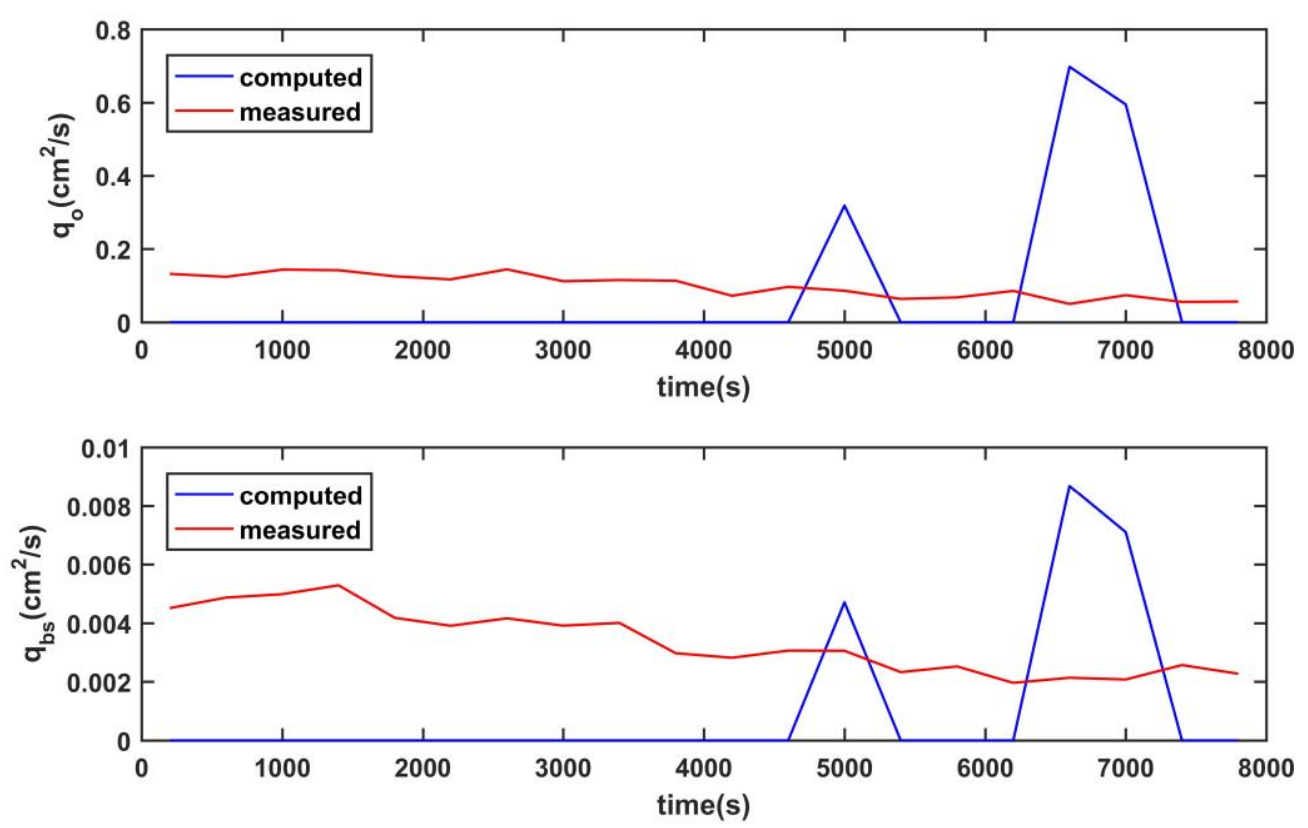

Figure 7.4: Water overtopping rate $\mathrm{q}_{\mathrm{o}}$ and sand overwash rate $\mathrm{q}_{\mathrm{bs}}$ during Test $\mathrm{P}$

\subsection{Beach Profile Evolution}

The initial, measured and computed profiles for the $\mathrm{Z}, \mathrm{N}$ and $\mathrm{P}$ tests are compared in Figures $7.5,7.6$ and 7.7, respectively, where the initial profile at $t=0$ is plotted to indicate the degree of the profile change at the given time. The profiles are plotted at $\mathrm{t}=2000 \mathrm{~s}$ and $\mathrm{t}=4000 \mathrm{~s}$ for the $\mathrm{Z}$ test. For the $\mathrm{N}$ and $\mathrm{P}$ tests, the profiles are 
plotted at $\mathrm{t}=2000 \mathrm{~s}, \mathrm{t}=4,000 \mathrm{~s}$ and $\mathrm{t}=8,000 \mathrm{~s}$. The profile changes are less than $2 \mathrm{~mm}$ for $\mathrm{x}<11 \mathrm{~m}$ and hence these figures are limited to $\mathrm{x}>11 \mathrm{~m}$. CSHORE cannot consistently predict small accretional and erosional profile changes of quasiequilibrium profiles caused by periodic sand placement and overwash.
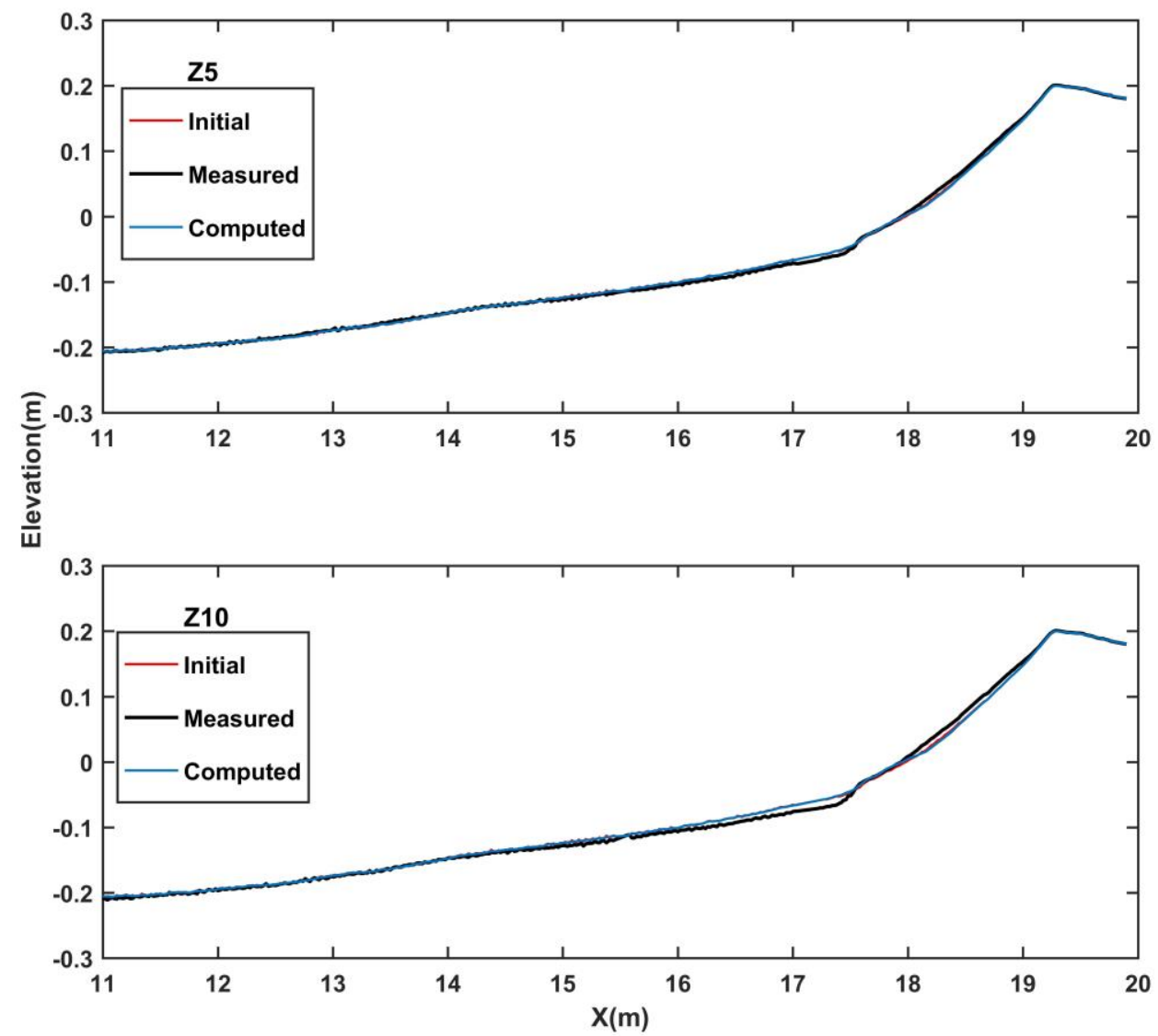

Figure 7.5: Initial, measured and computed profiles for $\mathrm{t}=2,000 \mathrm{~s}$ and $\mathrm{t}=4,000 \mathrm{~s}$ of Test Z 

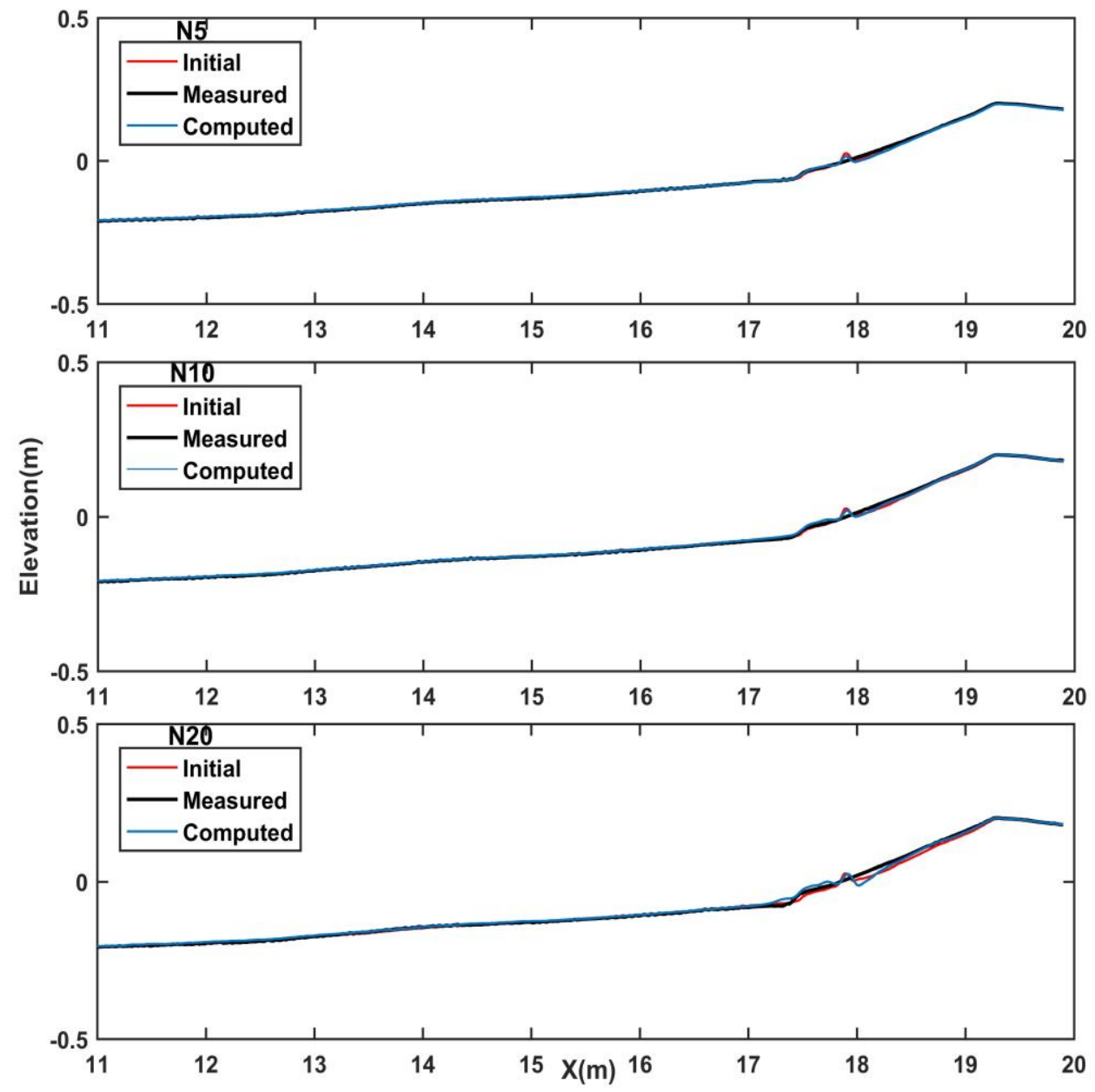

Figure 7.6: Initial, measured and computed profiles at $\mathrm{t}=2,000 \mathrm{~s}, \mathrm{t}=4,000 \mathrm{~s}$ and $\mathrm{t}=8,000 \mathrm{~s}$ for Test $\mathrm{N}$ 

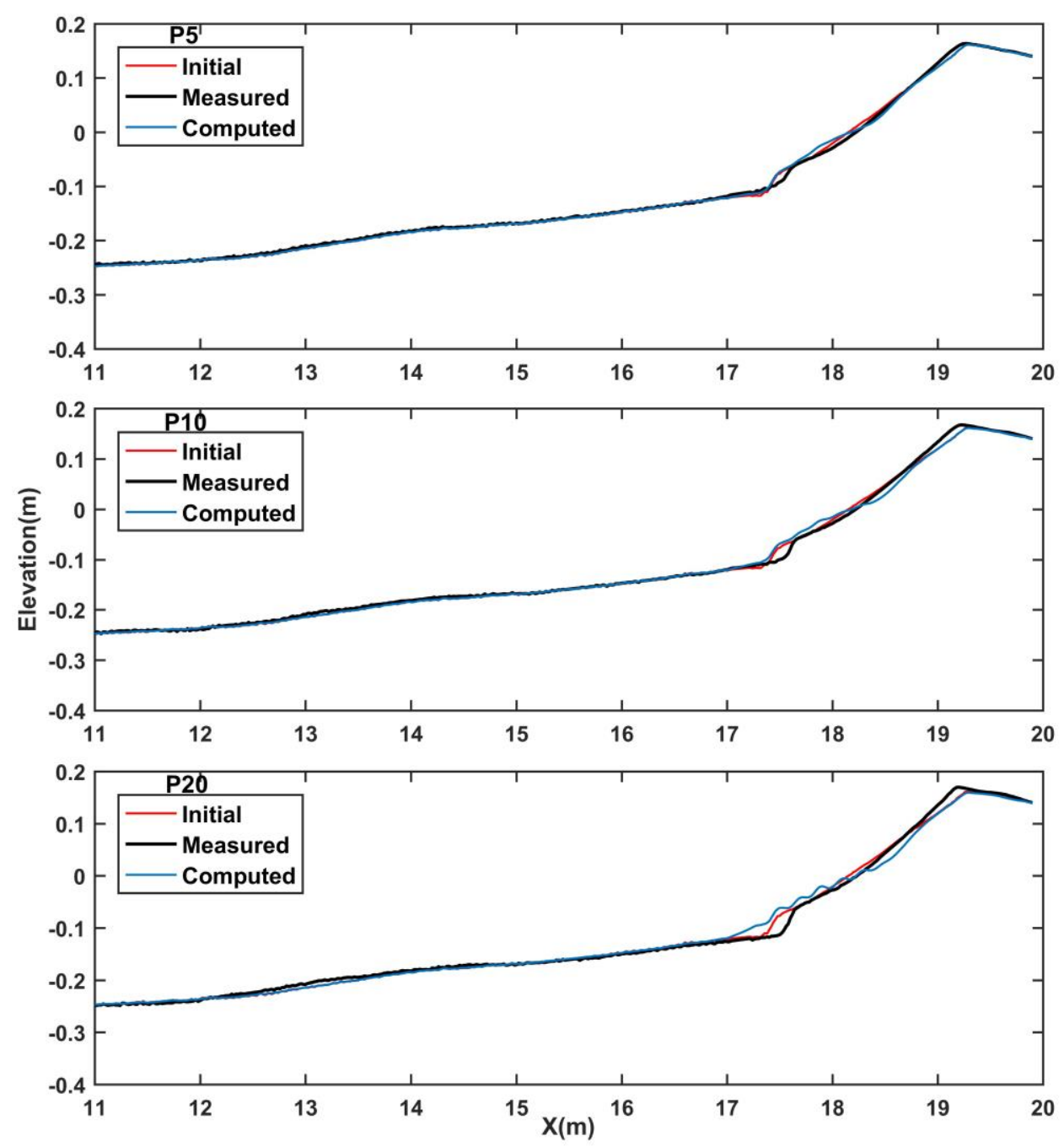

Figure 7.7: Initial, measured and computed profiles at $\mathrm{t}=2,000 \mathrm{~s}, \mathrm{t}=4,000 \mathrm{~s}$ and $\mathrm{t}=8,000 \mathrm{~s}$ for Test $\mathrm{P}$ 


\section{Chapter 8}

\section{CONCLUSIONS}

\subsection{Experimental Findings}

Three tests consisting of fifty 400-s runs were conducted in a small-scale experiment to quantify the differences among quasi-equilibrium profiles in the inner surf zone on a sand beach under the conditions of zero, negative (offshore), and positive (onshore) net cross-shore sand transport. A step-like feature formed at the toe of the foreshore and migrated in the three tests. The negative net sand transport resulting from periodic sand placement near the shoreline translated the foreshore slope seaward and made the beach profile steeper. The positive net sand transport caused by wave overtopping and overwash, shifted the shoreline landward and made the inner surf zone profile gentler. However, the profile changes among the three tests were relatively small and the shoreline shifts were less than $0.1 \mathrm{~m}$. The conventional model based on the conservation of sand volume and the cross-shore translation of an entire active profile underpredicts the shoreline changes measured in this experiment because only a portion of the profile translated.

\subsection{Analytical Modeling}

An analytical model for an equilibrium profile with net cross-shore sand transport is developed by approximating the bed load and suspended load formulas by Kobayashi et al. (2008) in the inner surf zone. The analytical model produces the equilibrium profile equation by Dean (1991) for the case of zero net cross-shore sand transport. The model predicts the seaward (landward) shift of the equilibrium profile caused by negative (positive) net cross-shore sand transport. The model cannot 
predict the migration of the step. The predicted horizontal shift is the maximum at the shoreline and approaches zero at the closure depth. Two parameters in the model are calibrated using the three tests. The equilibrium profile parameter $\mathrm{A}$ is calibrated using the equilibrium profile with net sand transport rate $q_{n}=0$. The bed load parameter $\alpha$ calibrated for the two tests with $\mathrm{q}_{\mathrm{n}}<0$ and $\mathrm{q}_{\mathrm{n}}>0$ differs by a factor of two. The calibrated model is used to estimate the seaward shift of the shoreline on periodically-nourished beaches of prototype scale. The estimated shift is of the order of $1 \mathrm{~m}$ or less but will need to be verified using large-scale laboratory data

The analytical model will need to be extended to oblique waves and verified using field data. Oblique waves and longshore current modify the net cross-shore sand transport rate [e.g., Kobayashi et al. (2009)] which is assumed constant in the inner surf zone. Long-term onshore sand transport from outside the inner surf zone (Dean and Houston 2016) may affect the inner surf zone profile. Extreme storms may cause significant offshore suspended sand transport beyond the closure depth [e.g., Madsen et al. (1994)]. Net cross-shore sand transport outside the closure depth is uncertain at present. The findings of this study may encourage careful analyses of nourished and overwashed beach profile and shoreline data in the future because the predicted shift is relatively small.

\subsection{Numerical Modeling}

The accuracy of cross-shore numerical model CSHORE is assessed using the three tests. The mean and standard deviation of free surface elevation and velocity are predicted within errors of about $20 \%$ as in previous comparisons. However, CSHORE cannot consistently predict small erosional and accretional profile changes of quasiequilibrium profiles caused by periodic sand placement and overwash. It is 
challenging to develop a reliable model that can predict long-term beach profile evolution including periodic beachfill placement or frequent overwash. 


\section{REFERENCES}

Dean, R.G. (1991). "Equilibrium beach profiles: Characteristics and applications." J. Coastal Res., 7(1), 53-84.

Dean, R.G., and Houston, J.R. (2016). "Determining shoreline response to sea level rise." Coastal Eng., 114, 1-8.

Figlus, J., Kobayashi, N., Gralher, C., and Iranzo, V. (2011). "Wave overtopping and overwash of dunes." J. Waterway, Port, Coastal, Ocean Eng., 10.1061/(ASCE)WW.1943-5460.0000060, 26-33.

Houston, J.R. (2016). "Beach nourishment as an adaptation strategy for sea level rise: A Florida east coast perspective." Shore \& Beach, 84(2), 3-12.

Jiménez, J.A., Sallenger, A.H., and Fauver, L. (2006). "Sediment transport and barrier island changes during massive overwash events." Proc. 30th Coastal Engineering Conf., World Scientific, Singapore, 2870-2879.

Kobayashi, N. (2016). "Coastal sediment transport modeling for engineering applications.” J. Waterway, Port, Coastal, Ocean Eng., 10.1061/(ASCE)WW. 1943-5460.0000347.

Kobayashi, N., Buck, M., Payo, A., and Johnson, B. (2009). "Berm and dune erosion during a storm." J. Waterway, Port, Coastal, Ocean Eng., 10.1061/(ASCE)0733-950X(2009)135:1(1), 1-10.

Kobayashi, N., and Jung, H. (2012). "Beach erosion and recovery.” J. Waterway, Port, Coastal, Ocean Eng., 10.1061/(ASCE)WW.1943-5460.0000147, 473483.

Kobayashi, N., Payo, A., and Schmied, L. (2008). "Cross-shore suspended sand and bed load transport on beaches." J. Geophys. Res., 113(C7), C07001.

Kriebel, D.L., Kraus, N.C., and Larson, M. (1991). "Engineering methods for predicting beach profile response." Proc. Coastal Sediments 1991, ASCE, Reston, VA, 557-571. 
Madsen, O.S., Chisholm, T.A., and Wright, L.D. (1994). "Suspended sediment transport in inner shelf waters during extreme storms." Proc. 24th Coastal Engineering Conf., World Scientific, Singapore, 1849-1864.

Rosati, J.D., and Stone, G.W. (2009). "Geomorphologic evolution of barrier islands along the northern U.S. Gulf of Mexico and implications for engineering design in barrier restoration." J. Coastal Res., 25(1), 8-22.

USACE (U.S. Army Corps of Engineers). (2003). Coastal engineering manual, Washington, D.C. 
Appendix

\section{CROSS-SHORE SEDIMENT TRANSPORT TESTS}


A.1 Zero (Z) Net Cross-shore Sediment Transport Test

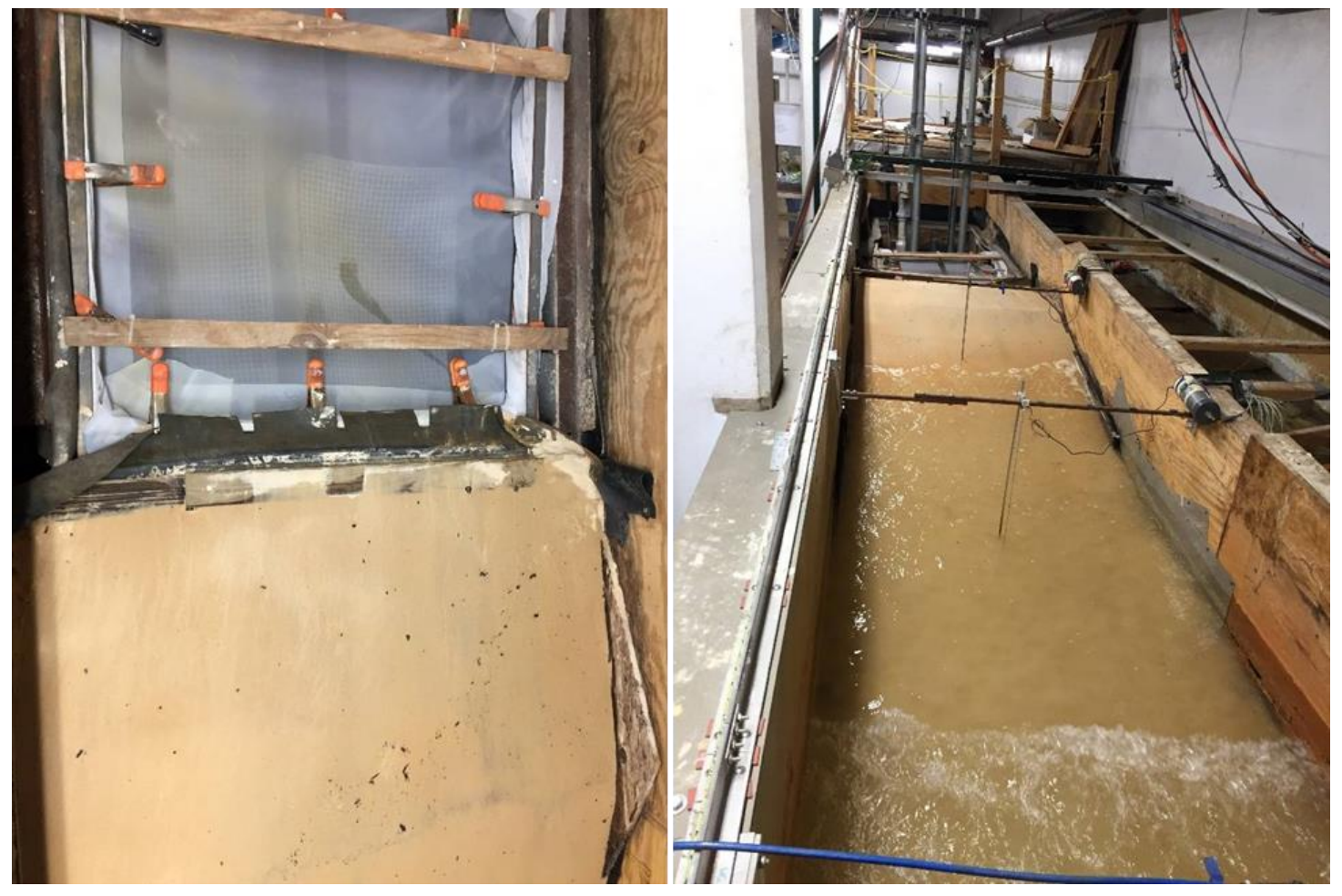



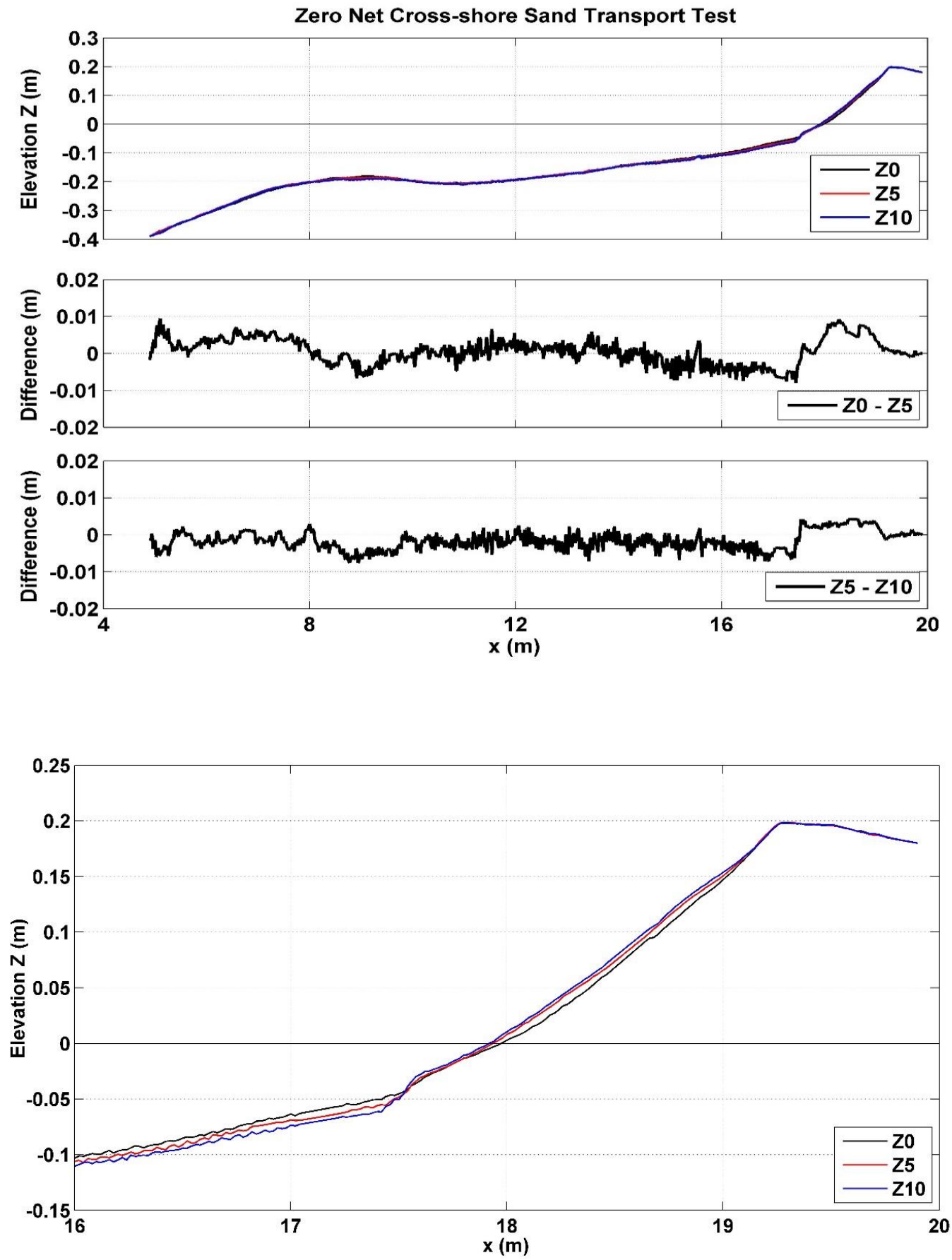

Figure A.1: Zero $(\mathrm{Z})$ net cross-shore sediment transport test with 10 runs indicated by the numeral 1-10. For example, Z5 is run 5 in test $\mathrm{Z}$. The measured profiles were $\mathrm{Z} 0$ before the $\mathrm{Z}$ test, $\mathrm{Z} 5$ after 5 runs, and $\mathrm{Z} 10$ after 10 runs. The elevation $\mathrm{z}$ is zero at the still water level in 88 -cm water depth. 
Table A.1: Incident wave characteristics for Test $\mathrm{Z}$

\begin{tabular}{lcccccc}
\hline Run & $\boldsymbol{H}_{\boldsymbol{m} \boldsymbol{o}}(\mathbf{c m})$ & $\boldsymbol{H}_{\boldsymbol{r} \boldsymbol{s}}(\mathbf{c m})$ & $\boldsymbol{H}_{\boldsymbol{s}}(\mathbf{c m})$ & $\boldsymbol{T}_{\boldsymbol{p}}(\mathbf{s})$ & $\boldsymbol{T}_{\boldsymbol{s}}(\mathbf{s})$ & \multicolumn{1}{l}{$\boldsymbol{R}$} \\
\hline $\mathbf{Z 1}$ & 16.33 & 11.54 & 15.53 & 2.62 & 2.09 & 0.128 \\
$\mathbf{Z 2}$ & 16.46 & 11.64 & 15.62 & 2.62 & 2.09 & 0.127 \\
$\mathbf{Z 3}$ & 16.33 & 11.55 & 15.50 & 2.62 & 2.04 & 0.129 \\
$\mathbf{Z 4}$ & 16.52 & 11.68 & 15.74 & 2.62 & 2.05 & 0.131 \\
$\mathbf{Z 5}$ & 16.71 & 11.81 & 15.85 & 2.62 & 2.06 & 0.123 \\
$\mathbf{Z 6}$ & 16.47 & 11.65 & 15.77 & 2.62 & 2.09 & 0.129 \\
$\mathbf{Z 7}$ & 16.79 & 11.87 & 16.02 & 2.62 & 2.09 & 0.127 \\
$\mathbf{Z 8}$ & 16.89 & 11.94 & 16.12 & 2.62 & 2.08 & 0.121 \\
$\mathbf{Z 9}$ & 16.98 & 12.00 & 16.28 & 2.62 & 2.06 & 0.129 \\
$\mathbf{Z 1 0}$ & 16.99 & 12.01 & 16.28 & 2.62 & 2.08 & 0.128 \\
\hline Average & $\mathbf{1 6 . 6 5}$ & $\mathbf{1 1 . 7 7}$ & $\mathbf{1 5 . 8 7}$ & $\mathbf{2 . 6 2}$ & $\mathbf{2 . 0 7}$ & $\mathbf{0 . 1 2 7}$ \\
\hline
\end{tabular}


Table A.2: $\quad$ Mean free-surface elevation $\bar{\eta}(\mathrm{cm})$ at seven wave gauge locations

\begin{tabular}{llllllll}
\hline Run & WG1 & WG2 & WG3 & WG4 & WG5 & WG6 & WG7 \\
\hline Z1 & -0.12 & -0.11 & -0.18 & -0.10 & 0.29 & 0.41 & 0.55 \\
$\mathbf{Z 2}$ & -0.17 & -0.16 & -0.18 & -0.07 & 0.34 & 0.41 & 0.56 \\
$\mathbf{Z 3}$ & -0.15 & -0.27 & -0.17 & -0.06 & 0.35 & 0.40 & 0.54 \\
$\mathbf{Z 4}$ & -0.14 & -0.12 & -0.18 & -0.06 & 0.35 & 0.41 & 0.55 \\
$\mathbf{Z 5}$ & -0.13 & -0.17 & -0.17 & -0.06 & 0.37 & 0.42 & 0.58 \\
$\mathbf{Z 6}$ & -0.09 & -0.19 & -0.19 & -0.07 & 0.27 & 0.32 & 0.42 \\
$\mathbf{Z 7}$ & -0.19 & -0.26 & -0.20 & -0.04 & 0.36 & 0.46 & 0.73 \\
$\mathbf{Z 8}$ & -0.19 & -0.33 & -0.22 & -0.06 & 0.38 & 0.46 & 0.73 \\
$\mathbf{Z 9}$ & -0.15 & -0.12 & -0.19 & -0.04 & 0.38 & 0.42 & 0.57 \\
Z10 & -0.20 & -0.14 & -0.18 & -0.02 & 0.36 & 0.44 & 0.54 \\
\hline Average & $\mathbf{- 0 . 1 5}$ & $\mathbf{- 0 . 1 9}$ & $\mathbf{- 0 . 1 9}$ & $\mathbf{- 0 . 0 6}$ & $\mathbf{0 . 3 5}$ & $\mathbf{0 . 4 2}$ & $\mathbf{0 . 5 8}$ \\
\hline
\end{tabular}

Table A.3: Free-surface standard deviation $\sigma_{\eta}(\mathrm{cm})$ at seven wave gauge locations

\begin{tabular}{llllllll}
\hline Run & WG1 & WG2 & WG3 & WG4 & WG5 & WG6 & WG7 \\
\hline $\mathbf{Z 1}$ & 3.93 & 3.94 & 4.05 & 3.46 & 2.29 & 2.05 & 1.70 \\
$\mathbf{Z 2}$ & 3.97 & 3.98 & 4.07 & 3.47 & 2.31 & 2.07 & 1.72 \\
$\mathbf{Z 3}$ & 3.93 & 3.95 & 4.04 & 3.44 & 2.31 & 2.07 & 1.72 \\
$\mathbf{Z 4}$ & 3.99 & 4.00 & 4.07 & 3.46 & 2.32 & 2.07 & 1.72 \\
$\mathbf{Z 5}$ & 4.04 & 4.05 & 4.13 & 3.46 & 2.31 & 2.06 & 1.73 \\
$\mathbf{Z 6}$ & 3.99 & 3.97 & 4.12 & 3.50 & 2.45 & 2.20 & 1.90 \\
$\mathbf{Z 7}$ & 4.06 & 4.04 & 4.17 & 3.48 & 2.37 & 2.09 & 1.86 \\
$\mathbf{Z 8}$ & 4.10 & 4.08 & 4.18 & 3.49 & 2.39 & 2.10 & 1.87 \\
$\mathbf{Z 9}$ & 4.11 & 4.08 & 4.21 & 3.49 & 2.39 & 2.10 & 1.86 \\
$\mathbf{Z 1 0}$ & 4.12 & 4.10 & 4.20 & 3.51 & 2.37 & 2.10 & 1.87 \\
\hline Average & $\mathbf{4 . 0 2}$ & $\mathbf{4 . 0 2}$ & $\mathbf{4 . 1 2}$ & $\mathbf{3 . 4 8}$ & $\mathbf{2 . 3 5}$ & $\mathbf{2 . 0 9}$ & $\mathbf{1 . 8 0}$ \\
\hline
\end{tabular}


Table A.4: Wet probability $P_{w}$, its mean free-surface elevation $\bar{\eta}(\mathrm{cm})$ and freesurface standard deviation $\sigma_{\eta}(\mathrm{cm})$ at WG8

\begin{tabular}{lllllll}
\hline Run & $\boldsymbol{t}(\boldsymbol{s})$ & $\boldsymbol{P}_{\boldsymbol{w}}$ & $\boldsymbol{Z}_{\boldsymbol{b}}(\mathbf{c m})$ & $\overline{\boldsymbol{h}}(\mathbf{c m})$ & $\overline{\boldsymbol{\eta}}(\boldsymbol{c m})$ & $\boldsymbol{\sigma}_{\boldsymbol{\eta}}(\mathbf{c m})$ \\
\hline $\mathbf{Z 1}$ & 0 & & 8.30 & & & \\
$\mathbf{Z 2}$ & 200 & 0.31 & 8.35 & 1.39 & 9.74 & 0.59 \\
$\mathbf{Z 3}$ & 1000 & 0.27 & 8.57 & 0.68 & 9.25 & 0.58 \\
$\mathbf{Z 4}$ & 1400 & 0.33 & 8.68 & 0.58 & 9.26 & 0.57 \\
$\mathbf{Z 5}$ & 1800 & $\mathrm{NA}$ & 8.79 & $\mathrm{NA}$ & $\mathrm{NA}$ & $\mathrm{NA}$ \\
\hline & 2000 & & 8.85 & & & \\
\hline $\mathbf{Z 6}$ & 2200 & $\mathrm{NA}$ & 8.89 & $\mathrm{NA}$ & $\mathrm{NA}$ & $\mathrm{NA}$ \\
$\mathbf{Z 7}$ & 2600 & 0.31 & 8.99 & 0.58 & 9.57 & 0.53 \\
$\mathbf{Z 8}$ & 3000 & 0.30 & 9.09 & 0.65 & 9.74 & 0.53 \\
$\mathbf{Z 9}$ & 3400 & 0.34 & 9.18 & 0.62 & 9.80 & 0.53 \\
$\mathbf{Z 1 0}$ & 3800 & 0.33 & 9.28 & 0.58 & 9.86 & 0.58 \\
\hline & 4000 & & 9.33 & & & \\
\hline Average & & $\mathbf{0 . 3 1}$ & & $\mathbf{0 . 7 2}$ & $\mathbf{9 . 4 7}$ & $\mathbf{0 . 5 6}$ \\
\hline NA & & & & &
\end{tabular}

NA implies "not available” data 
Table A.5: $\quad$ Mean cross-shore velocity $\bar{U}$ and standard deviation $\sigma_{U}$ of the 2D ADV co-located with WG4 at $x=8.30 \mathrm{~m}$, Red Vectrino co-located with WG5 at $x=12.90 \mathrm{~m}$ and Blue Vectrino co-located with WG6 at $x=15.52 \mathrm{~m}$

\begin{tabular}{lllllll}
\hline \multirow{2}{*}{ Run } & \multicolumn{2}{l}{ 2D ADV at WG4 } & \multicolumn{2}{c}{ Red Vectrino at WG5 } & \multicolumn{2}{c}{ Blue Vectrino at WG6 } \\
& $\overline{\boldsymbol{U}}(\mathbf{c m} / \mathbf{s})$ & $\boldsymbol{\sigma}_{\mathbf{U}}(\mathbf{c m} / \mathbf{s})$ & $\overline{\boldsymbol{U}}(\mathbf{c m} / \mathbf{s})$ & $\boldsymbol{\sigma}_{\mathbf{U}}(\mathbf{c m} / \mathbf{s})$ & $\overline{\boldsymbol{U}}(\mathbf{c m} / \mathbf{s})$ & $\boldsymbol{\sigma}_{\mathbf{U}}(\mathbf{c m} / \mathbf{s})$ \\
\hline $\mathbf{Z 1}$ & -8.57 & 22.73 & -3.13 & 14.91 & $\mathrm{NA}$ & $\mathrm{NA}$ \\
$\mathbf{Z 2}$ & -8.24 & 22.55 & -2.90 & 14.99 & -3.79 & 16.27 \\
$\mathbf{Z 3}$ & -8.03 & 22.60 & -2.94 & 15.02 & -4.18 & 16.03 \\
$\mathbf{Z 4}$ & -8.16 & 22.37 & -3.00 & 15.00 & -3.87 & 16.34 \\
$\mathbf{Z 5}$ & -7.51 & 22.16 & -2.97 & 14.96 & -4.18 & 16.17 \\
$\mathbf{Z 6}$ & -8.59 & 22.48 & -3.33 & 15.08 & -3.58 & 16.55 \\
$\mathbf{Z 7}$ & -7.75 & 22.48 & $\mathrm{NA}$ & $\mathrm{NA}$ & $\mathrm{NA}$ & $\mathrm{NA}$ \\
$\mathbf{Z 8}$ & -8.41 & 22.82 & -3.41 & 14.84 & -3.88 & 16.34 \\
$\mathbf{Z 9}$ & -7.82 & 22.91 & -3.12 & 14.89 & -3.76 & 16.29 \\
$\mathbf{Z 1 0}$ & -8.36 & 22.61 & -3.12 & 15.09 & -4.21 & 16.29 \\
\hline Average & $\mathbf{- 8 . 1 4}$ & $\mathbf{2 2 . 5 7}$ & $\mathbf{- 3 . 1 0}$ & $\mathbf{1 4 . 9 8}$ & $\mathbf{- 3 . 9 3}$ & $\mathbf{1 6 . 2 9}$ \\
\hline
\end{tabular}

NA implies "not available" data 


\section{A.2 Negative (N) Net Cross-shore Sediment Transport Test}
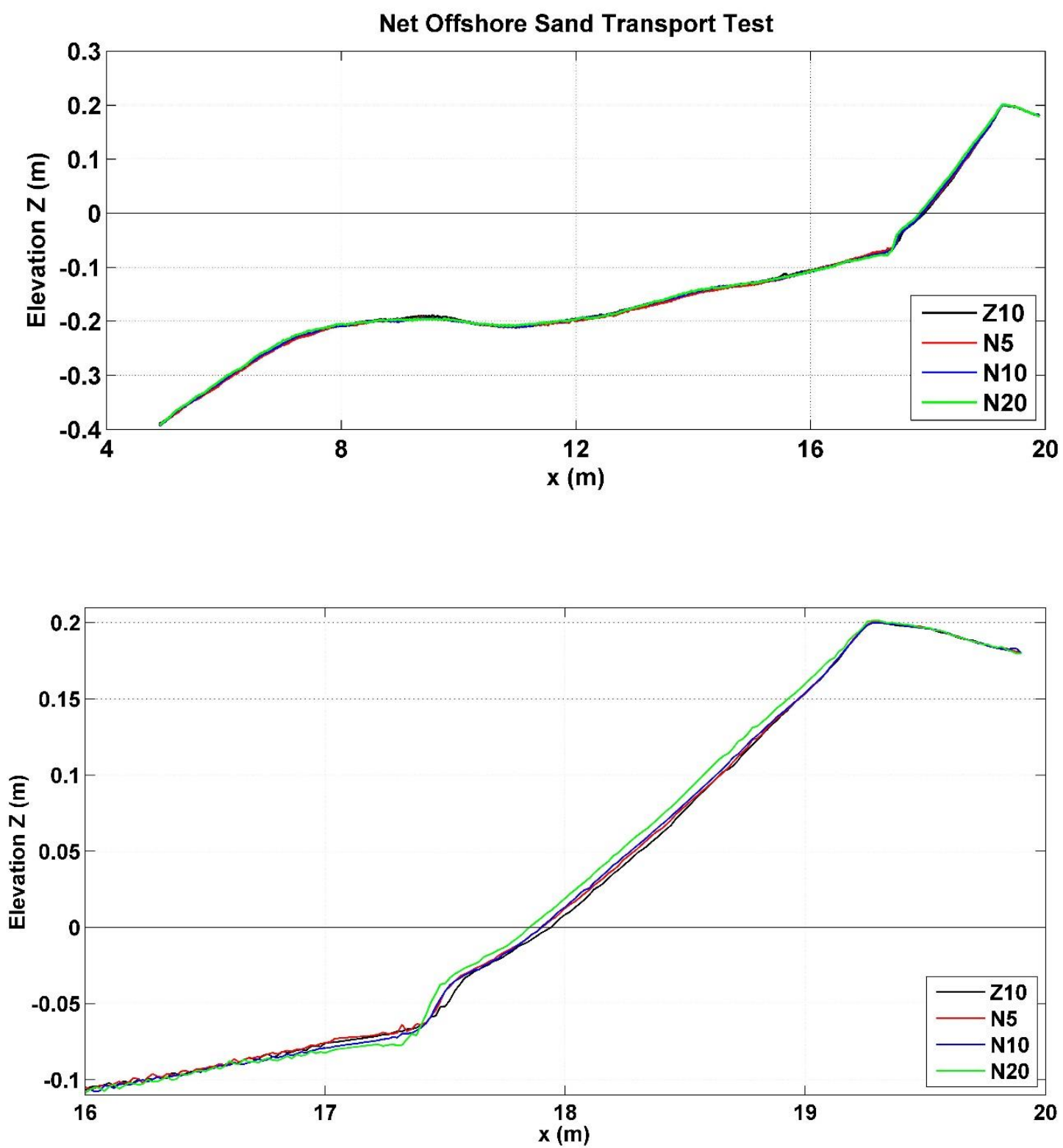

Figure A.2: Negative $(\mathrm{N})$ net cross-shore sediment transport test with 20 runs. The initial profile N0 corresponds to the profile Z10 added with the placed sand at the shoreline 


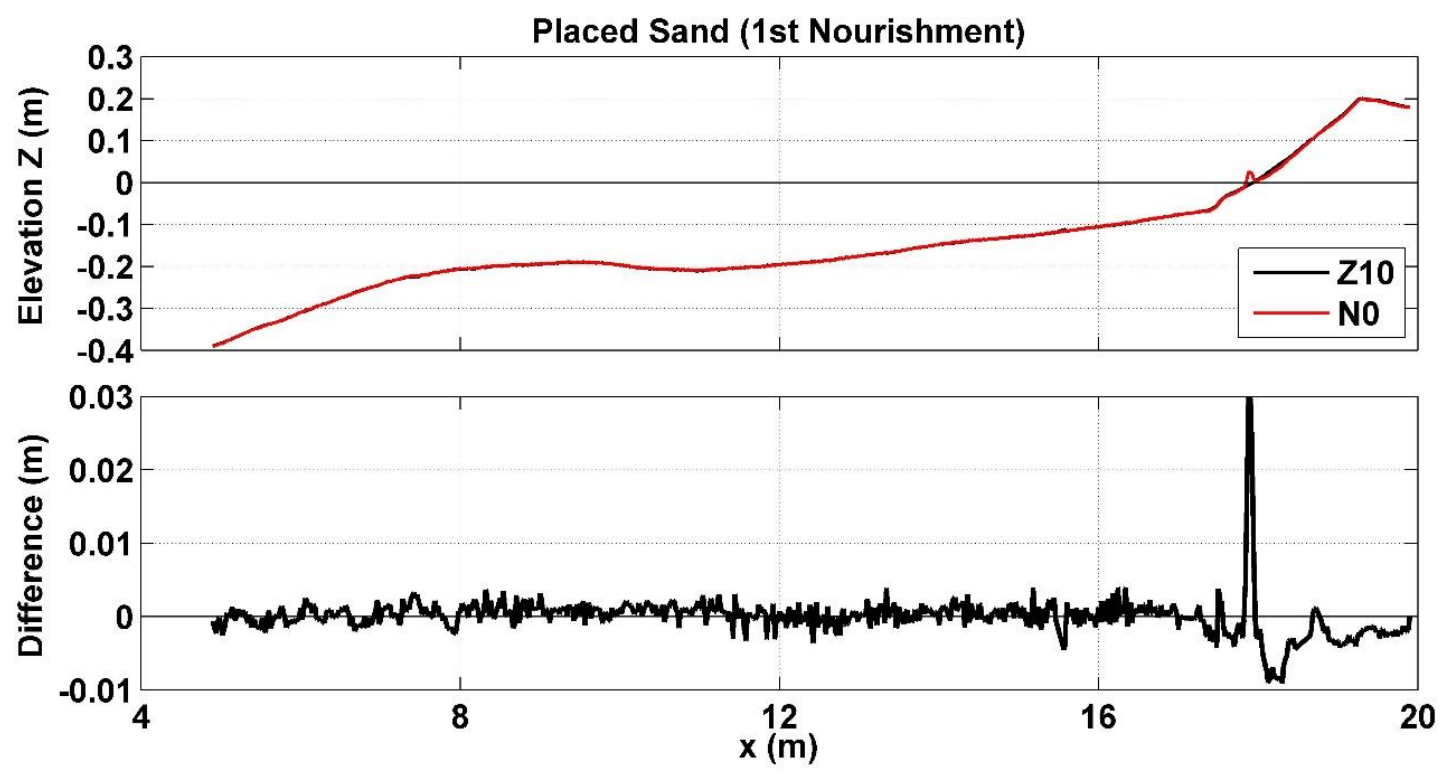

Figure A.3 Final profile for zero net cross-shore sand transport test (Z10) and initial profile for net offshore sand transport test (N0) with placed sand

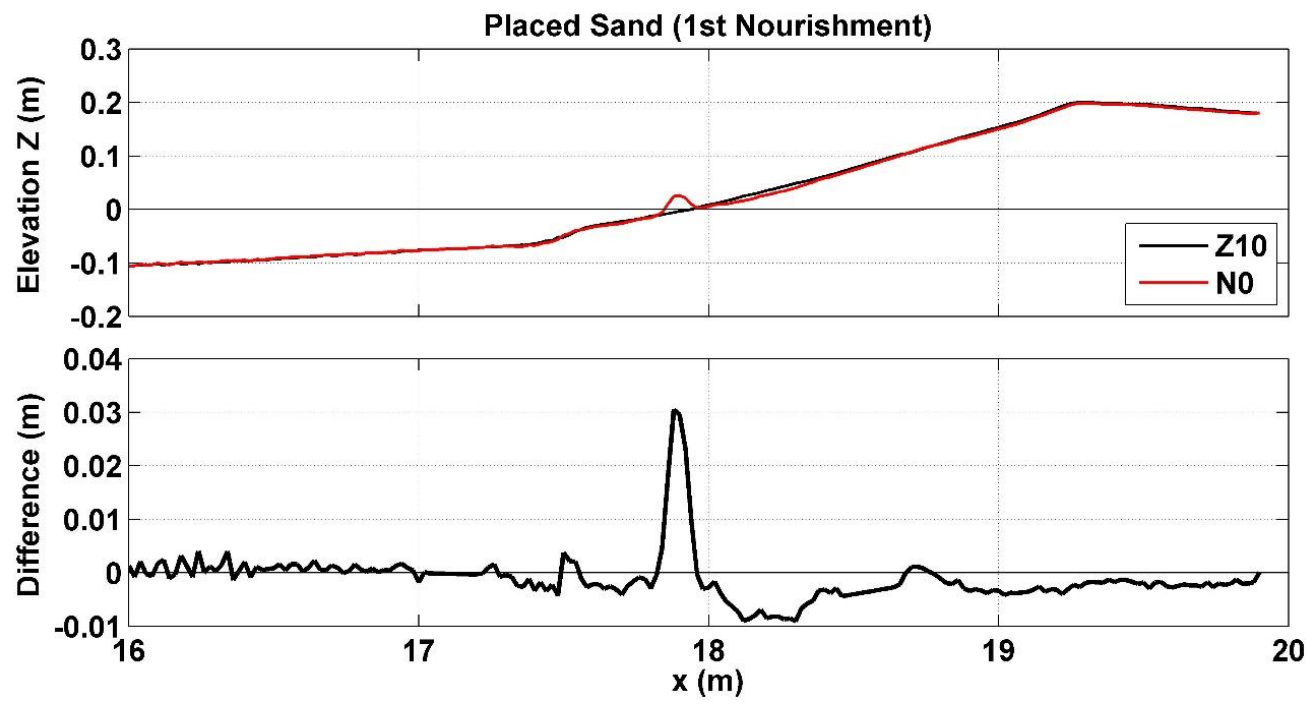

Figure A.4: Enlarged view of Figure A.3 near the shoreline

$*$ Cross dune area (dune difference area above 0$)=22 \mathrm{~cm}^{2}$ 

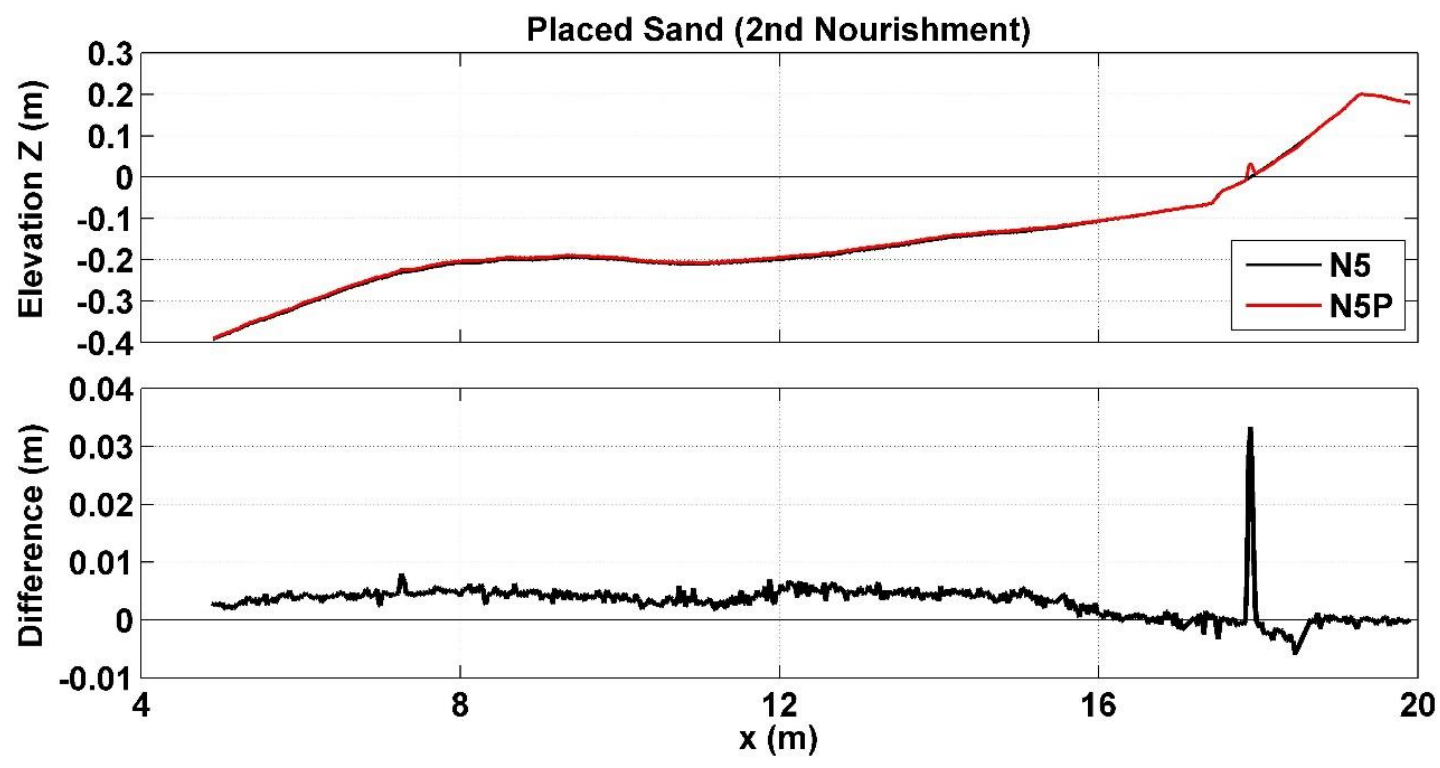

Figure A.5: Profile after 5 runs for net offshore sand transport test (N5) and profile with placed sand for net offshore sand transport test (N5P)

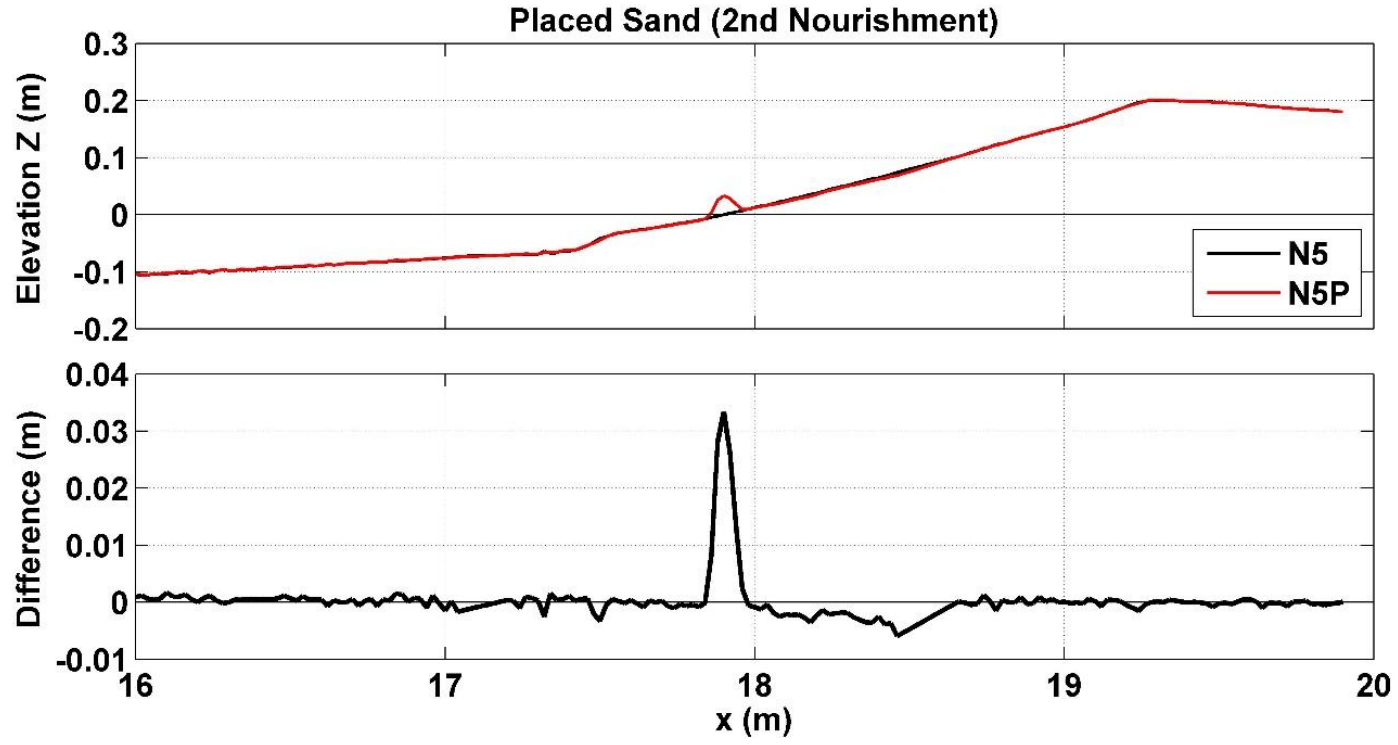

Figure A.6: Enlarged view of Figure A.5 near the shoreline

* Cross dune area (dune difference area above 0$)=22 \mathrm{~cm}^{2}$ 


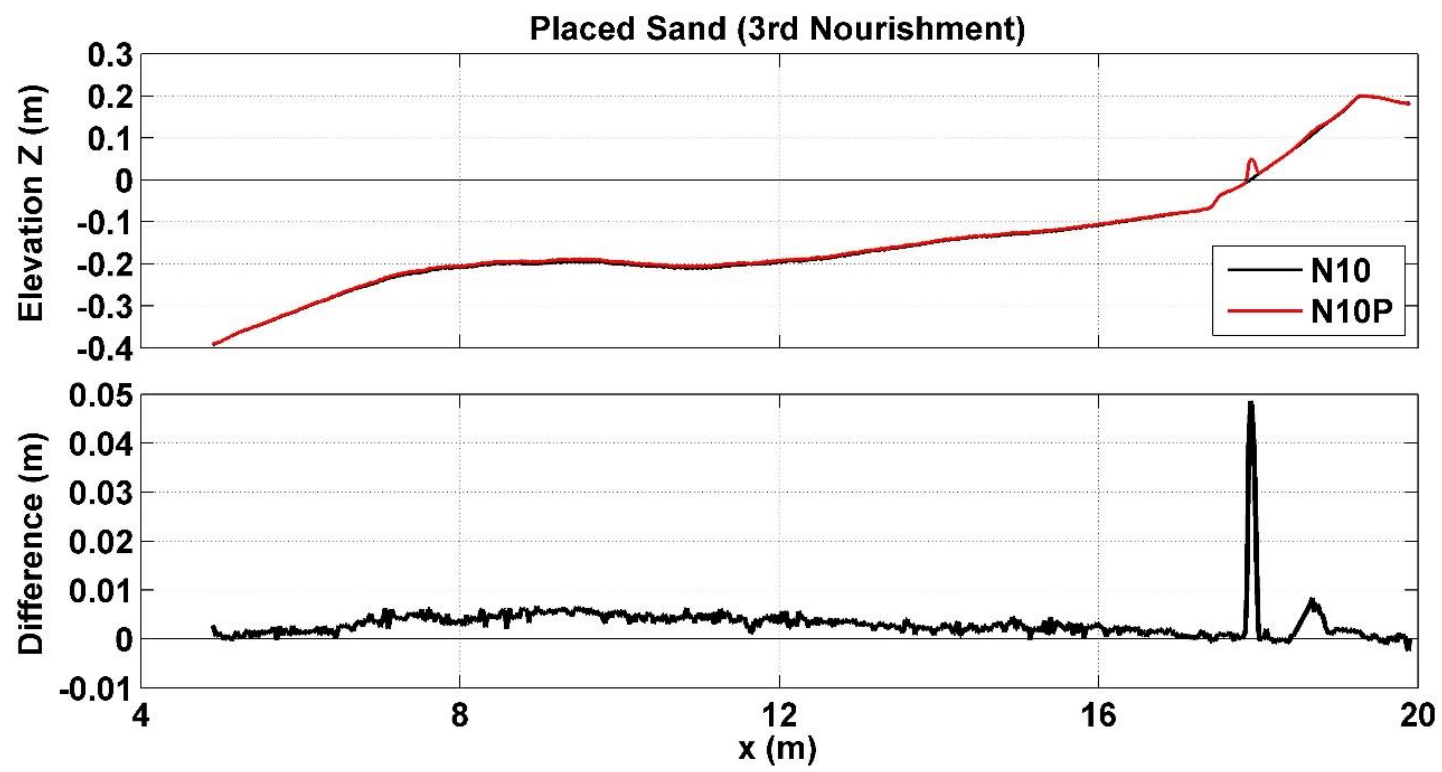

Figure A.7: Profile before sand placement (N10), and profile (N10P) with the placed sand after run N10 and before run N11

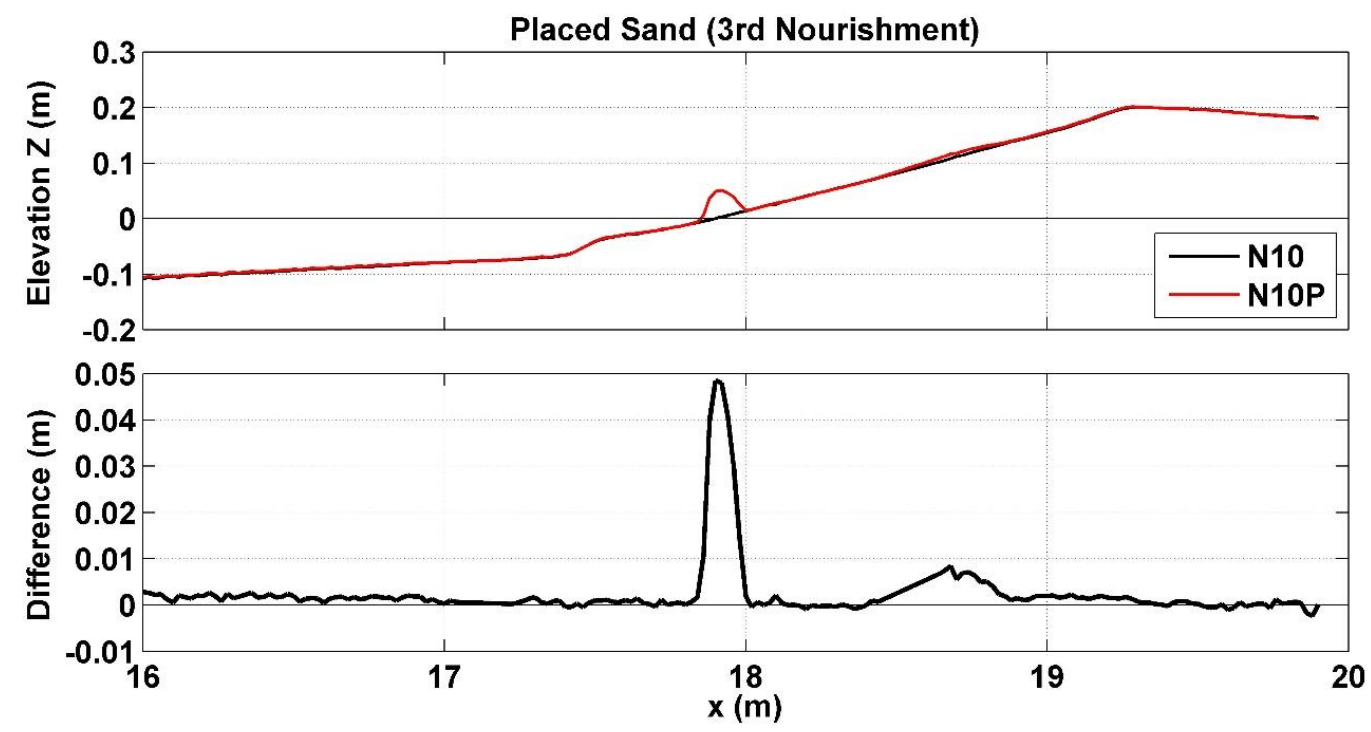

Figure A.8: Enlarged view of Figure A.7 near the shoreline

* Cross dune area (dune difference area above 0$)=45 \mathrm{~cm}^{2}$ 

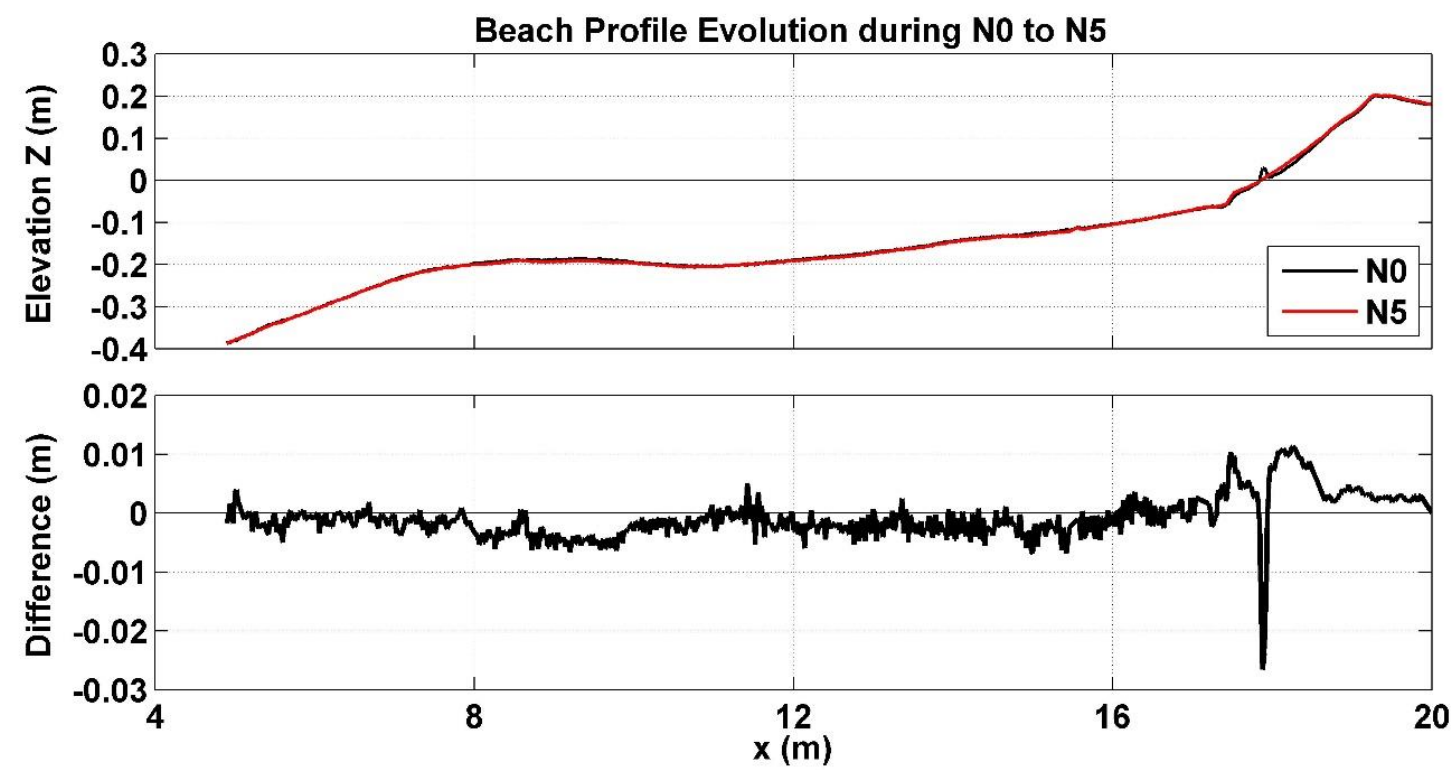

Figure A.9: Initial dune profile (N0) and profile after 5 runs (N5) for net offshore sand transport test. Sand was placed again after run N5 to produce the profile N5P with placed sand before run N6

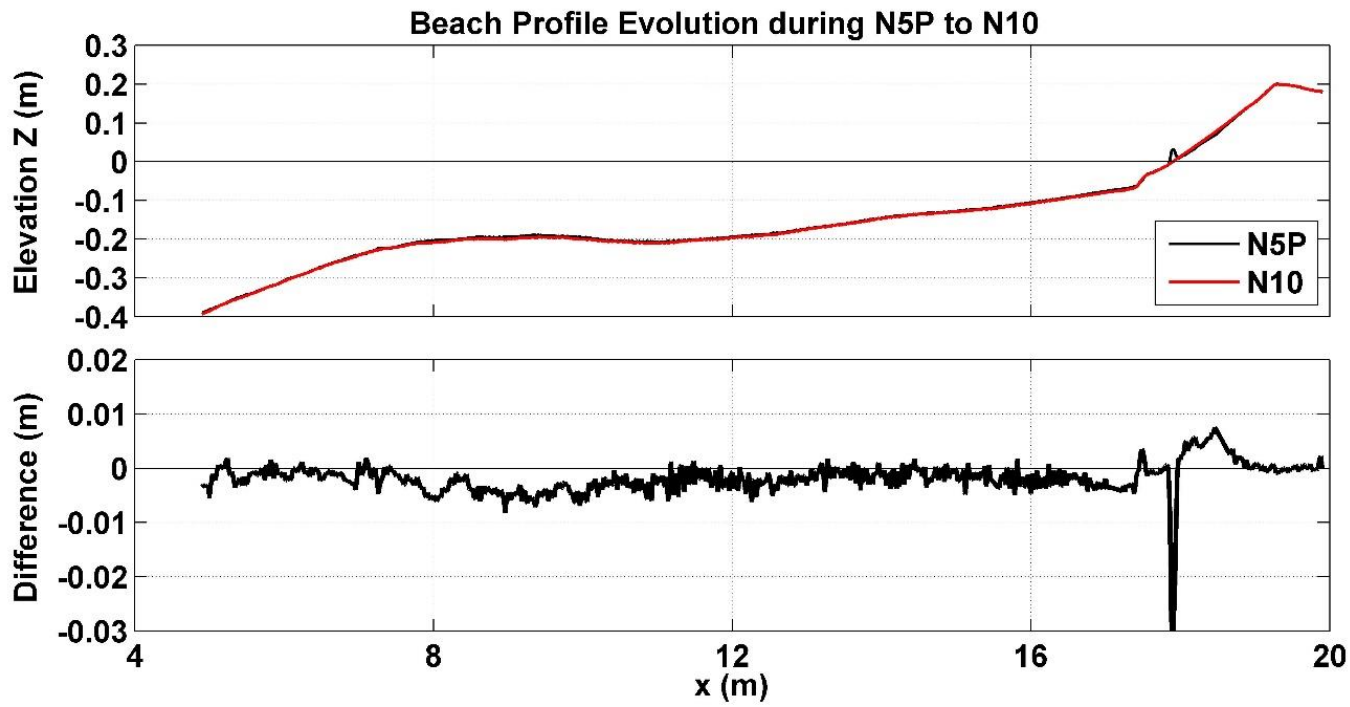

Figure A.10: Profile with placed sand and profile after 5 additional runs (N10) for net offshore sand transport test 

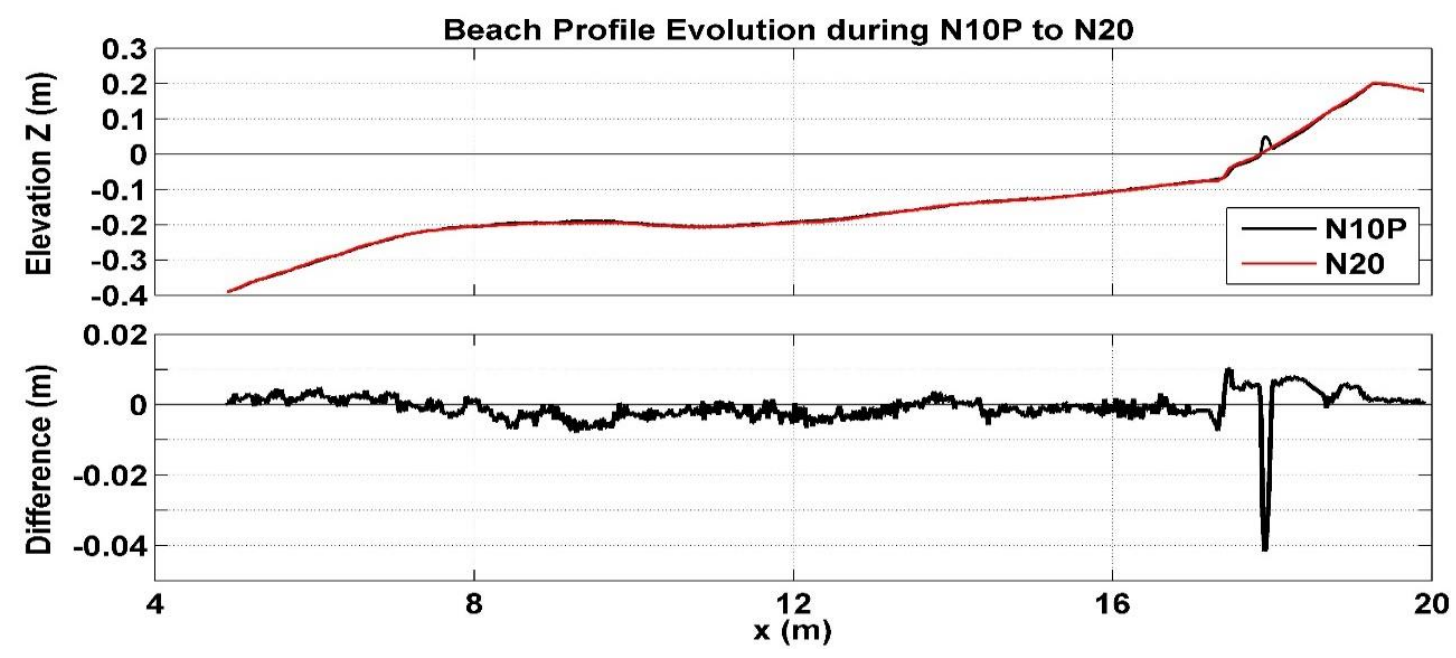

Figure A.11: Measured profiles N10P and N20 after additional 10 runs for net offshore sediment transport test 


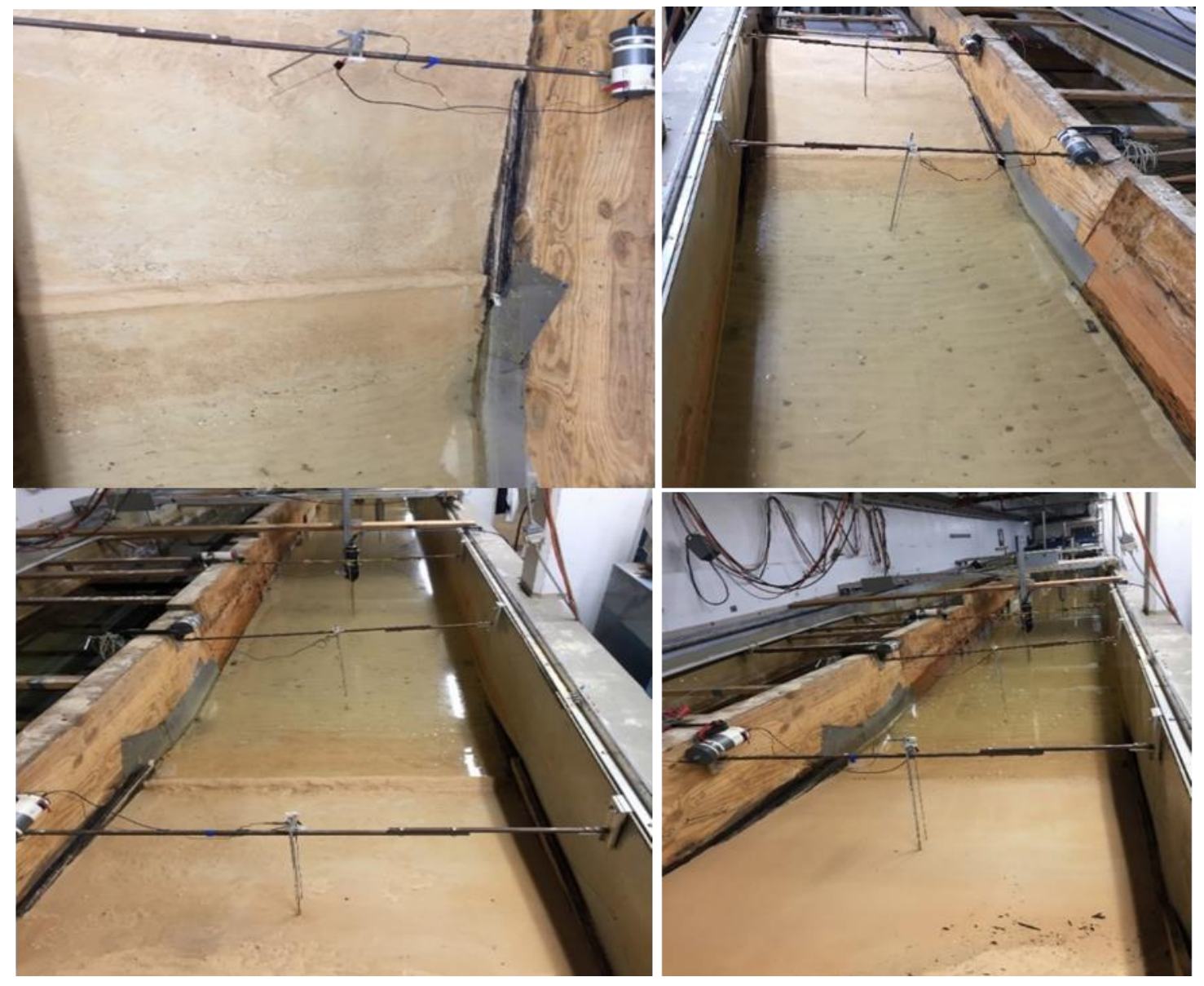

Figure A.12: Placed sand near the shoreline for $\mathrm{N}$ test with no wave overtopping and overwash 
Table A.6: Incident wave characteristics for Test $\mathrm{N}$

\begin{tabular}{|c|c|c|c|c|c|c|}
\hline Run & $H_{m o}(\mathrm{~cm})$ & $H_{r m s}(\mathbf{c m})$ & $\boldsymbol{H}_{s}(\mathbf{c m})$ & $T_{p}(\mathbf{s})$ & $T_{s}(\mathbf{s})$ & $R$ \\
\hline N1 & 16.79 & 11.87 & 16.11 & 2.62 & 2.06 & 0.129 \\
\hline N2 & 16.85 & 11.91 & 16.18 & 2.62 & 2.09 & 0.140 \\
\hline N3 & 16.96 & 12.00 & 16.26 & 2.62 & 2.07 & 0.142 \\
\hline N4 & 17.09 & 12.09 & 16.35 & 2.62 & 2.09 & 0.133 \\
\hline N5 & 17.14 & 12.12 & 16.52 & 2.62 & 2.08 & 0.135 \\
\hline N6 & 16.63 & 11.76 & 16.00 & 2.62 & 2.10 & 0.130 \\
\hline N7 & 16.87 & 11.93 & 16.19 & 2.62 & 2.07 & 0.131 \\
\hline N8 & 16.98 & 12.00 & 16.33 & 2.62 & 2.07 & 0.134 \\
\hline N9 & 17.08 & 12.07 & 16.37 & 2.62 & 2.07 & 0.137 \\
\hline N10 & 17.04 & 12.05 & 16.34 & 2.62 & 2.06 & 0.129 \\
\hline N11 & 17.73 & 12.53 & 16.99 & 2.62 & 2.07 & 0.127 \\
\hline N12 & 18.18 & 12.85 & 17.52 & 2.62 & 2.09 & 0.132 \\
\hline N13 & 18.46 & 13.06 & 17.64 & 2.62 & 2.03 & 0.132 \\
\hline N14 & 18.52 & 13.10 & 17.85 & 2.62 & 2.04 & 0.141 \\
\hline N15 & 18.56 & 13.12 & 17.85 & 2.62 & 2.03 & 0.139 \\
\hline N16 & 18.51 & 13.09 & 17.75 & 2.62 & 2.06 & 0.129 \\
\hline N17 & 18.30 & 12.94 & 17.45 & 2.62 & 2.03 & 0.125 \\
\hline N18 & 18.49 & 13.07 & 17.75 & 2.62 & 2.08 & 0.133 \\
\hline N19 & 18.44 & 13.04 & 17.73 & 2.62 & 2.04 & 0.137 \\
\hline N20 & 18.42 & 13.03 & 17.57 & 2.62 & 2.01 & 0.131 \\
\hline Average & 17.65 & 12.48 & 16.94 & 2.62 & 2.06 & 0.133 \\
\hline
\end{tabular}


Table A.7: $\quad$ Mean free-surface elevation $\bar{\eta}(\mathrm{cm})$ at seven wave gauge locations

\begin{tabular}{|c|c|c|c|c|c|c|c|}
\hline Run & WG1 & WG2 & WG3 & WG4 & WG5 & WG6 & WG7 \\
\hline N1 & -0.15 & -0.15 & -0.19 & -0.03 & 0.35 & 0.43 & 0.58 \\
\hline $\mathbf{N} 2$ & -0.17 & -0.19 & -0.17 & -0.03 & 0.38 & 0.44 & 0.61 \\
\hline N3 & -0.14 & -0.13 & -0.19 & 0.00 & 0.37 & 0.46 & 0.60 \\
\hline N4 & -0.14 & -0.13 & -0.18 & -0.02 & 0.38 & 0.46 & 0.57 \\
\hline N5 & -0.14 & -0.14 & -0.19 & -0.01 & 0.37 & 0.48 & 0.62 \\
\hline N6 & -0.14 & -0.12 & -0.19 & -0.04 & 0.34 & 0.41 & NR \\
\hline N7 & -0.16 & -0.14 & -0.21 & -0.03 & 0.36 & 0.43 & 0.52 \\
\hline N8 & -0.14 & -0.18 & -0.17 & -0.01 & 0.38 & 0.46 & 0.47 \\
\hline N9 & -0.18 & -0.15 & -0.19 & -0.02 & 0.36 & 0.44 & 0.57 \\
\hline N10 & -0.14 & -0.14 & -0.18 & 0.01 & 0.39 & 0.48 & 0.66 \\
\hline N11 & -0.09 & -0.14 & -0.20 & -0.05 & 0.36 & 0.51 & 0.64 \\
\hline N12 & -0.18 & -0.24 & -0.24 & 0.00 & 0.42 & 0.52 & 0.61 \\
\hline N13 & -0.17 & -0.14 & -0.18 & 0.00 & 0.40 & 0.50 & 0.66 \\
\hline N14 & -0.14 & -0.16 & -0.18 & 0.02 & 0.45 & 0.50 & 0.80 \\
\hline N15 & -0.15 & -0.15 & -0.17 & 0.02 & 0.46 & 0.54 & 0.65 \\
\hline N16 & -0.18 & -0.18 & -0.18 & 0.03 & 0.45 & 0.56 & 0.81 \\
\hline N17 & -0.11 & -0.13 & -0.17 & 0.02 & 0.43 & 0.52 & NR \\
\hline N18 & -0.12 & -0.24 & -0.19 & 0.02 & 0.42 & 0.48 & 0.73 \\
\hline N19 & -0.15 & -0.13 & -0.18 & 0.04 & 0.45 & 0.54 & 0.73 \\
\hline N20 & -0.12 & -0.14 & -0.17 & 0.03 & 0.44 & 0.52 & 0.66 \\
\hline Average & -0.15 & -0.16 & -0.19 & 0.00 & 0.40 & 0.48 & 0.64 \\
\hline
\end{tabular}


Table A.8: Free-surface standard deviation $\sigma_{\eta}(\mathrm{cm})$ at eight wave gauge locations

\begin{tabular}{|c|c|c|c|c|c|c|c|}
\hline Run & WG1 & WG2 & WG3 & WG4 & WG5 & WG6 & WG7 \\
\hline N1 & 4.05 & 4.07 & 4.15 & 3.48 & 2.33 & 2.07 & 1.81 \\
\hline N2 & 4.08 & 4.08 & 4.16 & 3.48 & 2.33 & 2.05 & 1.81 \\
\hline N3 & 4.09 & 4.11 & 4.18 & 3.50 & 2.34 & 2.07 & 1.82 \\
\hline N4 & 4.13 & 4.15 & 4.22 & 3.50 & 2.34 & 2.07 & 1.82 \\
\hline N5 & 4.14 & 4.16 & 4.22 & 3.49 & 2.35 & 2.07 & 1.83 \\
\hline N6 & 4.02 & 4.02 & 4.12 & 3.41 & 2.35 & 2.06 & 1.69 \\
\hline N7 & 4.08 & 4.10 & 4.15 & 3.45 & 2.35 & 2.07 & 1.68 \\
\hline N8 & 4.10 & 4.12 & 4.18 & 3.45 & 2.36 & 2.07 & 1.69 \\
\hline N9 & 4.13 & 4.15 & 4.20 & 3.45 & 2.37 & 2.07 & 1.68 \\
\hline N10 & 4.13 & 4.15 & 4.20 & 3.48 & 2.37 & 2.07 & 1.71 \\
\hline N11 & 4.33 & 4.40 & 4.28 & 3.85 & 2.62 & 2.28 & 1.53 \\
\hline N12 & 4.45 & 4.52 & 4.38 & 3.88 & 2.65 & 2.30 & 1.54 \\
\hline N13 & 4.52 & 4.59 & 4.44 & 3.88 & 2.65 & 2.29 & 1.51 \\
\hline N14 & 4.53 & 4.60 & 4.45 & 3.91 & 2.65 & 2.28 & 1.53 \\
\hline N15 & NA & 4.61 & 4.46 & 3.89 & 2.66 & 2.30 & 1.50 \\
\hline N16 & 4.54 & 4.60 & 4.46 & 3.90 & 2.66 & 2.29 & 1.50 \\
\hline N17 & 4.48 & 4.55 & 4.42 & 3.85 & 2.64 & 2.30 & 1.94 \\
\hline N18 & 4.53 & 4.59 & 4.44 & 3.85 & 2.66 & 2.30 & 1.96 \\
\hline N19 & 4.51 & 4.59 & 4.44 & 3.86 & 2.66 & 2.30 & 2.03 \\
\hline $\mathbf{N} 20$ & 4.51 & 4.59 & 4.43 & 3.85 & 2.65 & 2.28 & 2.06 \\
\hline Average & 4.28 & 4.34 & 4.30 & 3.67 & 2.50 & 2.18 & 1.73 \\
\hline
\end{tabular}


Table A.9: Wet probability $P_{w}$, its mean free-surface elevation $\bar{\eta}(\mathrm{cm})$ and freesurface standard deviation $\sigma_{\eta}(\mathrm{cm})$ for WG8

\begin{tabular}{|c|c|c|c|c|c|c|}
\hline Run & $t(s)$ & $\boldsymbol{P}_{w}$ & $Z_{b}(\mathrm{~cm})$ & $\bar{h}(\mathrm{~cm})$ & $\bar{\eta}(\mathrm{cm})$ & $\sigma_{\eta}(\mathrm{cm})$ \\
\hline & 0 & & 9.01 & & & \\
\hline N1 & 200 & 0.29 & 9.04 & 1.43 & 10.47 & 0.68 \\
\hline $\mathbf{N} 2$ & 600 & 0.32 & 9.11 & 0.65 & 9.76 & 0.54 \\
\hline N3 & 1000 & 0.27 & 9.18 & 0.64 & 9.82 & 0.55 \\
\hline N4 & 1400 & 0.28 & 9.25 & 0.67 & 9.92 & 0.56 \\
\hline \multirow[t]{2}{*}{ N5 } & 1800 & 0.30 & 9.32 & 0.72 & 10.04 & 0.52 \\
\hline & 2000 & & 9.36 & & & \\
\hline N6 & 2200 & 0.28 & 9.42 & 1.34 & 10.76 & 0.55 \\
\hline N7 & 2600 & 0.29 & 9.54 & 0.71 & 10.25 & 0.53 \\
\hline N8 & 3000 & 0.25 & 9.66 & 0.71 & 10.37 & 0.57 \\
\hline N9 & 3400 & 0.26 & 9.78 & 0.65 & 10.43 & 0.56 \\
\hline \multirow[t]{2}{*}{ N10 } & 3800 & 0.26 & 9.90 & 0.68 & 10.58 & 0.56 \\
\hline & 4000 & & 9.96 & & & \\
\hline N11 & 4200 & NR & 9.98 & NR & NR & NR \\
\hline N12 & 4600 & 0.30 & 10.02 & 0.64 & 10.66 & 0.51 \\
\hline N13 & 5000 & 0.33 & 10.06 & 0.57 & 10.63 & 0.45 \\
\hline N14 & 5400 & 0.28 & 10.10 & 0.65 & 10.75 & 0.50 \\
\hline \multirow[t]{2}{*}{ N15 } & 5800 & 0.32 & 10.14 & 0.57 & 10.71 & 0.45 \\
\hline & 6000 & & 10.17 & & & \\
\hline N16 & 6200 & 0.29 & 10.19 & 0.62 & 10.81 & 0.45 \\
\hline N17 & 6600 & 0.29 & 10.23 & 0.64 & 10.87 & 0.45 \\
\hline N18 & 7000 & 0.32 & 10.27 & 0.51 & 10.78 & 0.43 \\
\hline N19 & 7400 & 0.23 & 10.31 & 0.63 & 10.94 & 0.48 \\
\hline \multirow[t]{2}{*}{$\mathbf{N} 20$} & 7800 & 0.31 & 10.35 & 0.55 & 10.90 & 0.46 \\
\hline & 8000 & & 10.38 & & & \\
\hline Average & & 0.29 & & 0.71 & 10.49 & 0.52 \\
\hline
\end{tabular}

* $t=0$ is initial profile; $t=4000$ is final profile. NR implies "not reliable" data 
Table A.10: Mean cross-shore velocity $\bar{U}$ and standard deviation $\sigma_{U}$ of the 2D ADV co-located with WG4 at $x=8.30 \mathrm{~m}$, Red Vectrino co-located with WG5 at $x=12.90 \mathrm{~m}$ and Blue Vectrino co-located with WG6 at $x=15.52 \mathrm{~m}$

\begin{tabular}{|c|c|c|c|c|c|c|}
\hline \multirow{2}{*}{ Run } & \multicolumn{2}{|c|}{ 2D ADV at WG4 } & \multicolumn{2}{|c|}{ Red Vectrino at WG5 } & \multicolumn{2}{|c|}{ Blue Vectrino at WG6 } \\
\hline & $\bar{U}(\mathrm{~cm} / \mathrm{s})$ & $\sigma_{\mathrm{U}}(\mathrm{cm} / \mathrm{s})$ & $\bar{U}(\mathrm{~cm} / \mathrm{s})$ & $\sigma_{\mathrm{U}}(\mathrm{cm} / \mathrm{s})$ & $\bar{U}(\mathrm{~cm} / \mathrm{s})$ & $\sigma_{\mathrm{U}}(\mathrm{cm} / \mathrm{s})$ \\
\hline $\mathbf{N} 1$ & -8.86 & 22.62 & -3.11 & 14.61 & -3.82 & 15.73 \\
\hline $\mathbf{N} 2$ & -8.48 & 22.61 & -3.74 & 14.49 & -3.80 & 15.76 \\
\hline $\mathbf{N 3}$ & -7.67 & 22.56 & -3.18 & 14.64 & -3.80 & 15.82 \\
\hline N4 & -7.85 & 22.64 & -3.26 & 14.61 & -4.22 & 15.73 \\
\hline N5 & -7.95 & 22.56 & -3.08 & 14.66 & -4.24 & 15.88 \\
\hline N6 & -7.83 & 22.64 & -3.10 & 14.62 & -3.60 & 15.89 \\
\hline N7 & -7.88 & 22.54 & -3.33 & 14.59 & -3.99 & 15.83 \\
\hline N8 & -8.08 & 23.01 & -3.47 & 14.69 & -3.99 & 15.82 \\
\hline N9 & -8.10 & 22.50 & -3.49 & 14.60 & -3.70 & 15.94 \\
\hline N10 & -7.79 & 22.66 & -3.57 & 14.69 & -4.24 & 15.68 \\
\hline N11 & -7.19 & 21.67 & -4.40 & NR & -4.26 & 15.48 \\
\hline N12 & -8.33 & 22.16 & -2.92 & 14.61 & -4.00 & 15.52 \\
\hline N13 & -7.75 & 22.38 & -3.19 & 14.55 & -4.10 & 16.60 \\
\hline N14 & -8.13 & 21.96 & -3.33 & 14.64 & NR & NR \\
\hline N15 & -8.15 & 22.22 & -3.16 & 14.52 & -4.38 & 15.81 \\
\hline N16 & -8.06 & 22.25 & -2.97 & 14.63 & -3.72 & 15.79 \\
\hline N17 & -8.20 & 22.33 & -2.86 & 14.70 & -3.78 & 15.95 \\
\hline N18 & -7.97 & 22.00 & -2.82 & 14.44 & -4.18 & 15.90 \\
\hline N19 & -7.63 & 22.09 & -3.10 & 14.63 & -4.08 & 15.72 \\
\hline $\mathbf{N} 20$ & -8.06 & 22.10 & NA & NA & NA & $\mathrm{NA}$ \\
\hline Average & -8.00 & 22.38 & -3.27 & 14.61 & -3.99 & 15.83 \\
\hline
\end{tabular}

NA implies "not available" data

NR implies "Not Reliable" data 


\section{A.3 Positive (P) Net Cross-shore Sediment Transport Test}
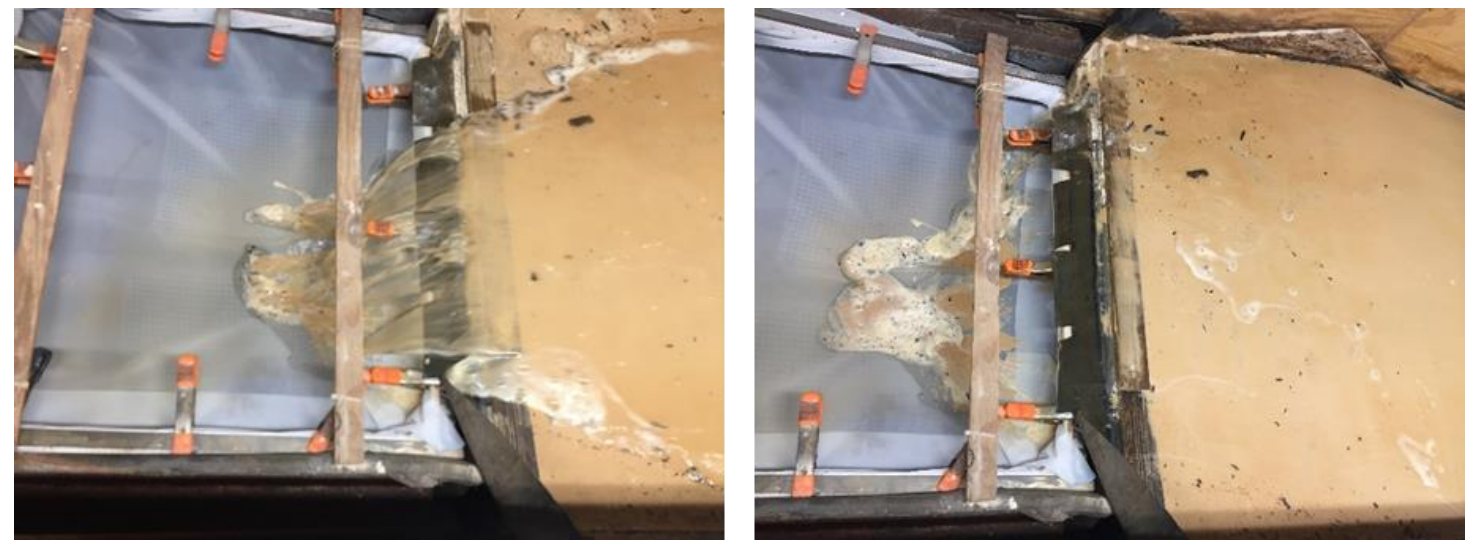

Figure A.13: Wave overtopping and overwash.
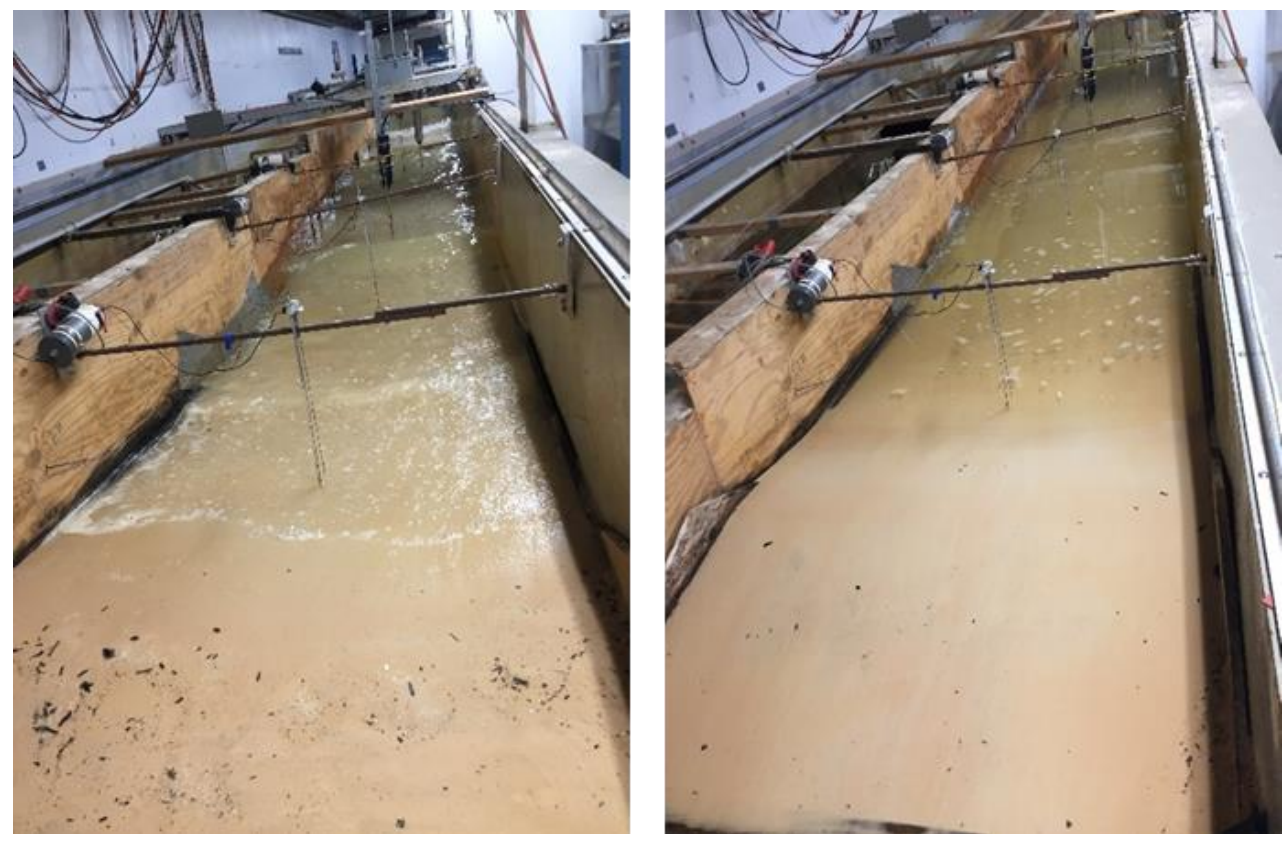

Figure A.14: Beach profiles during run $\mathrm{P} 1$ and run $\mathrm{P} 10$ for positive net cross-shore sediment transport test with water depth of $92 \mathrm{~cm}$ 

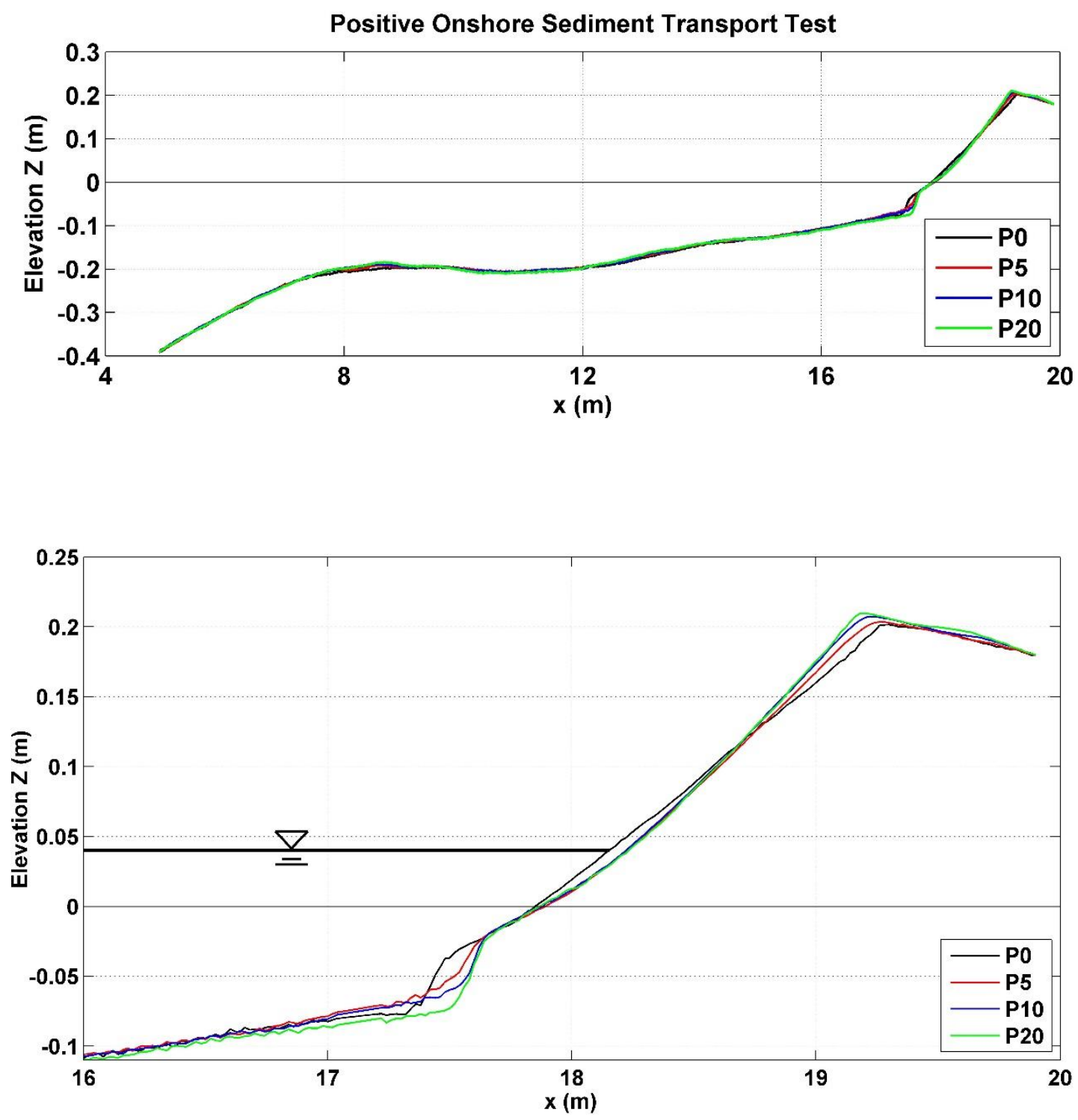

Figure A.15: Positive (P) net cross-shore sediment transport test with 20 runs where the still water level is located at the elevation of $\mathrm{z}=0.04 \mathrm{~m}$ 
Table A.11: Incident wave characteristics for Test $\mathrm{P}$

\begin{tabular}{lllllll}
\hline Run & $\boldsymbol{H}_{\boldsymbol{m} \boldsymbol{o}}(\mathbf{c m})$ & $\boldsymbol{H}_{\boldsymbol{r m s}}(\mathbf{c m})$ & $\boldsymbol{H}_{\boldsymbol{s}}(\mathbf{c m})$ & $\boldsymbol{T}_{\boldsymbol{p}}(\mathbf{s})$ & $\boldsymbol{T}_{\boldsymbol{s}}(\mathbf{s})$ & $\boldsymbol{R}$ \\
\hline P1 & 17.73 & 12.53 & 17.00 & 2.62 & 2.10 & 0.142 \\
P2 & 17.92 & 12.67 & 17.15 & 2.62 & 2.07 & 0.137 \\
P3 & 18.06 & 12.77 & 17.30 & 2.62 & 2.06 & 0.143 \\
P4 & 18.13 & 12.82 & 17.40 & 2.62 & 2.07 & 0.142 \\
P5 & 18.11 & 12.81 & 17.32 & 2.62 & 2.07 & 0.144 \\
P6 & 17.76 & 12.56 & 17.03 & 2.62 & 2.08 & 0.145 \\
P7 & 17.95 & 12.69 & 17.10 & 2.62 & 2.05 & 0.140 \\
P8 & 18.01 & 12.73 & 17.24 & 2.62 & 2.08 & 0.144 \\
P9 & 18.11 & 12.80 & 17.41 & 2.62 & 2.07 & 0.147 \\
P10 & 18.15 & 12.83 & 17.45 & 2.62 & 2.07 & 0.150 \\
P11 & 17.74 & 12.54 & 17.04 & 2.62 & 2.09 & 0.145 \\
P12 & 17.98 & 12.71 & 17.07 & 2.62 & 2.06 & 0.143 \\
P13 & 18.11 & 12.81 & 17.42 & 2.62 & 2.06 & 0.149 \\
P14 & 18.20 & 12.87 & 17.55 & 2.62 & 2.07 & 0.144 \\
P15 & 18.16 & 12.84 & 17.58 & 2.62 & 2.05 & 0.148 \\
P16 & 18.18 & 12.86 & 17.45 & 2.62 & 2.06 & 0.149 \\
P17 & 18.18 & 12.85 & 17.53 & 2.62 & 2.05 & 0.151 \\
P18 & 18.16 & 12.84 & 17.42 & 2.62 & 2.07 & 0.153 \\
P19 & 18.34 & 12.97 & 17.63 & 2.62 & 2.06 & 0.147 \\
P20 & 18.29 & 12.93 & 17.51 & 2.62 & 2.03 & 0.147 \\
\hline Average & $\mathbf{1 8 . 0 6}$ & $\mathbf{1 2 . 7 7}$ & $\mathbf{1 7 . 3 3}$ & $\mathbf{2 . 6 2}$ & $\mathbf{2 . 0 7}$ & $\mathbf{0 . 1 4 6}$ \\
\hline
\end{tabular}


Table A.12: Mean free-surface elevation $\bar{\eta}(\mathrm{cm})$ at seven wave gauge locations

\begin{tabular}{lccccccc}
\hline Run & WG1 & WG2 & WG3 & WG4 & WG5 & WG6 & WG7 \\
\hline P1 & -0.09 & -0.13 & -0.10 & -0.10 & 0.22 & 0.20 & 0.34 \\
P2 & -0.10 & -0.14 & -0.07 & -0.12 & 0.22 & 0.27 & 0.35 \\
P3 & -0.13 & -0.14 & -0.07 & -0.14 & 0.22 & 0.27 & 0.33 \\
P4 & -0.12 & -0.14 & -0.07 & -0.11 & 0.21 & 0.24 & 0.33 \\
P5 & -0.09 & -0.14 & -0.07 & -0.10 & 0.23 & 0.28 & 0.32 \\
P6 & -0.08 & -0.09 & -0.08 & -0.09 & 0.23 & 0.25 & 0.36 \\
P7 & -0.11 & -0.12 & -0.07 & -0.15 & 0.25 & 0.24 & 0.33 \\
P8 & -0.08 & -0.15 & -0.07 & -0.12 & 0.23 & 0.30 & 0.34 \\
P9 & -0.11 & -0.12 & -0.07 & -0.13 & 0.24 & 0.30 & 0.36 \\
P10 & -0.10 & -0.13 & -0.07 & -0.12 & 0.24 & 0.31 & 0.55 \\
P11 & -0.09 & -0.12 & -0.11 & -0.13 & 0.18 & 0.23 & 0.30 \\
P12 & -0.18 & -0.13 & -0.08 & -0.12 & 0.22 & 0.26 & 0.46 \\
P13 & -0.10 & -0.15 & -0.07 & -0.13 & 0.23 & 0.32 & 0.36 \\
P14 & -0.09 & -0.12 & -0.08 & -0.15 & 0.25 & 0.33 & 0.33 \\
P15 & -0.12 & -0.13 & -0.07 & -0.12 & 0.24 & 0.29 & 0.33 \\
P16 & -0.13 & -0.13 & -0.07 & -0.15 & 0.24 & 0.30 & 0.38 \\
P17 & -0.09 & -0.13 & -0.07 & -0.14 & 0.26 & 0.26 & 0.36 \\
P18 & -0.11 & -0.15 & -0.07 & -0.12 & 0.22 & 0.29 & 0.32 \\
P19 & -0.17 & -0.14 & -0.08 & -0.15 & 0.26 & 0.31 & 0.37 \\
P20 & -0.12 & -0.15 & -0.07 & -0.12 & 0.25 & 0.32 & 0.37 \\
\hline Average & $\mathbf{- 0 . 1 1}$ & $\mathbf{- 0 . 1 3}$ & $\mathbf{- 0 . 0 8}$ & $\mathbf{- 0 . 1 3}$ & $\mathbf{0 . 2 3}$ & $\mathbf{0 . 2 8}$ & $\mathbf{0 . 3 6}$ \\
\hline & & & & & & \\
\hline
\end{tabular}


Table A.13: Free-surface standard deviation $\sigma_{\eta}(\mathrm{cm})$ at seven wave gauge locations

\begin{tabular}{llllllll}
\hline Run & WG1 & WG2 & WG3 & WG4 & WG5 & WG6 & WG7 \\
\hline P1 & 4.32 & 4.32 & 4.36 & 3.99 & 2.94 & 2.68 & 2.44 \\
P2 & 4.38 & 4.38 & 4.42 & 4.01 & 2.98 & 2.71 & 2.46 \\
P3 & 4.42 & 4.41 & 4.44 & 4.03 & 2.97 & 2.72 & 2.47 \\
P4 & 4.44 & 4.44 & 4.45 & 4.04 & 3.00 & 2.72 & 2.47 \\
P5 & 4.43 & 4.44 & 4.46 & 4.03 & 2.98 & 2.71 & 2.49 \\
P6 & 4.35 & 4.34 & 4.35 & 4.01 & 2.95 & 2.70 & 2.47 \\
P7 & 4.40 & 4.39 & 4.41 & 4.00 & 2.98 & 2.70 & 2.48 \\
P8 & 4.42 & 4.41 & 4.41 & 4.05 & 2.98 & 2.72 & 2.47 \\
P9 & 4.46 & 4.44 & 4.43 & 4.06 & 2.97 & 2.73 & 2.49 \\
P10 & 4.46 & 4.45 & 4.44 & 4.08 & 2.97 & 2.73 & 2.65 \\
P11 & 4.37 & 4.33 & 4.36 & 4.05 & 2.96 & 2.69 & 2.47 \\
P12 & 4.44 & 4.39 & 4.41 & 4.06 & 2.97 & 2.68 & 2.46 \\
P13 & 4.47 & 4.42 & 4.45 & 4.10 & 2.97 & 2.68 & 2.47 \\
P14 & 4.49 & 4.45 & 4.48 & 4.11 & 2.96 & 2.68 & 2.46 \\
P15 & 4.47 & 4.45 & 4.47 & 4.11 & 2.97 & 2.65 & 2.44 \\
P16 & 4.47 & 4.46 & 4.46 & 4.13 & 2.96 & 2.67 & 2.44 \\
P17 & 4.48 & 4.45 & 4.46 & 4.14 & 2.97 & 2.66 & 2.42 \\
P18 & 4.47 & 4.44 & 4.46 & 4.10 & 2.97 & 2.64 & 2.42 \\
P19 & 4.51 & 4.49 & 4.51 & 4.13 & 2.98 & 2.64 & 2.43 \\
P20 & 4.51 & 4.48 & 4.49 & 4.11 & 2.96 & 2.65 & 2.43 \\
\hline Average & 4.44 & $\mathbf{4 . 4 2}$ & $\mathbf{4 . 4 4}$ & $\mathbf{4 . 0 7}$ & $\mathbf{2 . 9 7}$ & $\mathbf{2 . 6 9}$ & $\mathbf{2 . 4 7}$ \\
\hline & & & & & & & \\
\hline
\end{tabular}


Table A.14: Wet probability $P_{w}$, its mean free-surface elevation $\bar{\eta}(\mathrm{cm})$ and freesurface standard deviation $\sigma_{\eta}(\mathrm{cm})$ for WG8

\begin{tabular}{|c|c|c|c|c|c|c|}
\hline Run & $t(s)$ & $\boldsymbol{P}_{w}$ & $Z_{b}(\mathrm{~cm})$ & $\bar{h}(\mathrm{~cm})$ & $\bar{\eta}(\mathrm{cm})$ & $\sigma_{\eta}(\mathrm{cm})$ \\
\hline & 0 & & 10.38 & & & \\
\hline P1 & 200 & 0.62 & 10.33 & 1.71 & 12.04 & 0.99 \\
\hline $\mathbf{P 2}$ & 600 & 0.63 & 10.24 & 1.45 & 11.69 & 1.03 \\
\hline P3 & 1000 & 0.62 & 10.16 & 1.45 & 11.61 & 1.03 \\
\hline P4 & 1400 & 0.64 & 10.07 & 1.52 & 11.59 & 1.07 \\
\hline \multirow[t]{2}{*}{ P5 } & 1800 & 0.65 & 9.98 & 1.42 & 11.40 & 1.08 \\
\hline & 2000 & & 9.94 & & & \\
\hline P6 & 2200 & 0.66 & 9.96 & 2.09 & 12.05 & 1.06 \\
\hline P7 & 2600 & 0.65 & 10.00 & 1.79 & 11.79 & 1.05 \\
\hline P8 & 3000 & 0.65 & 10.05 & 1.52 & 11.57 & 1.07 \\
\hline P9 & 3400 & 0.63 & 10.10 & 1.61 & 11.71 & 1.06 \\
\hline \multirow[t]{2}{*}{ P10 } & 3800 & 0.63 & 10.14 & 1.66 & 11.80 & 1.24 \\
\hline & 4000 & & 10.17 & & & \\
\hline P11 & 4200 & 0.61 & 10.16 & 2.28 & 12.44 & 1.05 \\
\hline P12 & 4600 & 0.61 & 10.15 & 1.51 & 11.66 & 1.06 \\
\hline P13 & 5000 & 0.64 & 10.15 & 1.53 & 11.68 & 1.06 \\
\hline P14 & 5400 & 0.62 & 10.14 & 1.57 & 11.71 & 1.06 \\
\hline \multirow[t]{2}{*}{ P15 } & 5800 & 0.61 & 10.13 & 1.63 & 11.76 & 1.06 \\
\hline & 6000 & & 10.13 & & & \\
\hline P16 & 6200 & 0.63 & 10.12 & 1.58 & 11.70 & 1.07 \\
\hline P17 & 6600 & 0.60 & 10.11 & 1.63 & 11.74 & 1.07 \\
\hline P18 & 7000 & 0.61 & 10.11 & 1.57 & 11.68 & 1.08 \\
\hline P19 & 7400 & 0.62 & 10.10 & 1.68 & 11.78 & 1.07 \\
\hline \multirow[t]{2}{*}{ P20 } & 7800 & 0.60 & 10.09 & 1.53 & 11.62 & 1.08 \\
\hline & 8000 & & 10.09 & & & \\
\hline Average & & 0.63 & & 1.64 & 11.75 & 1.07 \\
\hline
\end{tabular}


Table A.15: Mean cross-shore velocity $\bar{U}$ and standard deviation $\sigma_{U}$ of the 2D ADV co-located with WG4 at $x=8.30 \mathrm{~m}$, Red Vectrino co-located with WG5 at $x=12.90 \mathrm{~m}$ and Blue Vectrino co-located with WG6 at $x=15.52 \mathrm{~m}$

\begin{tabular}{|c|c|c|c|c|c|c|}
\hline \multirow{2}{*}{ Run } & \multicolumn{2}{|c|}{ 2D ADV at WG4 } & \multicolumn{2}{|c|}{ Red Vectrino at WG5 } & \multicolumn{2}{|c|}{ Blue Vectrino at WG6 } \\
\hline & $\bar{U}(\mathrm{~cm} / \mathrm{s})$ & $\sigma_{\mathrm{U}}(\mathrm{cm} / \mathrm{s})$ & $U(\mathrm{~cm} / \mathrm{s})$ & $\sigma_{\mathrm{U}}(\mathrm{cm} / \mathrm{s})$ & $\bar{U}(\mathrm{~cm} / \mathrm{s})$ & $\sigma_{\mathrm{U}}(\mathrm{cm} / \mathrm{s})$ \\
\hline P1 & -7.68 & 22.08 & -3.79 & 15.76 & -3.29 & 17.18 \\
\hline $\mathbf{P 2}$ & -7.87 & 22.39 & -3.88 & 15.84 & -3.36 & 17.28 \\
\hline P3 & -8.16 & 22.46 & -4.07 & 15.78 & -4.19 & 17.11 \\
\hline P4 & -7.85 & 22.53 & -3.73 & 15.80 & -3.88 & 17.27 \\
\hline P5 & -8.49 & 22.83 & -3.89 & 15.89 & -3.61 & 17.31 \\
\hline P6 & -7.54 & 21.78 & -3.90 & 16.09 & -3.88 & 17.20 \\
\hline P7 & -8.24 & 22.37 & -3.80 & 15.89 & -3.66 & 17.18 \\
\hline P8 & -8.00 & 23.08 & NA & NA & NA & NA \\
\hline P9 & -7.41 & 22.81 & -3.67 & 15.92 & NR & NR \\
\hline P10 & -8.66 & 22.80 & -3.32 & 15.95 & -3.48 & 17.17 \\
\hline P11 & -7.94 & 22.60 & -3.76 & 15.87 & -3.39 & 17.22 \\
\hline P12 & -8.37 & 22.85 & NA & NA & NA & NA \\
\hline P13 & -8.91 & 22.53 & -3.92 & 15.75 & -3.38 & 17.15 \\
\hline P14 & -8.04 & 22.96 & -4.24 & 15.77 & -3.24 & 16.99 \\
\hline P15 & -8.12 & 22.65 & -4.14 & 15.80 & -3.15 & 16.85 \\
\hline P16 & -8.10 & 22.70 & -4.21 & 15.81 & -3.62 & 16.85 \\
\hline P17 & -8.14 & 22.70 & NR & NR & -3.14 & 16.95 \\
\hline P18 & -7.99 & 22.52 & -4.19 & 15.74 & -3.27 & 16.89 \\
\hline P19 & -7.62 & 22.77 & NR & NR & -3.79 & 16.99 \\
\hline P20 & -7.89 & 22.85 & -4.05 & 15.85 & -3.63 & 16.87 \\
\hline Average & -8.05 & 22.61 & -3.91 & 15.84 & -3.53 & 17.09 \\
\hline
\end{tabular}

NA implies "not available" data

NR implies "not reliable" data 

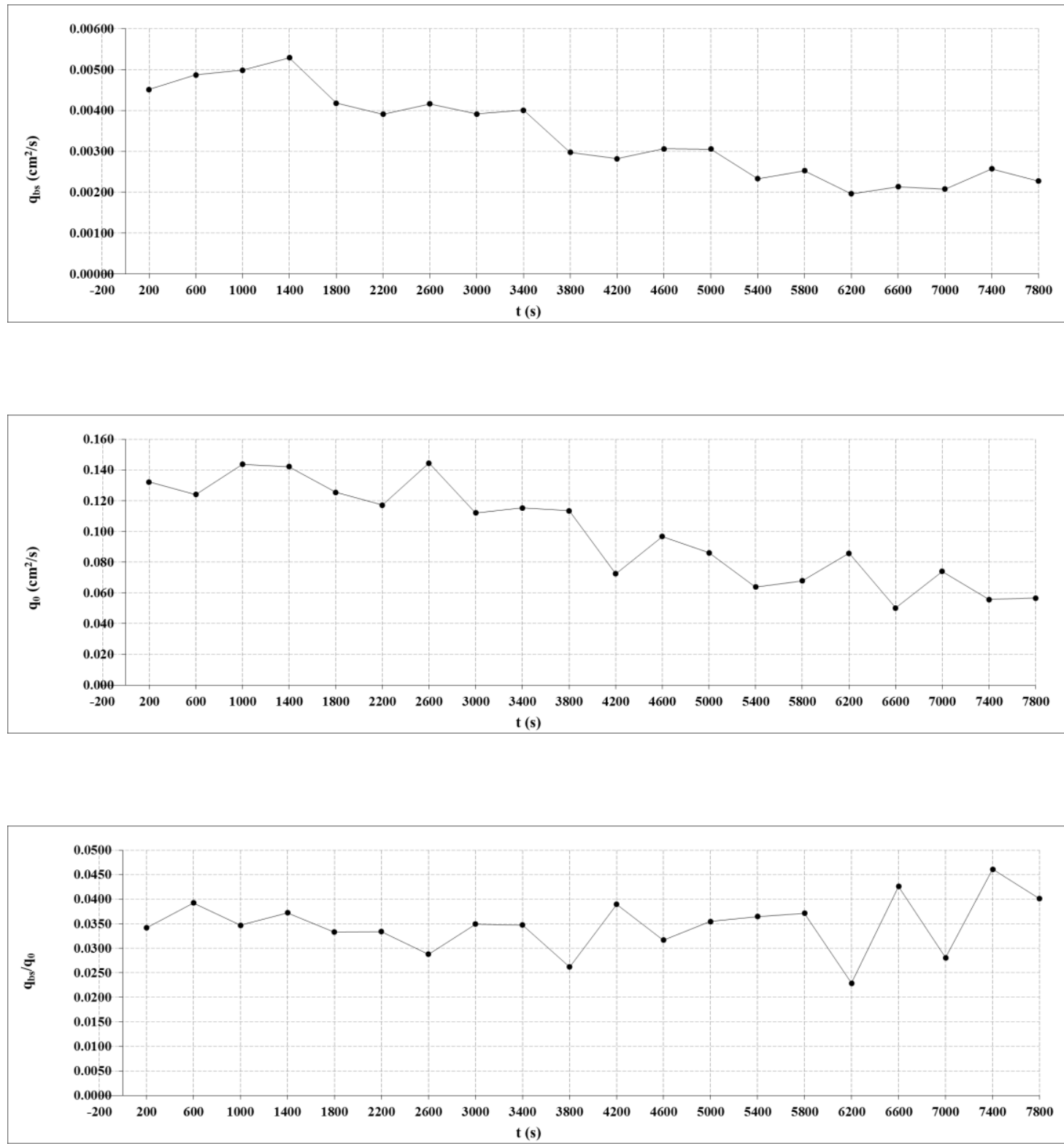

Figure A.16: Temporal variation of sand overwash rate $\mathrm{q}_{\mathrm{bs}}$ (top), wave overtopping rate $\mathrm{q}_{\mathrm{o}}$ (middle) and their ratio $\mathrm{q}_{\mathrm{bs}} / \mathrm{q}_{\mathrm{o}}$ (bottom) 